FY 2007

\title{
STUDY OF THE ADVANTAGES OF INTERNAL PERMANENT MAGNET DRIVE MOTOR WITH SELECTABLE WINDINGS FOR HYBRID ELECTRIC VEHICLES
}

Prepared by:

Oak Ridge National Laboratory

Mitch Olszewski, Program Manager

\section{Submitted to:}

Energy Efficiency and Renewable Energy

FreedomCAR and Vehicle Technologies

Vehicle Systems Team

Susan A. Rogers, Technology Development Manager

November 2007 
NATIONAL LABORATORY

MANAGED BY UT-BATTELLE

FOR THE DEPARTMENT OF ENERGY
Engineering Science and Technology Division

\section{STUDY OF THE ADVANTAGES OF INTERNAL PERMANENT MAGNET DRIVE MOTOR WITH SELECTABLE WINDINGS FOR HYBRID-ELECTRIC VEHICLES}

\author{
P. J. Otaduy \\ J. S. Hsu \\ D. J. Adams
}

Publication Date: November 2007

Prepared by the

OAK RIDGE NATIONAL LABORATORY

Oak Ridge, Tennessee 37831

managed by

UT-BATTELLE, LLC

for the

UT-BATTELLE

ORNL-27 (4-00)

U.S. DEPARTMENT OF ENERGY

Under contract DE-AC05-00OR22725 


\title{
DOCUMENT AVAILABILITY
}

Reports produced after January 1, 1996, are generally available free via the U.S. Department of Energy (DOE) Information Bridge:

Web site: http://www.osti.gov/bridge

Reports produced before January 1, 1996, may be purchased by members of the public from the following source:

\author{
National Technical Information Service \\ 5285 Port Royal Road \\ Springfield, VA 22161 \\ Telephone: 703-605-6000 (1-800-553-6847) \\ TDD: $703-487-4639$ \\ Fax: 703-605-6900 \\ E-mail: info@ntis.fedworld.gov \\ Web site: http://www.ntis.gov/support/ordernowabout.htm
}

Reports are available to DOE employees, DOE contractors, Energy Technology Data Exchange (ETDE) representatives, and International Nuclear Information System (INIS) representatives from the following source:

Office of Scientific and Technical Information

P.O. Box 62

Oak Ridge, TN 37831

Telephone: 865-576-8401

Fax: 865-576-5728

E-mail: reports@osti.gov

Web site: http://www.osti.gov/contact.html

This report was prepared as an account of work sponsored by an agency of the United States Government. Neither the United States government nor any agency thereof, nor any of their employees, makes any warranty, express or implied, or assumes any legal liability or responsibility for the accuracy, completeness, or usefulness of any information, apparatus, product, or process disclosed, or represents that its use would not infringe privately owned rights. Reference herein to any specific commercial product, process, or service by trade name, trademark, manufacturer, or otherwise, does not necessarily constitute or imply its endorsement, recommendation, or favoring by the United States Government or any agency thereof. The views and opinions of authors expressed herein do not necessarily state or reflect those of the United States Government or any agency thereof. 


\section{CONTENTS}

Page

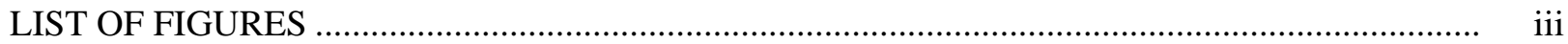

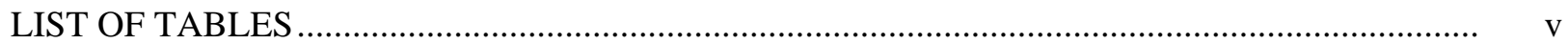

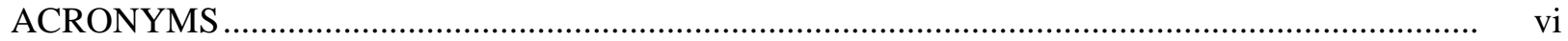

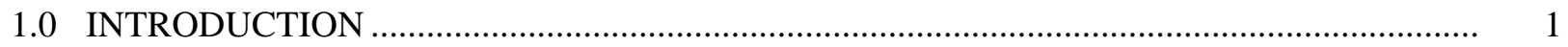

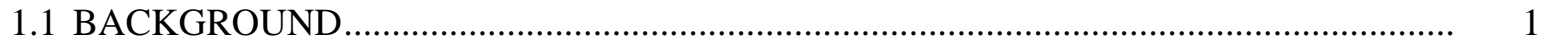

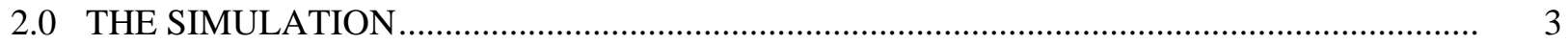

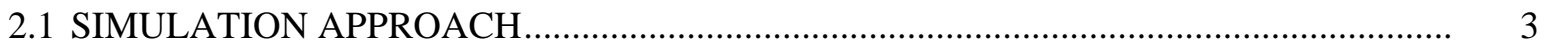

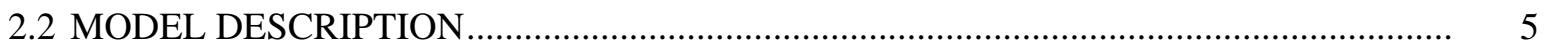

3.0 DRIVING CYCLE ANALYSIS OF THE REFERENCE VEHICLE WITH

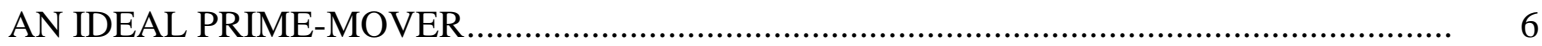

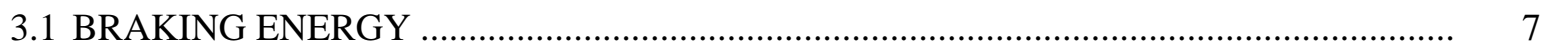

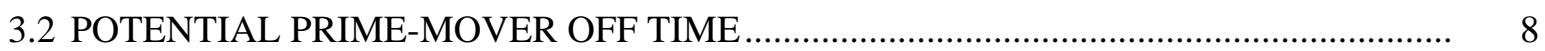

3.3 COMBUSTION ENGINES VS. ELECTRIC MOTOR AS PRIME-MOVERS.................... 8

4.0 EVALUATION OF FACTOR-OF-TWO TURN-SWITCHING FOR A BASE IPM

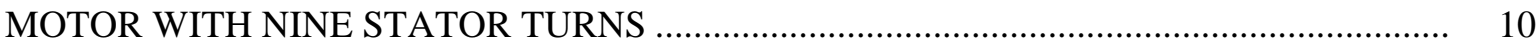

4.1 EV FOLLOWING STANDARD DRIVING CYCLES ................................................... 10

4.1.1 Performance Comparison of Vehicles EV1 and EV2 on the US06 Cycle................. 11

4.1.2 Analysis of EV1's Failure to Perform on the US06 Cycle ....................................... 14

4.1.3 Effect of Magnetic Saturation on the Computation of Vehicle Performance ............. 15

4.1.4 Comparison of Battery Power Requirements for EV1 and EV2 Vehicles.................. 16

4.1.5 Comparison of EV1 and EV2 Battery Energy Storage Requirements....................... 18

4.1.6 Comparison of Overall Efficiencies of EV1 and EV2 ........................................... 20

4.1.7 Impact of Turn-Switching on EV's Battery Size and Cost ..................................... 21

4.1.8 Vehicle Range with Minimum Battery Size Required for Power Delivery............... 23

4.1.9 Difference in Battery Size Required by EV1 and EV2 ............................................ 24

4.2 HEV FOR STANDARD DRIVING CYCLE STARTS …................................................ 25

4.2.1 Battery Energy and Power Requirements for HEV1 and HEV2 …........................ 25

4.2.1.1 Change in HEV battery energy and power needs with turn-switching......... 26

4.2.1.2 Impact of turn-switching on battery size and cost of HEVs ........................ 28

5.0 STATOR RECONFIGURATION CONCLUSIONS .......................................................

6.0 MECHANISMS FOR IMPLEMENTATION OF STATOR-TURN SWITCHING .................. 32

6.1 THE ELECTRONICALLY-COMMUTATED CONNECTION-CHANGE SWITCHER.... 34

6.1.1 Performance Simulation of the Electronically-Commutated Configuration

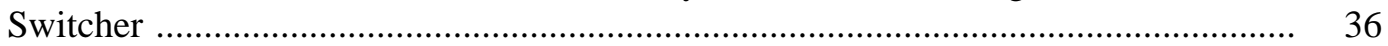

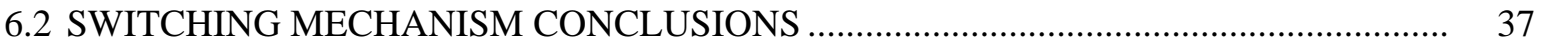

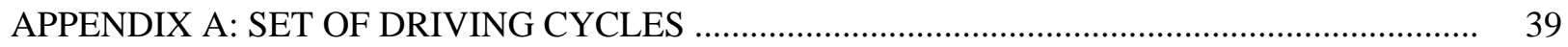

APPENDIX B: SIMULATION OF SERIES TO PARALLEL COMMUTATION STAGES.............. 43

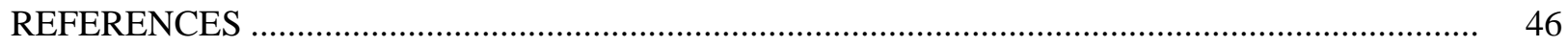




\section{LIST OF FIGURES}

Figure

Page

1 Characteristic parameters of the reference vehicle

2 Road propulsion energy and gasoline equivalent needed for each driving cycle:

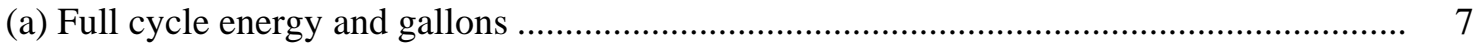

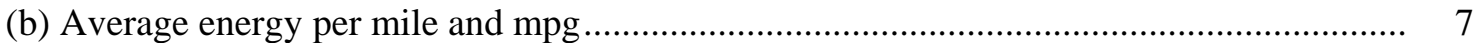

$3 \quad$ Percent of total propulsion energy used for braking in each driving cycle .............................. 8

4 Percent of time the electric motor in the reference vehicle can be OFF for each driving cycle

Characteristic parameters of the base electric IPM motor.

Terminal voltage for the US06 cycle:

(a) EV1's nine-turn IPM motor, and (b) EV2's 9-18 turn switching IPM motor

Stator current along the US06 cycle:

(a) EV1's nine-turn IPM motor, and (b) EV2's 9-18 turn-switching IPM motor.

Efficiency of electrical-to-mechanical conversation along the US06 cycle:

(a) EV1's nine-turn IPM motor, and (b) EV2's 9-18 turn-switching IPM motor.

Efficiency of power electronics, battery, and cabling vs. speed for the US06 cycle:

(a) EV1, and (b) EV2

Output torque as a function of vehicle speed for the US06 cycle:

(a) EV1's nine-turn IPM motor, and (b) EV2's 9-18 turn-switching IPM motor.

Breakdown of forces on the prime-mover's axle from rolling resistance, linear and rotational acceleration, air resistance, and transmission loss for the US06 cycle

(a) Failed zones, colored red, of EV1 on the US06 cycle

(b) Power demand and supply for EV1's nine-turn motor on the US06 cycle

(c) Terminal voltage for EV1's nine-turn motor on the US06 cycle

(d) Stator current for EV1's nine-turn motor on the US06 cycle

13 Failure zones for EV1 in the US06 cycle due to the nine-turn motor:

(a) With magnetic saturation, and (b) Without magnetic saturation

Peak and average power demand on the battery for EV1 and EV2:

(a) Raw, and (b) Adjusted for failed periods

Peak/average ratio of battery power demand for EV1 and EV2:

(a) Raw, and (b) Adjusted for failed periods....

16 Percent change of peak and average battery power demand relative to base motor

(adjusted for failed periods).

17 Total battery energy demand with ideal propulsion with EV1's 9-turn motor and with EV2's 9-18 turn-switching motor....

Average battery energy demand per mile with ideal propulsion with EV1's

9-turn motor and with EV2's 9-18 turn-switching motor.

Change in average battery energy demand with 9-18 turn-switching motor:

(a) Total energy, and (b) Average energy per mile .

Overall efficiency from battery to road for EV1 and EV2.

21 Change in overall efficiency from battery to road with 9-18 turn-switching:

(a) Absolute net efficiency, and (b) Relative to efficiency of EV1.

Battery power demand, weight, and cost per mile for EV1 and EV2

23 Average EV battery energy demand, weight, and cost per mile with ideal base

9-turn motor and 9-18 turn-switching motor prime-movers.

24 Range of vehicle with the battery sized to meet the cycles' power demand when configured with the base 9-turn and the 9-18 turn-switching motors 


\section{LIST OF FIGURES (cont'd)}

Figure

26 Change in battery energy demand, weight, and cost per mile using the

9-18 turn-switching motor instead of the base 9-turn motor for propulsion............................ 25

27 Energy required for HEV from 0-20 mph for each cycle’s initial start ................................. 26

28 Peak power required for HEV from $0-20 \mathrm{mph}$ for each cycle's initial start.......................... 26

29 Change in energy required for HEV from 0-20 mph with the turn-switching motor .............. 27

30 Change in power required for HEV from 0-20 mph with the turn-switching motor............... 27

31 Percent change requirement for HEV with turn-switching motor from 0-20 mph:

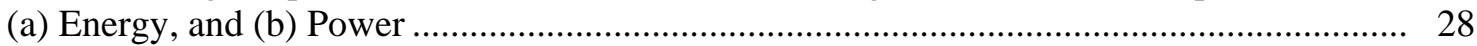

32 HEV battery size and cost based on energy required for $0-20 \mathrm{mph}$ start ............................ 28

$33 \quad$ EV battery size and cost based on power required for $0-20$ mph start ................................ 29

34 Change in HEV battery size and cost based on power required from $0-20 \mathrm{mph}$.................... 30

35 Percent change in HEV battery size and cost from $0-20 \mathrm{mph}$............................................. 30

36 Conventional motor windings schematic:

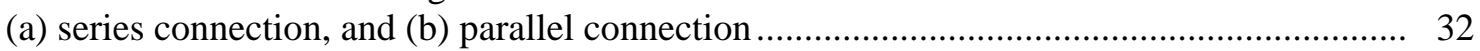

$37 \quad$ Series to parallel connection-change switch schematic................................................... 32

38 Current and voltage waveforms at serial winding opening transition .................................... 33

39 Disk positioning and schematic for parallel connection of one phase .................................. 35

40 Disk positioning and schematic for SCR gate triggering right before parallel

41 Disk positioning and schematic for series connection for one phase ..................................... 36

42 Disk positioning and schematic of SCR gate triggering immediately before

43 Current and voltage waveforms at series winding opening transition with the electronically-commutated configuration switcher .......................................................... 37

44 Simulation of series-to-parallel winding reconfiguration with the electronicallycommutated configuration switcher ..................................................................................... 37

A1 (a) Driving cycles: same time scale with the nine-turn motor: red = failure and black = OFF.

(b) Driving cycles with the nine-turn motor: red = failure, black $=$ OFF, and orange $=$ nine turns

A2 Driving cycles with the 9-18 turn-switching motor: black $=$ OFF, orange $=9$ turns, and green $=18$ turns

B1 Simulation circuit for serial contact opening showing inverter, motor, and mechanical switches

B2 Simulation circuit for opening a series configured winding with the electronicallycommutated connection-change switcher

B3 Simulation of winding opening from series configuration followed by reconnection in parallel configuration using the electronically-commutated connection-change switcher .. 45 


\section{LIST OF TABLES}

Table

Page

1 ID number and name assignment, distance in miles, duration in seconds, maximum speed in mph, and number of intermediate full stops for the driving cycle analyzed

2 Time in seconds the prime-movers in EV1 and EV2 failed to meet the power demand, EV1's energy deficit in percent of cycle total, total time the prime-mover was OFF, and time the prime-movers succeeded in supplying the vehicle's demand for each driving cycle

3 Summary of savings achieved by stator turn-switching... 


\section{ACRONYMS}

ac

d-axis

emf

$\mathrm{EV}$

FHDS

FUDS

HDV

$\mathrm{HEV}$

IGBT

IPM

$\mathrm{kJ}$

$\mathrm{mmf}$

mpg

mph

$\mathrm{Nm}$

NYCC

NYCT

PE

PM

SCR

SP

SPDT alternating current direct-axis

electromotive force electric vehicle

Federal Highway Driving Cycle

Federal Urban Driving Cycle

Heavy Duty Vehicle

hybrid-electric vehicle

insulated gate bipolar transistor internal permanent magnet

kJoule

magneto-motive force miles-per-gallon miles per hour Newton meter

New York City cycle New York City Truck cycle power electronics permanent magnet silicon-controlled rectifier single-pole single-pole-double-throw 


\subsection{INTRODUCTION}

This report describes research performed on the viability of changing the effectively active number of turns in the stator windings of an internal permanent magnet (IPM) electric motor to strengthen or weaken the magnetic fields in order to optimize the motor's performance at specific operating speeds and loads.

Analytical and simulation studies have been complemented with research on switching mechanisms to accomplish the task. The simulation studies conducted examine the power and energy demands on a vehicle following a series of standard driving cycles and the impact on the efficiency and battery size of an electrically propelled vehicle when it uses an IPM motor with turn-switching capabilities. Both full driving cycle electric propulsion and propulsion limited starting from zero to a set speed have been investigated.

\subsection{BACKGROUND}

Torque is produced in an electric machine by the interaction of two magnetic fields; one in the rotor and the other in the stator. The magnitude of the torque is proportional to the product of the magnitudes of the two magnetic fields. Most often the stator's magnetic field is produced by electric currents circulating though coils wound around the stator teeth and the rotor's magnetic field is produced by either (a) reaction-currents induced in the rotor - induction machines, (b) by reaction magnetic poles reluctance machines and hysteresis machines, (c) by reaction eddy currents - eddy current machines, (d) by permanent magnets (PMs) on the surface or inside the rotor - PM and IPM machines, or (e) by combinations of the above. In surface-mounted PM machines, the rotor's magnetic field produced by the PMs is essentially of constant magnitude.

As the rotor's magnetic field crosses the stator coils, a voltage, also referred to as the back-electromotive force (emf), is induced at the stator terminals. The amount of electric current circulating in the stator coils, and thus the strength of the magnetic field they produce, depends on the coils' impedance and the vector difference between the applied terminal voltage and the induced back-emf.

Below the base speed, the combination of low induced back-emf, low stator inductance, and the need to keep the stator current below pre-determined safe limits forces the reduction of the effective terminal voltage below its maximum possible value. Since the torque is proportional to the number of turns and the magnitude of the current, the maximum torque that can be produced in this operating region is traditionally constant.

As speed increases, the stator coils' impedance and the back-emf increase. Consequently, for a fixed voltage machine, the magnitude of the current in the coils decreases with increasing rotor speed, as do the strength of the stator's magnetic flux and the output torque. When the magnitude of the back-emf equals that of the terminal voltage, the stator's magnetic field is zero since no current circulates in the coils. Consequently, no torque is produced and higher speeds cannot be achieved.

Traditional approaches to extend the speed range of PM motors is to weaken the rotor's magnetic flux as the speed increases thus decreasing the magnitude of the back-emf and allowing higher electric currents to circulate in the stator windings. The drawback inherent to this approach is that the linked rotor field is suppressed and additional current and complexity in the drive system and/or stator are needed. In addition to the current invested to suppress the rotor's field, extra current is needed to compensate for the reduction in the magnitude of the rotor's field in order to attain the same torque. 
A promising alternative way to produce more torque in the low-speed operating region and to extend the operating speed range is to change the effective number of turns involved in the electrical-to-mechanical energy transformation. Increasing the number of turns increases the torque produced with the same amount of current, which is of particular interest in the low-speed region. Reducing the effective number of turns in the stator windings reduces the back-emf without expending stator current to weaken the magnitude of the linked rotor's field. As a result, higher currents can be reached at a given speed with the same terminal voltage limit. This extends the operating speed region by allowing torque generation at higher speeds without having to boost the terminal voltage.

A motor with the capability to change the number of turns continuously in one turn steps for optimal performance can be simulated readily but consideration of added cost, complexity, and energy losses associated with the switches may not justify the performance gains. Instead, considering that the stator coils are often made with several wires bundled together and welded at the ends instead of a single thicker wire; the simplest implementation of turn-changing appears to be by factors of two or more. A factor of two is the most feasible since it can be accomplished by splitting the wires in each phase, into two groups and connecting their ends in parallel or in series to have $\mathrm{N}$ or $2 \mathrm{~N}$ turns per phase, respectively, depending on the motor's speed and load demand. At low speeds, having twice the number of turns doubles the torque for the same current limit and decreases the need for voltage regulation. At high speeds, switching back to the reduced number of active turns reduces the back-emf for the same speed, thus increasing the speed-range of operation. As shown in this study, adjustment of the number of stator turns up and down appropriately results in better performance with better copper and battery voltage utilization over the whole range of operation. 


\subsection{THE SIMULATION}

This report presents the main results obtained via simulation for two vehicles as they follow eight different standard driving profiles. Firstly, as full electric vehicles (EVs) with electric propulsion over the full driving cycle, named EV1 and EV2, and secondly as hybrid-electric vehicles (HEVs) that are electrically propelled between the speeds of zero and 20 miles per hour (mph), named HEV1 and HEV2.

Vehicles EV1 and HEV1 are the same and are fitted with a typical IPM motor with nine turns in its stator windings. Vehicles EV2 and HEV2 are also the same but are instead fitted with a modified version of the same IPM motor which is capable of switching the configuration of the stator windings between 9-18 turns.

\subsection{SIMULATION APPROACH}

The most practical approach to modeling the performance of a PM motor with saliency is based on lumped-parameters and the $\mathrm{d}-\mathrm{q}$ transformation. The fundamental governing equations are

$$
\begin{array}{ll}
V_{q}=R I_{q}+\omega_{e} L_{d} I_{d}+\omega_{e} \lambda_{m} & , \\
V_{d}=R I_{d}-\omega_{e} L_{q} I_{q} & \text {, and } \\
P_{\text {converted }}=\frac{3}{2} \omega_{e} I_{q}\left[\left(L_{q}-L_{d}\right) I_{d}+\lambda_{m}\right] .
\end{array}
$$

These lumped-parameter equations facilitate understanding the phenomena involved in electromechanical power conversion but require the determination of lumped inductances, resistance, and flux linkages with the degree of detail appropriate for the simulation goals. Most challenging is the characterization of magnetic saturation since the magnetic flux paths can vary significantly not only with the rotor's position relative to the rotating field generated by the stator's current, but also with the magnitude of the current. This effect is especially important in the case of IPM machines. The preferred method to obtain values of the lumped parameters, $L_{d}, L_{q}$, and $\lambda_{m}$, as a function of stator magneto-motive force (mmf) is through direct measurement. Most often though, lumped parameters are obtained by computations using finite elements and/or semi-empirical calculations based on geometry, equivalent circuits, and adjustment factors.

The motor's lumped parameters can be expressed in terms of a set of hypothetical single turn values and the number of turns as follows:

$$
\begin{aligned}
& R=R_{1} N_{t}, \\
& L_{d}=L_{d 1} N_{t}{ }^{2}, \\
& L_{q}=L_{q_{1}} N_{t}{ }^{2}, \text { and } \\
& \lambda_{m}=\lambda_{m 1} N_{t} .
\end{aligned}
$$

Note that Eq. (3a) is valid when $\mathrm{R}_{1}$ is independent of $\mathrm{N}_{\mathrm{t}}$. When rewiring by splitting the original wires into $\mathrm{N}_{\mathrm{t}}$ groups and connecting them in series, $R=R_{0} N_{t}{ }^{2}$, where $\mathrm{R}_{0}$ represents the original stator resistance, then the power equation, Eq. (2), in terms of the number of turns, $\mathrm{N}_{\mathrm{t}}$, and the per turn parameters, becomes 


$$
P_{\text {converted }}=\frac{3}{2} \omega_{e} I_{q}\left[\left(L_{q_{1}}-L_{d 1}\right) I_{d}+\frac{\lambda_{m 1}}{N_{t}}\right] N_{t}^{2}
$$

The fundamental relationships for terminal voltage and phase current with their respective phase angles referred to the direct-axis (d-axis) are

$$
\begin{aligned}
& V_{t}=\sqrt{V_{d}^{2}+V_{q}^{2}}, \quad \tan (\beta)=\frac{V_{q}}{V_{d}}, \text { and } \\
& I_{t}=\sqrt{I_{d}^{2}+I_{q}^{2}}, \quad \tan (\gamma)=\frac{I_{q}}{I_{d}} .
\end{aligned}
$$

The angle between the current and the voltage is then

$$
\alpha=\beta-\gamma .
$$

Consequently, the power factor is $p f=\cos (\alpha)$, and the power input is

$$
P_{\text {input }}=\frac{3}{2} V_{t} I_{t} \cos (\alpha)=\frac{3}{2}\left(V_{d} I_{d}+V_{q} I_{q}\right)
$$

The efficiency is then

$$
\text { Efficiency }=\frac{P_{\text {converted }}-P_{\text {mag_loss }}}{P_{\text {input }}}=1-\frac{P_{\text {ohmic_loss }}+P_{\text {hyst }}+P_{\text {eddy }}}{P_{\text {input }}},
$$

where the ohmic losses and the two components of the magnetic losses, hysteresis and eddy current, are given by ${ }^{1}$

$$
\begin{aligned}
& P_{\text {ohm }}=R I_{t}{ }^{2}, \\
& P_{\text {hyst }}=k_{h} B_{\text {gap }}{ }^{n h} \omega M_{s}, \\
& P_{\text {eddy }}=k_{\text {edd }} B_{\text {gap }}{ }^{n e} \omega^{2} M_{s},
\end{aligned}
$$

where

$$
\begin{aligned}
& B_{g a p} \text { represents the average magnetic flux density, in Tesla, crossing the gap, } \\
& \omega \text { represents the electrical frequency in } \mathrm{rad} / \mathrm{s}, \\
& k_{h}=5.80 \mathrm{E}-3 \mathrm{~W} / \mathrm{lb} / \mathrm{T}^{\mathrm{nh}} \\
& n h=1.93 \\
& k_{e d d}=9.30 \mathrm{E}-6 \mathrm{~W} / \mathrm{lb} / \mathrm{T}^{\mathrm{ne}} \\
& n e=2.0 \text { and } \\
& M_{s} \text { is the mass of the stator in } \mathrm{lb} \text {. }
\end{aligned}
$$

The focus of performance optimization can be on power output or on efficiency. For automotive applications it seems appropriate to focus on efficiency. In this study, at every time step of a driving 
cycle, the number of stator turns that produced the maximum electric motor efficiency was selected. The simulation was implemented and the calculations performed numerically with LabVIEW's programming environment.

\subsection{MODEL DESCRIPTION}

The simulation includes a vehicle model that computes the road propulsion power; i.e., the power at the vehicle's tire-road contact needed to follow a specified speed vs. time driving profile, subject to wind speed, and road slope perturbations. To facilitate comparison with other studies, it was assumed that the vehicles traveled over level ground without climatic wind. Power transmission losses between the primemover's output axle and the tires were added to determine the power demand that must be delivered by the vehicle's prime-mover. In our EV1 and EV2 vehicles, the prime-movers are IPM electric motors with 9 and 9-18 stator turn windings, respectively.

To model the performance of a IPM motor, the standard d-q transformation approach described in Eqs. (1-9) above was followed. By making the values of $L_{d}, L_{q}$, and $\lambda_{m}$ dependent on the value of the stator's mmf $N_{t}{ }^{*} I$ to account for the effects of saturation, and also dependent on the number of turns chosen, the IPM simulator allowed changing the number of effective stator turns at will. At every time step the optimal voltage, electrical current, and control angles needed to meet the power demand with best efficiency were computed for each of the set of stator turns desired. The number of turns yielding the best efficiency was selected and the corresponding power level, voltage, current, and control angle characteristics became the demand for the inverter. A model of the inverter and cabling losses computed the power demand for the battery. The total power demand on the battery at each time step also included the battery's losses. 


\subsection{DRIVING CYCLE ANALYSIS OF THE REFERENCE VEHICLE WITH AN IDEAL PRIME-MOVER}

In order to establish a base for evaluating the desirability of any particular prime-mover, the demands a reference vehicle will pose to its prime-mover on different driving cycles were investigated. Figure 1 summarizes the pertinent mechanical characteristics of the reference vehicle.

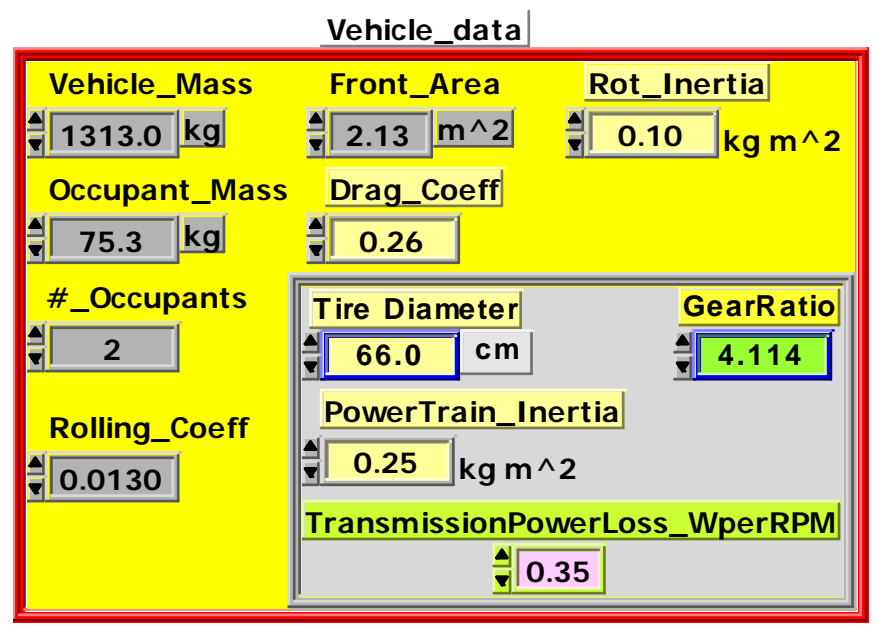

Fig. 1. Characteristic parameters of the reference vehicle.

Table 1 lists the main characteristics of a set of eight driving cycles preloaded in the simulation program developed for this study. These driving cycles consist of speed vs. time histories and are shown graphically in Appendix A. In the simulation program, the user can select one or more from among the listed cycles, create a custom cycle, or perform studies of vehicles operating at constant speed.

Table 1. ID number and name assignment, distance in miles, duration in seconds, maximum speed in mph, and number of intermediate full stops for the driving cycles analyzed

\begin{tabular}{|c|c|c|c|c|c|c|c|}
\hline \multicolumn{2}{|c|}{ Cycle Numbering } & \multicolumn{2}{|c|}{ Distances } & Duration & \multicolumn{2}{|c|}{ MaxSpeed } & \# of Stops \\
\hline$\# 1$ & FUDS & 7.45 & $\mathrm{mi}$ & 1372 & 57 & mijh & 17 \\
\hline$\# 2$ & FHDS & 10.26 & $\mathrm{mi}$ & 764 & 60 & & 0 \\
\hline$\# 3$ & HDV_FUDS & 5.552 & $\mathrm{mi}$ & 1040 & 58 & mi,h & 6 \\
\hline$\# 4$ & NewEurope & 6.843 & $\mathrm{mi}$ & 1160 & 75 & milh & 12 \\
\hline$\# 5$ & NYCity & 1.18 & $\mathrm{mi}$ & 565 & 28 & mijh & 9 \\
\hline$\# 6$ & NYCityTruck & 2.134 & $\mathrm{mi}$ & 1012 & 34 & milh & 7 \\
\hline$\# 7$ & US06 & 8.007 & $\mathrm{mi}$ & 601 & 80 & mishth & 4 \\
\hline$\# 8$ & US06_hwy & 6.2 & $\mathrm{mi}$ & 369 & 80 & mijh & $\mathbf{0}$ \\
\hline
\end{tabular}

The amount of energy needed for propulsion and for braking depends not only on the driving cycle, road slope, and wind but also on the vehicle characteristics. Figures 2(a) and 2(b) show the total energy that the reference vehicle delivered at the tire-road interface in absolute terms and normalized with the cycle distance, respectively, in order to fully run each of the eight driving cycles over level ground and without wind. The gallons of gasoline and miles-per-gallon (mpg) scales have been produced using the raw 
energy content of gasoline: $32 \mathrm{MJ} / \mathrm{liter}=121 \mathrm{MJ} /$ gallon. Consequently, the range between 140-240 mpg shown in Fig. 2(b) correspond to that which could be maximally attained by the vehicle with a primemover that converted the fuel's chemical energy to mechanical energy with $100 \%$ efficiency. For instance, the reference vehicle will not be able to do better in the US06 cycle than the $145 \mathrm{mpg}$ it takes with an ideal engine. When the actual efficiency of the engine is considered, all mileage values in Fig. 2(b) will be significantly lower.

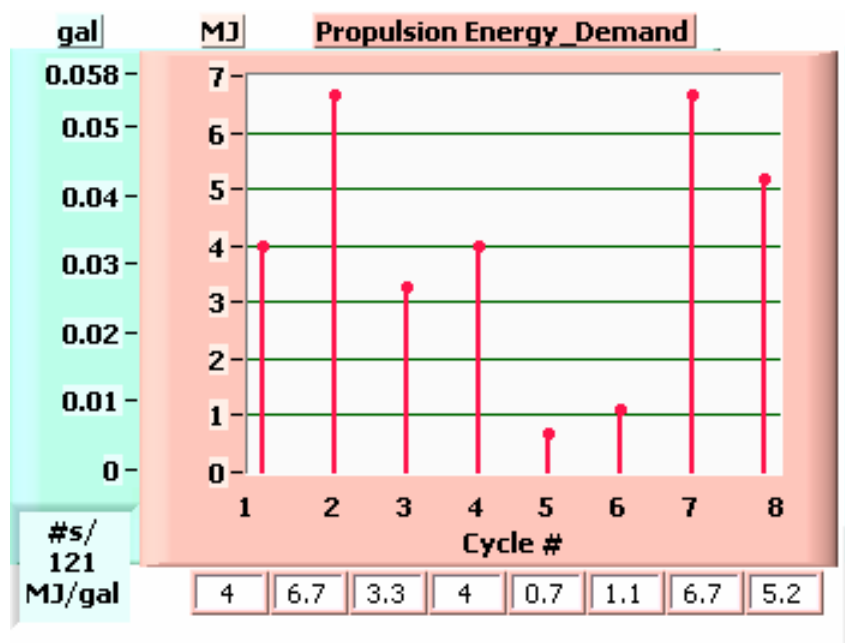

(a) Full cycle energy and gallons.

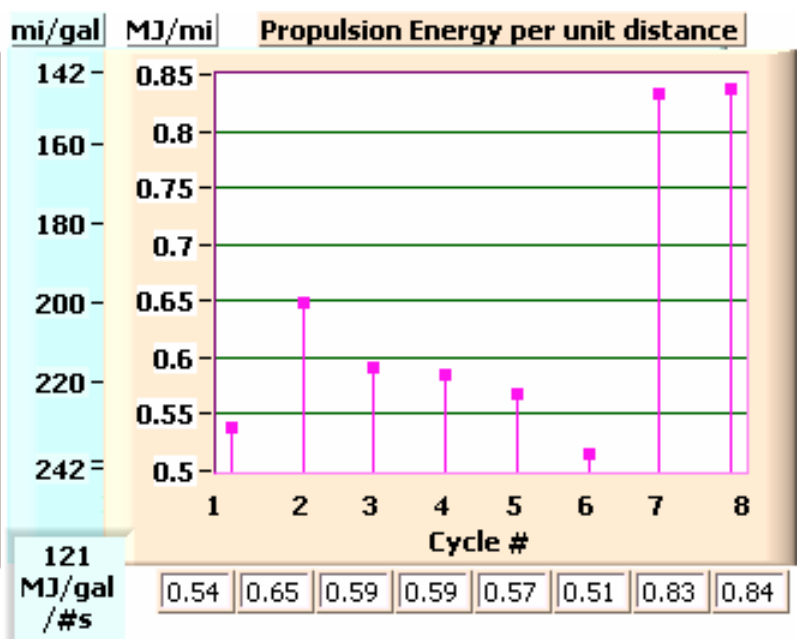

(b) Average energy per mile and mpg.

Fig. 2. Road propulsion energy and gasoline equivalent needed for each driving cycle.

Note that if the prime-mover is an electrical motor, even if the motor converted electrical energy to mechanical energy with $100 \%$ efficiency, the mpg will also be significantly lower than those in Fig. 2(b), because of the losses involved in generating, storing, and retrieving from the battery the electrical energy it uses. Hybrid vehicles that use the engine to generate the electricity have gasoline-to-electrical equivalencies between $27-38 \%$ of the ideal value. When the actual efficiency of the motor is considered, the mileage values are proportionally lower than $27-38 \%$ of the values shown in Fig. 2(b).

\subsection{BRAKING ENERGY}

Among the significant characteristics of the components of a driving cycle are the amounts of time the vehicle spends idling, coasting, and braking. Braking periods are intervals of time during which the vehicle speed is reduced at a rate such that its reduction of kinetic energy is larger than the combined energy losses due to air-drag, tire rolling resistance, and mechanical power transmission.

The potential for regenerative braking depends on the vehicle and on how it is driven. Figure 3 shows the energy needed for braking, expressed in terms of per cent of the total propulsion energy shown in Fig. 2(a). As Fig. 3 shows, it is more appropriate to consider regenerative braking for driving cycles like New York City's where 46\% of the energy invested for propulsion is used in braking, than for the Federal Highway Driving Cycle (FHDS) which uses only 8\% in braking. 


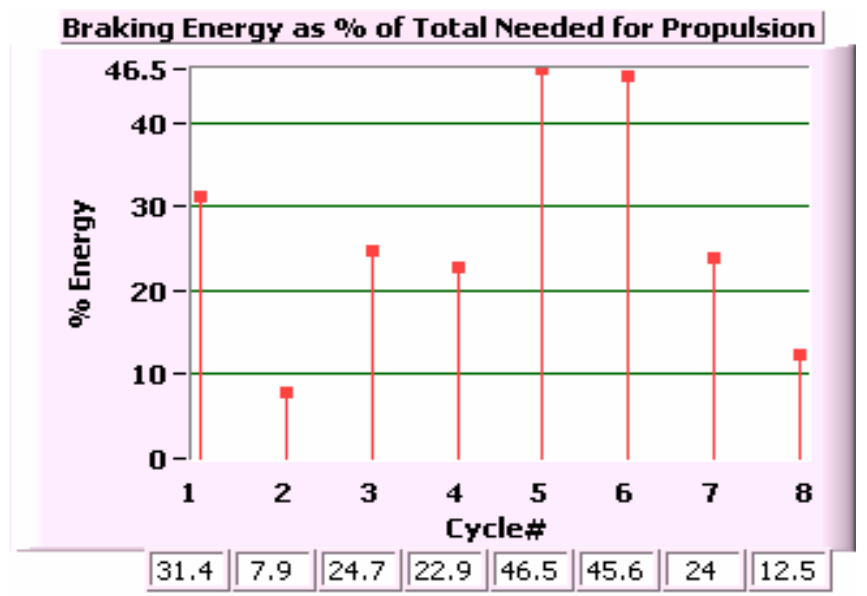

Fig. 3. Percent of total propulsion energy used for braking in each driving cycle.

\subsection{POTENTIAL PRIME-MOVER OFF TIME}

A prime-mover with the capability to be reliably turned ON and OFF almost instantly, as for electric motors, has the advantage over present technology combustion engines of consuming zero power during idling, coasting, and braking periods. Coasting periods are intervals of time during which the vehicle speed is reduced at a rate such that its change in kinetic energy equals the moving losses.

Figure 4 shows the percent of time the prime-mover could be turned fully-OFF for each driving cycle; i.e., the percentage of time the vehicle is idling, coasting, or braking. The OFF-time periods range from a low of $10 \%$ for FHDS to a high of $68 \%$ for the New York City Truck cycle (NYCT). The OFF-time indicates the fuel penalty incurred by prime-movers, like combustion engines, that run continuously at idle or higher speeds even when no propulsion power is required.

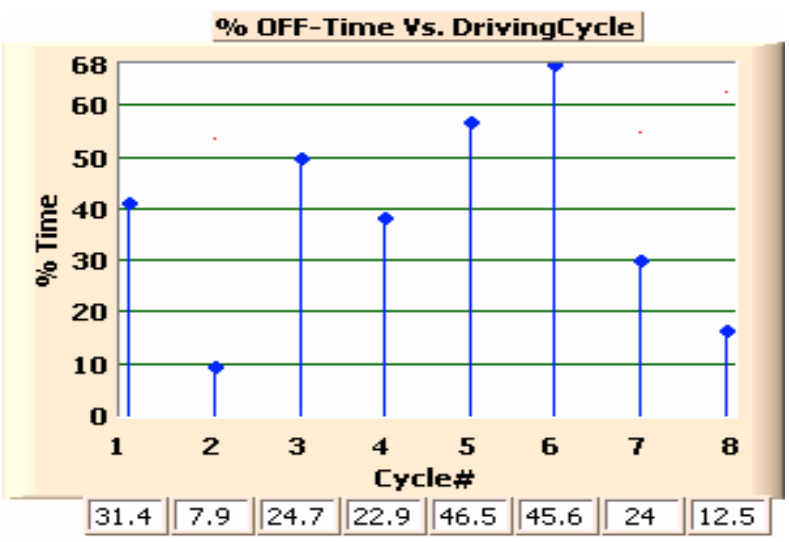

Fig. 4. Percent of time the electric motor in the reference vehicle can be OFF for each driving cycle.

\subsection{COMBUSTION ENGINES VS. ELECTRIC MOTOR AS PRIME-MOVERS}

The energy savings associated with motor-OFF periods and energy gains possible with regenerative braking, give electric drives a clear advantage over combustion engines. In addition, mechanical transmission losses can be significantly reduced with electric propulsion by placing the traction motors directly on the wheels. 
However, for periods in which mechanical energy is needed at the tires for propulsion, a combustion engine may be more efficient than an electric motor. The engine transforms chemical energy in the fuel directly to mechanical energy, while the electric motor involves an intermediate step of converting the fuel's chemical energy to electricity.

The electric motor advantage as a prime-mover will be greater for driving cycles with long OFF-periods and with high regenerative braking energy potentials (see figures in Appendix A).

The best option may be a HEV in which propulsion is produced almost exclusively by an engine that is turned OFF during non-propulsion periods. Wheel-mounted motors would perform regenerative braking and provide engine OFF-ON transition power and emergency propulsion. 


\subsection{EVALUATION OF FACTOR-OF-TWO TURN-SWITCHING FOR A BASE IPM MOTOR WITH NINE STATOR TURNS}

The electrical characteristics of the base reference electric motor are shown in Fig. 5. Note that the number of turns is 9, the maximum current is $212 \mathrm{~A}$, and the voltage limit is $250 \mathrm{~V}$.

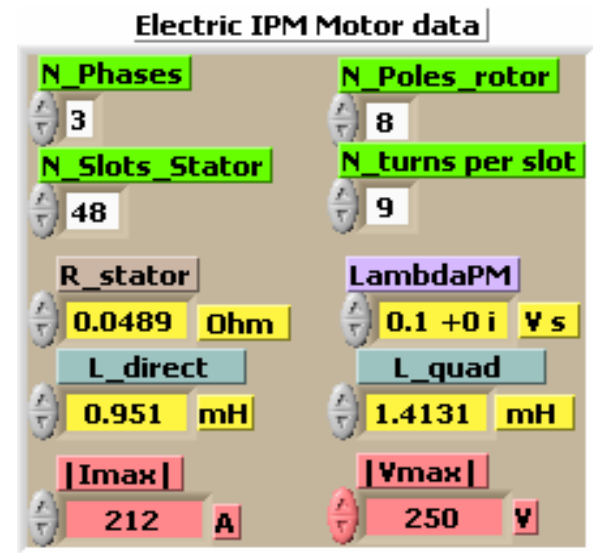

Fig. 5. Characteristic parameters of the base electric IPM motor.

Switching the turns of the reference motor by a factor of 2 implies switching between 9-18 turns. Operation with 18 turns can be attained by grouping the wires in each phase into 2 bundles and connecting their ends in series. To operate with the original nine turns, the two bundles are connected in parallel. While operating with 18 turns, the motor's ohmic resistance and inductances are 4 times larger and the rotor-linked flux is twice as larger as that of the base 9-turn values shown in Fig. 5. The names EV1 and EV2 are used to refer to the vehicles using the base 9 turns and 9-18 switchable turns IPM motors as prime-movers, respectively. When the IPM motor in vehicle EV2 operates with nine turns, then it is identical to vehicle EV1.

\subsection{EV FOLLOWING STANDARD DRIVING CYCLES}

Appendix A shows the driving cycles color coded according to the performance of EV1.

Table 2 shows the time in seconds that the prime-mover failed to supply the full amount of power required, the energy deficit, the time it was turned OFF, and the time it performed as required for each driving cycle and vehicle. It shows that EV1 failed to follow the speed profile for time lengths between 2-43 seconds during five of the cycles; numbers $3,5,6,7$, and 8 . The energy deficits ranged from a negligible $0.03 \%$ to a significant $3.69 \%$ of the total cycle's energy demand. In the US06 cycle, the fixedturn-motor failed over $7 \%$ of the total cycle time, which corresponds to $10 \%$ of the time it was running, and failed to deliver $3.7 \%$ of the energy demanded by the vehicle. This US06 cycle failure is analyzed in Section 4.1.1 in more detail.

As Table 2 shows, the 9-18 turn-switching-motor in vehicle EV2 never failed to provide the full power demanded in any cycle. 
Table 2. Time in seconds the prime-movers in EV1 and EV2 failed to meet the power demand, EV1's energy deficit in percent of cycle total, total time the prime-mover was OFF, and time the prime-movers succeeded in supplying the vehicle's demand for each driving cycle

\begin{tabular}{|c|c|c|c|c|c|c|c|}
\hline \multirow{2}{*}{$\begin{array}{c}\text { Cycle } \\
\text { ID } \\
\#\end{array}$} & \multirow{2}{*}{$\begin{array}{l}\text { Driving } \\
\text { Cycle } \\
\text { Name }\end{array}$} & \multicolumn{2}{|c|}{$\begin{array}{l}\text { Failed Time } \\
\text { s }\end{array}$} & \multirow{2}{*}{$\begin{array}{c}\text { \% Energy } \\
\text { Defficit } \\
\text { EV1 }\end{array}$} & \multirow{2}{*}{$\begin{array}{c}\text { OFF } \\
\text { Time } \\
\mathbf{s}\end{array}$} & \multicolumn{2}{|c|}{$\begin{array}{c}\text { Success Time } \\
\mathbf{s}\end{array}$} \\
\hline & & EV1] & EV2 & & & EV1] & EV2 \\
\hline$\# 1$ & FUDS & 0 & $\mathbf{0}$ & 0 & 568 & 805 & 805 \\
\hline$\# 2$ & FHDS & $\mathbf{0}$ & $\mathbf{0}$ & D & 74 & 691 & 691 \\
\hline$\# 3$ & HDV_FUDS & 2 & 0 & 0.03 & 519 & 520 & 522 \\
\hline$\# 4$ & NewEurope & $\mathbf{0}$ & 0 & 0 & 447 & 714 & 714 \\
\hline$\# 5$ & NYCity & 7 & 0 & 1.97 & 323 & 236 & 243 \\
\hline \#6 & NYCityTruck & 4 & 0 & 0.14 & 689 & 320 & 324 \\
\hline$\# 7$ & US06 & 43 & 0 & 3.69 & 182 & 377 & 420 \\
\hline$\# 8$ & US06_hwy & 8 & $\mathbf{0}$ & 1.65 & 61 & 301 & 309 \\
\hline
\end{tabular}

Note that the power and energy demand averages shown in this study were computed over the amount of time the motor was actively generating torque (see Table 2.) If we computed over the cycle duration time in Table 1, the values shown for average power and energy demanded from the battery would decrease proportionally to the ratio between the two time references.

\subsubsection{Performance Comparison of Vehicles EV1 and EV2 on the US06 Cycle}

Figures 6(a) and 6(b) show the terminal voltages for EV1 and EV2, respectively, as a function of time for the US06 driving cycle. It is clear that the turn-switching-motor in EV2 makes better use of the available $250 \mathrm{~V}$. The turn-switching-motor requires less voltage regulation, places fewer switching demands on the electronic power drive, and therefore has better efficiency.

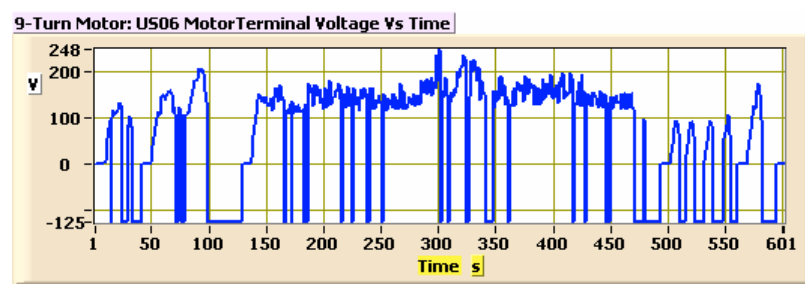

(a) EV1's nine-turn IPM motor.

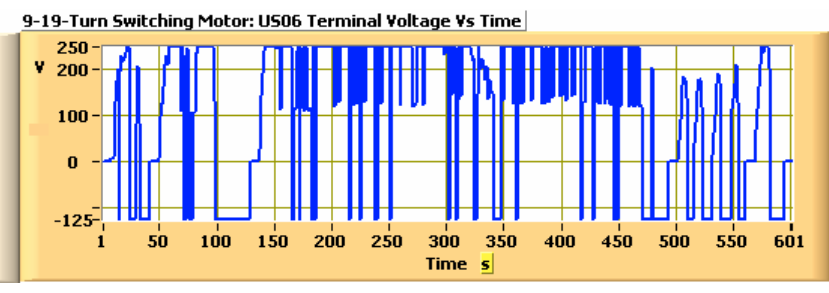

(b) EV2's 9-18 turn-switching IPM motor.

Fig. 6. Terminal voltage for the US06 cycle.

Similarly, Figs. 7(a) and 7(b) show the stator current for EV1 and EV2, respectively, as a function of time for the US06 driving cycle. These figures show consistently lower current levels for EV2 with the turnswitching-motor, which reduces ohmic losses and enables it to meet all power demands without ever reaching the 212 A maximum limit. 


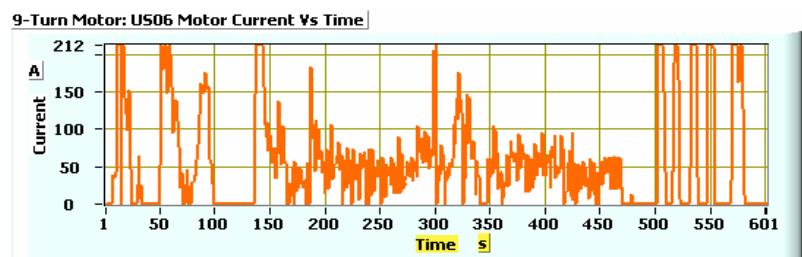

(a) EV1's nine-turn IPM motor.

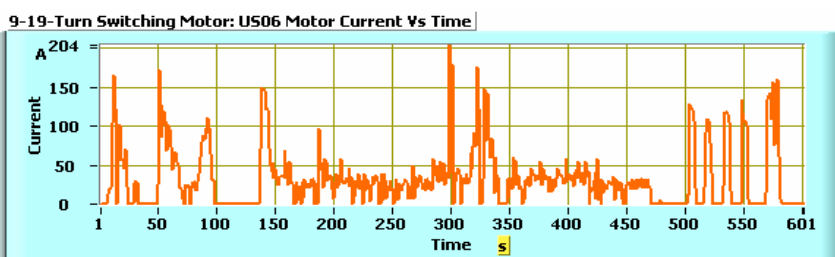

(b) EV2's 9-18 turn-switching IPM motor.

Fig. 7. Stator current along the US06 cycle.

Figures 8(a) and 8(b) show the efficiency of the motor in each vehicle as a function of time for the US06 driving cycle. There is a clear efficiency advantage of over $2 \%$ for the motor with turn-switching capability at most times.

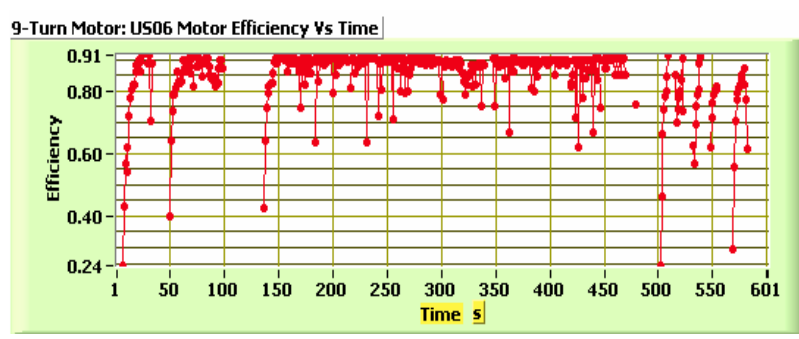

(a) EV1's nine-turn IPM motor.

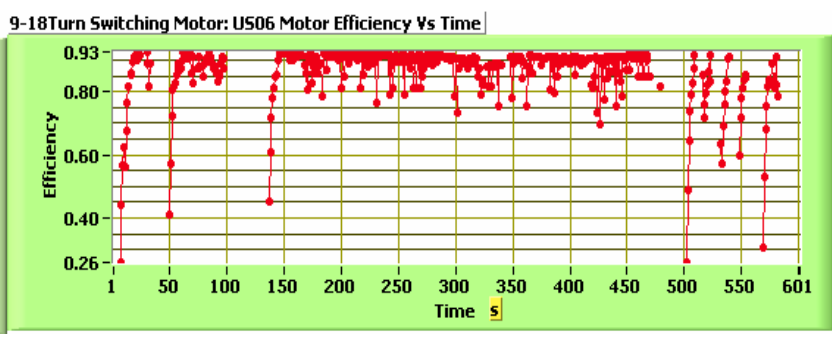

(b) EV2's 9-18 turn-switching IPM motor.

Fig. 8. Efficiency of electrical-to-mechanical conversion along the US06 Cycle.

Figures 9(a) and 9(b) show the efficiency of the remainder of the electrical components in each vehicle as a function of vehicle speed. There is a clear gain of efficiency in the electrical system of vehicle EV2, with the highest gains at low speeds. For instance, at $20 \mathrm{mph}$ the overall electrical system efficiencies are about $75 \%$ for EV1 and $91 \%$ for EV2 for a net gain of $16 \%$.

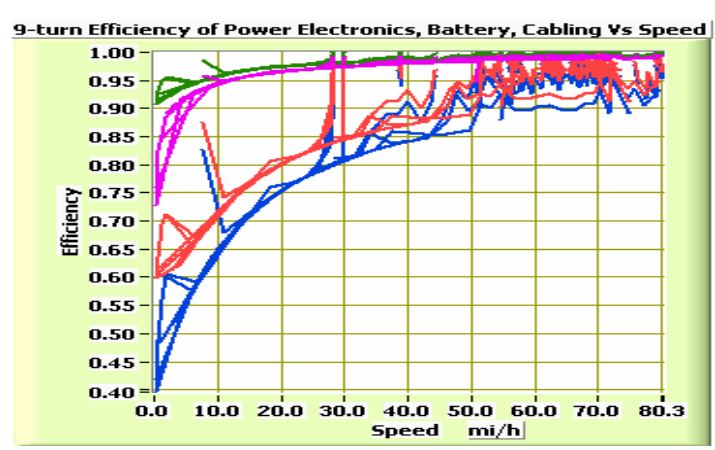

(a) EV1.

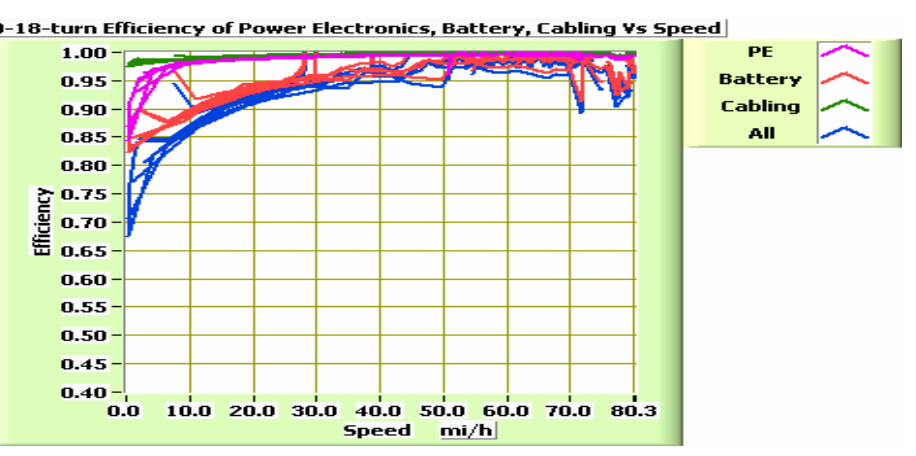

(b) EV2.

Fig. 9. Efficiency of power electronics (PEs), battery, and cabling vs. speed for the US06 cycle.

As summarized in Table 3, the overall increase in full vehicle efficiency for the US06 Cycle is 6\% when the turn-switching-motor is used; that is vehicle EV2 has 6\% higher efficiency than vehicle EV1 on the US06 cycle. 
Table 3. Summary of savings achieved by stator turn-switching (maximum and minimum values for each column are shown in bold face)

\begin{tabular}{|c|c|c|c|c|c|c|c|c|}
\hline \multirow{3}{*}{ Figure $\# \rightarrow$} & \multicolumn{4}{|c|}{ EV } & \multicolumn{4}{|c|}{ 0-20 mph HEV } \\
\hline & \multicolumn{4}{|c|}{ Vehicle Energy and Power Savings } & \multicolumn{4}{|c|}{ Vehicle Energy and Power Savings } \\
\hline & $19 b$ & $21 a$ & $21 b$ & 16 & 29 & $31 a$ & 30 & $31 b$ \\
\hline Cycle Name & $\begin{array}{l}\text { kJoule } \\
(\mathrm{kJ}) / \text { mile }\end{array}$ & $\begin{array}{c}\% \\
\text { Energy }\end{array}$ & $\begin{array}{c}\% \\
\text { Energy } \\
\text { Relative }\end{array}$ & $\begin{array}{c}\% \\
\text { Peak Power } \\
\text { Relative }\end{array}$ & kJ & $\begin{array}{c}\% \\
\text { Energy } \\
\text { Relative }\end{array}$ & kW & $\begin{array}{c}\% \\
\text { Power } \\
\text { Relative }\end{array}$ \\
\hline FUDS & 119 & 6.4 & 12.6 & 16.3 & 32 & 22.4 & 4.3 & 18.3 \\
\hline FHDS & 28 & 2.8 & 3.6 & 13.5 & 34 & 23.4 & 6 & 22 \\
\hline HDV-FUDS & 74 & 5 & 8.5 & 17.3 & 24 & 13.5 & 2.5 & 16.1 \\
\hline New Europe & 62 & 4.3 & 7 & 5.1 & 56 & 15.1 & 2.9 & 14.2 \\
\hline NYCity & 265 & 8.4 & 26.9 & 19.6 & 32 & 21.3 & 5 & 18.7 \\
\hline NYCityTruck & 175 & 6.3 & 16.7 & 17.3 & 38 & 17.1 & 9.1 & 38.9 \\
\hline US06 & 63 & 6 & 10.4 & INC & INC & INC & INC & INC \\
\hline US06 hwy & 43 & 3.7 & 5.1 & INC & INC & INC & INC & INC \\
\hline
\end{tabular}

Note, INC stands for Incomparable, because the base motor failed to fully satisfy the demand.

The motor's output torque as a function of vehicle speed for the US06 cycle is show in Figs. 10(a) and 10(b). The points above the 600 Newton meter (Nm) torque level shown in Fig. 10(b) that are missing in Fig. 10(a) correspond to instances in which the standard motor failed to fully deliver the power demanded by the vehicle.

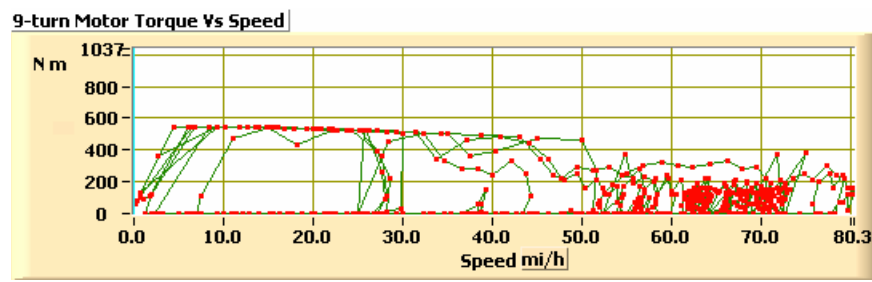

(a) EV1's nine-turn IPM motor.

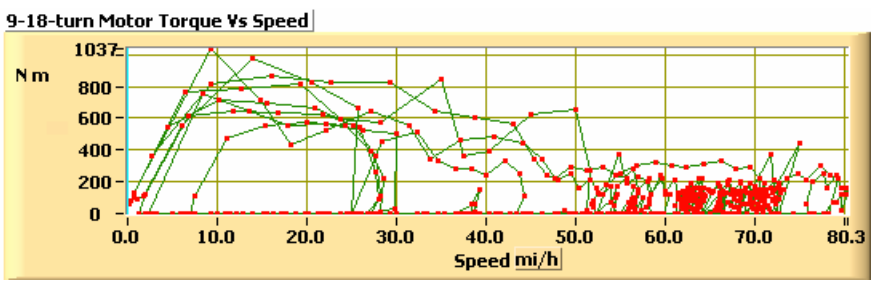

(b) EV2's 9-18 turn-switching IPM motor.

Fig. 10. Output torque as a function of vehicle speed for the US06 cycle.

For completeness, the components to the reference vehicle's force demand on the tires are shown in Fig. 11 in logarithmic scale. Multiplying by the vehicle's speed in $\mathrm{m} / \mathrm{s}$ will yield the propulsion power demand in W. These forces are common to both EV1 and EV2 vehicles. 
US06 BreakDown of Axle Force Demand Vs Time

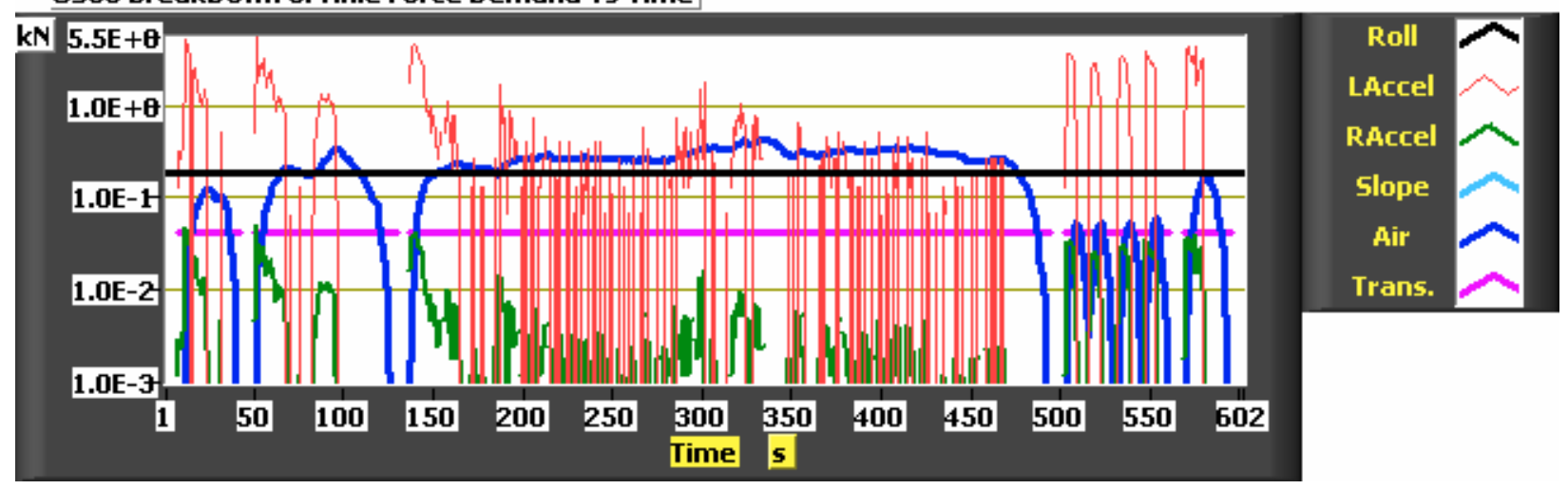

Fig. 11. Breakdown of forces on the prime-mover's axle from rolling resistance, linear and rotational acceleration, air resistance, and transmission loss for the US06 cycle.

Figure 11 shows the dominance of the acceleration components during acceleration periods, the importance of air resistance at high speeds, and the constancy and importance of the rolling resistance at all times which, below about $40 \mathrm{mph}$ and in the absence of accelerations, exceeds all others.

\subsubsection{Analysis of EV1's Failure to Perform on the US06 Cycle}

Figures 12(a)-(d) show various parameters as a function of time for vehicle EV1 on the full US06 cycle, first minute details, and midpoint details. Respectively, these parameters are vehicle speed, motor power demand, power output, terminal voltage, and stator current. The stator current curves in Fig. 12(d) clearly show that the times of failure coincide with instances when the motor attempted to draw more current than the allowed maximum limit.

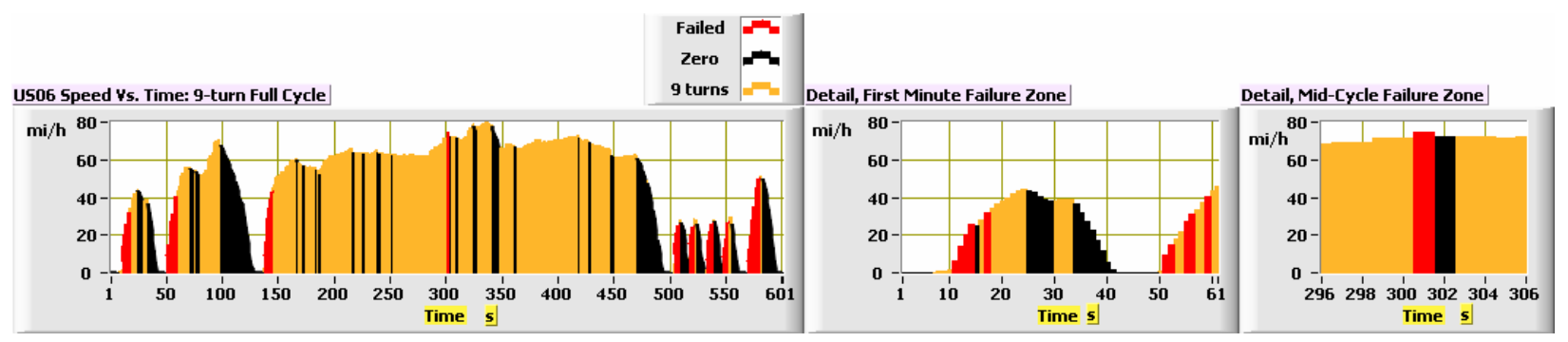

Fig. 12(a). Failed zones, colored red, of EV1 on the US06 cycle.

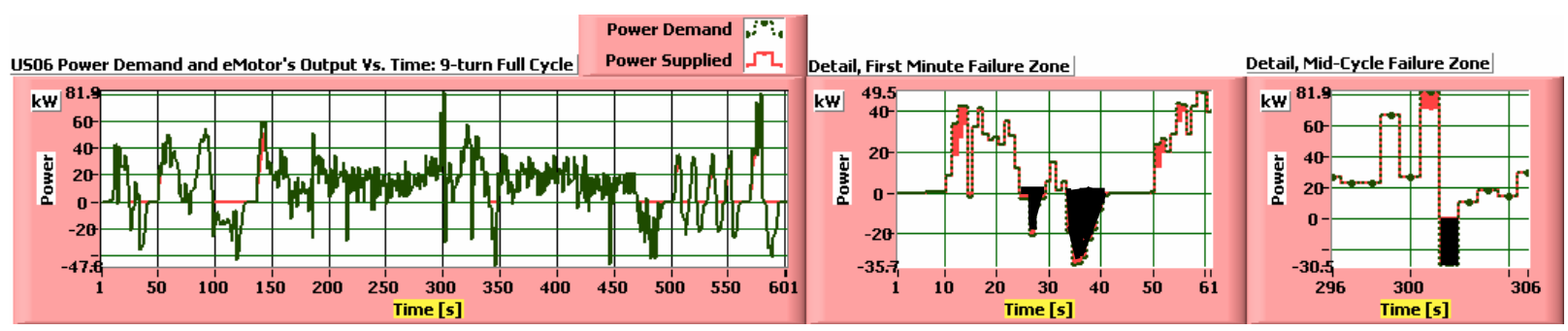

Fig. 12(b). Power demand and supply for EV1's nine-turn motor on the US06 cycle. 

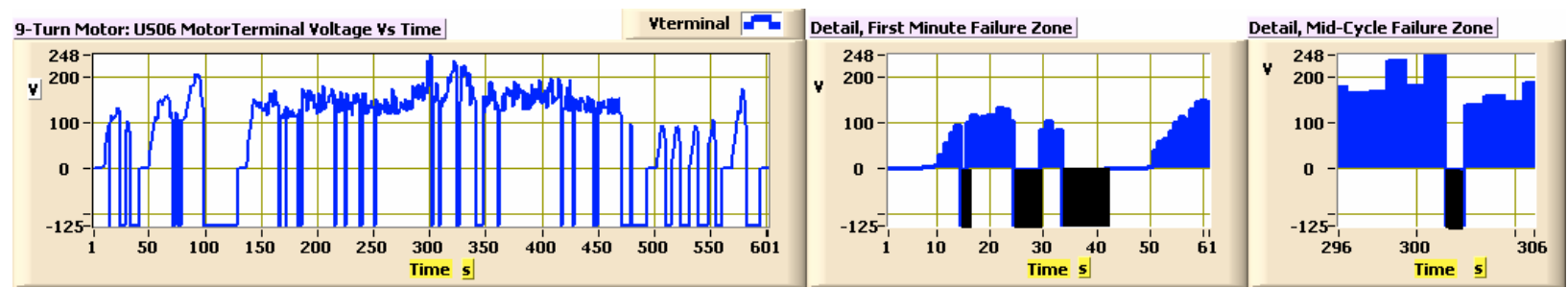

Fig. 12(c). Terminal voltage for EV1's nine-turn motor on the US06 cycle.
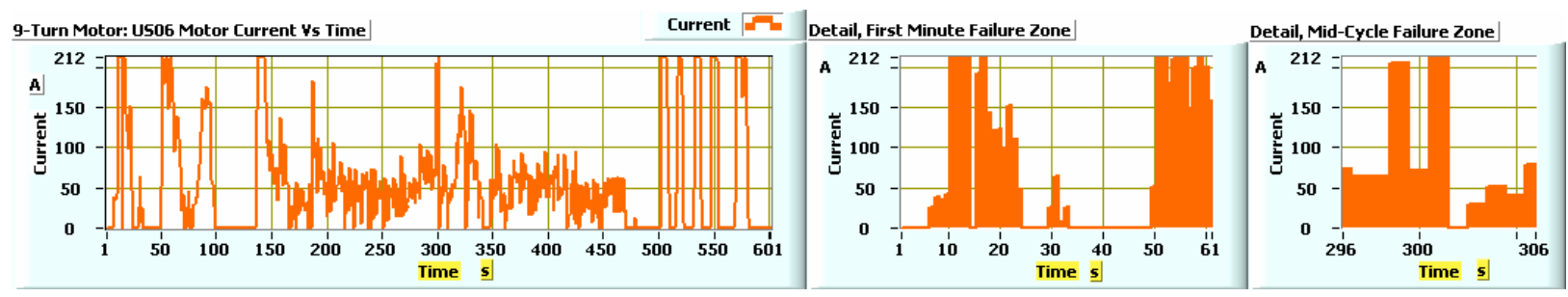

Fig. 12(d). Stator current for EV1's nine-turn motor on the US06 cycle.

Figure 12(c) shows that the voltage remained below the limit of $250 \mathrm{~V}$ for the duration of the cycle. Only once around the 300 second point did the voltage get within $2 \mathrm{~V}$ of the limit at a time when, as seen in Fig. 12(d), the current reached the 212 A limit.

Consequently, in order to fix EV1's performance problem, the current limit must be increased or more torque must be produced with the same amount of current by switching to a higher number of turns. It is clear though that voltage boosting will have no impact in this case since, as shown in Fig. 12(c), the available voltage is not being fully utilized at the critical times.

Note that the black zones in the voltage graphs of Fig.12(c) correspond to the back-emf generated by the rotor's PMs by the rotor as it turns. This voltage depends on the speed of the rotor and the number of turns in the stator.

Also note that in Fig. 12(b) the black-colored areas are negative power and represent the amount of active braking power required by the vehicle, which in turn indicates the amount of energy available for regeneration and recharging the battery.

\subsubsection{Effect of Magnetic Saturation on the Computation of Vehicle Performance}

The magnetic permeability of the iron used in the stator and rotor of an electric motor is not necessarily uniform since it depends on the strength of the local magnetic field. In a mathematical simulation, the simplest approach is to treat the magnetic permeability as a constant. A better approach is to model magnetic saturation as mathematically detailed as possible. Like the d-q model used in our simulation, Eqs. (1-9), in parametric models a common approach is to modify the value of pertinent model parameters with the strength of the stator's mmf, which equals the magnitude of the product of the stator current and the number of turns. Except for the case in Fig. 13(b), saturation has been included in all computations included in this study. 
US06 with 9-turn motor with magnetic saturation

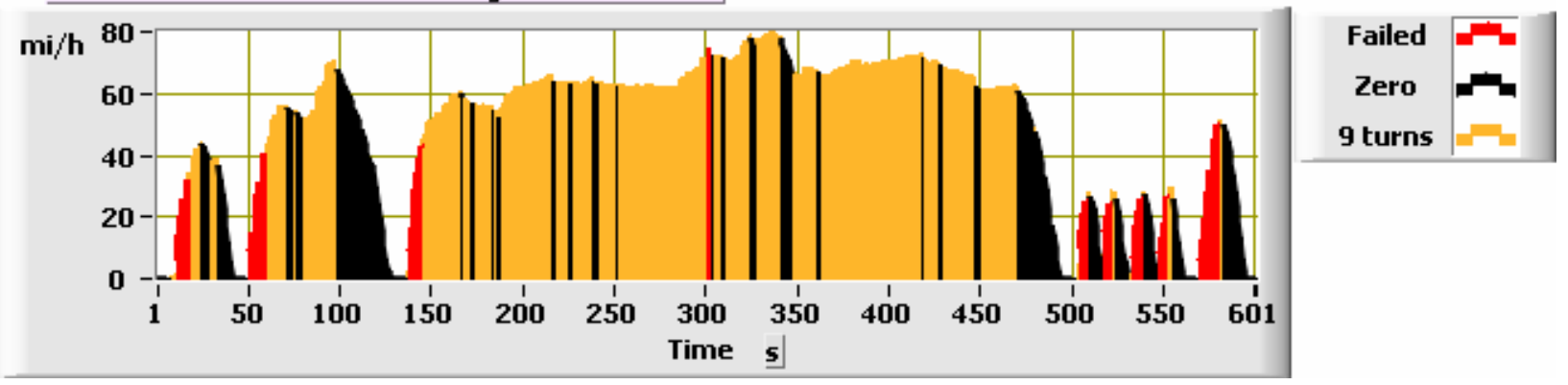

(a) With magnetic saturation.

US06 with 9-turn motor without magnetic saturation

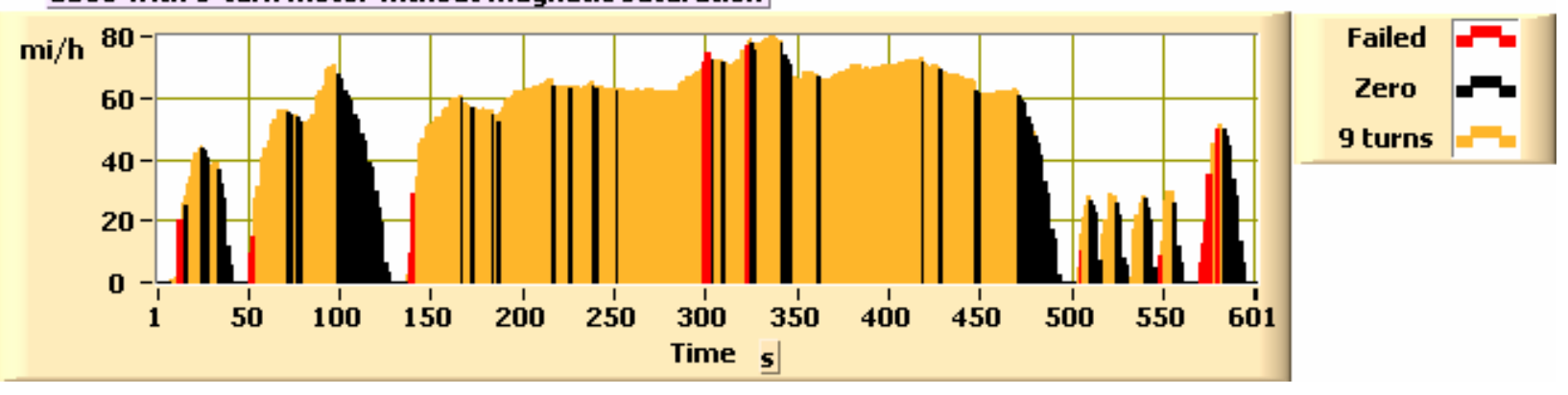

(b) Without magnetic saturation.

Fig. 13. Failure zones for EV1 in the US06 cycle due to the nine-turn motor.

Often, as shown in Figs. 13(a) and 13(b), neglecting saturation over-estimates the performance of an electric motor. The total red-colored area, indicating failure of the motor to supply the requested power, is significantly smaller in Fig. 13(b) without saturation, than in Fig. 13(a), which includes saturation effects.

\subsubsection{Comparison of Battery Power Requirements for EV1 and EV2 Vehicles}

Figures 14, 15, and 16 shows information pertaining to the peak and average power demanded from the battery of EV1 and EV2 in each driving cycle.

To facilitate comparative analyses of the performance of the two motors, some figures are accompanied by a (b) plot without crossed-out lines over EV1's data. In these cases, the (a) plot denotes raw data while the (b) plot denotes filtered data. Filtered data eliminates from consideration those cycle segments in which the motor of EV1 failed to meet the power demanded by the vehicle, thus giving the two motors a proper basis for comparison; but the cycles are not complete. Consequently, corrected figures - with a (b) plot without cross-outs - should only be used for comparative analysis between the two motors.

The information in Fig. 14(a) correctly indicates that for cycle \#7 (US06), the peak battery demand for EV2 is $120 \mathrm{~kW}$, while for EV1 it is about $104 \mathrm{~kW}$; but it would be erroneous to conclude that turnswitching would require a larger battery for this cycle, since it is lower because it failed to meet the vehicle's peak demand. The corrected data in Fig. 14(b) instead shows that, during those cycle segments where both motors fully met the vehicle's demand, the power demands for both motors appear to be similar, with a peak value of about $95 \mathrm{~kW}$. 


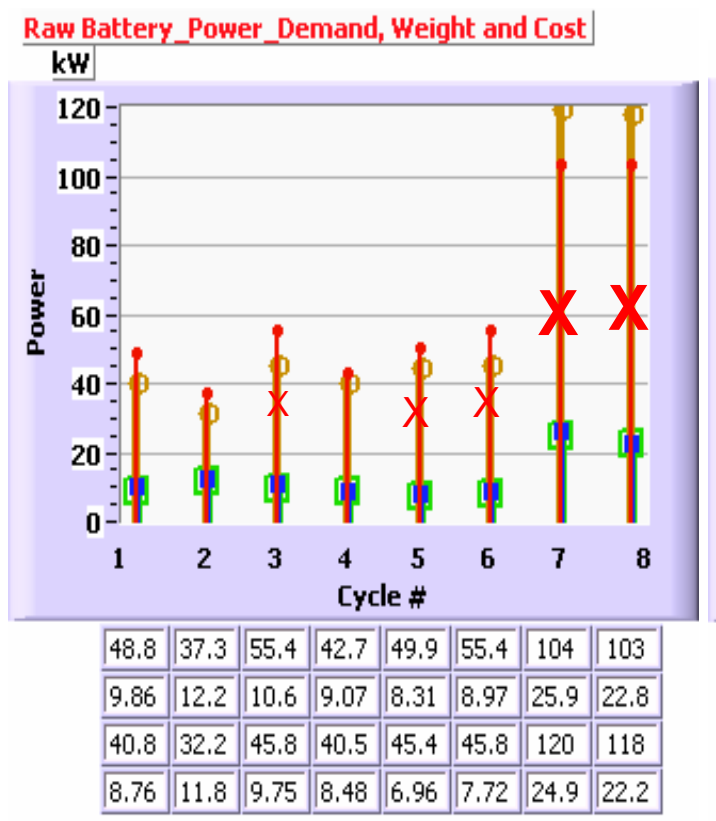

(a) Raw.

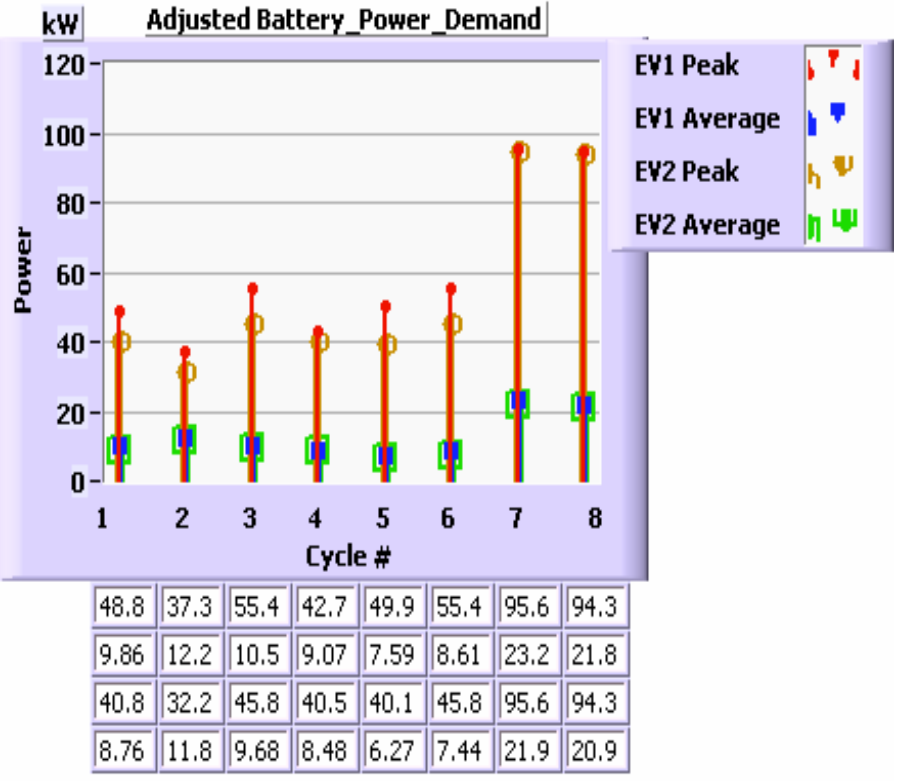

(b) Adjusted for failed periods.

Fig. 14. Peak and average power demand on the battery for EV1 and EV2.

Battery_Power_Demand Peak To Average Ratio

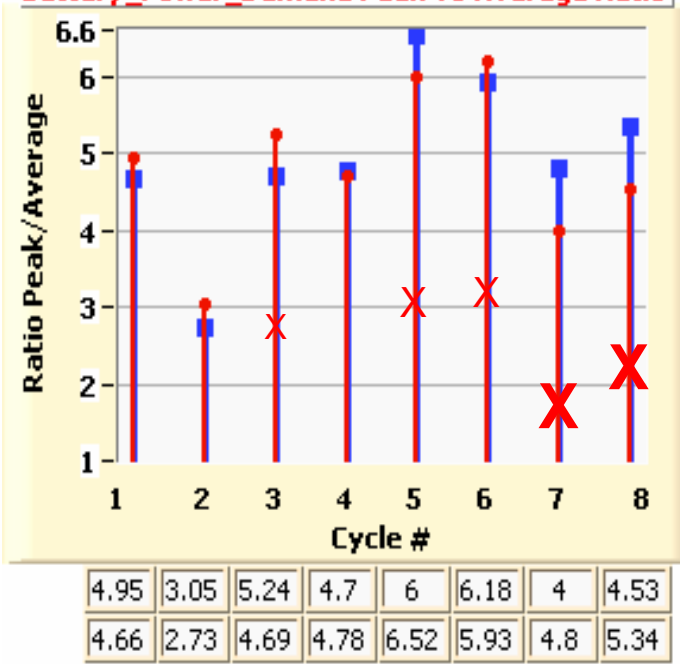

(a) Raw.
Adjusted Battery_Power_Demand Peak To Average Ratio

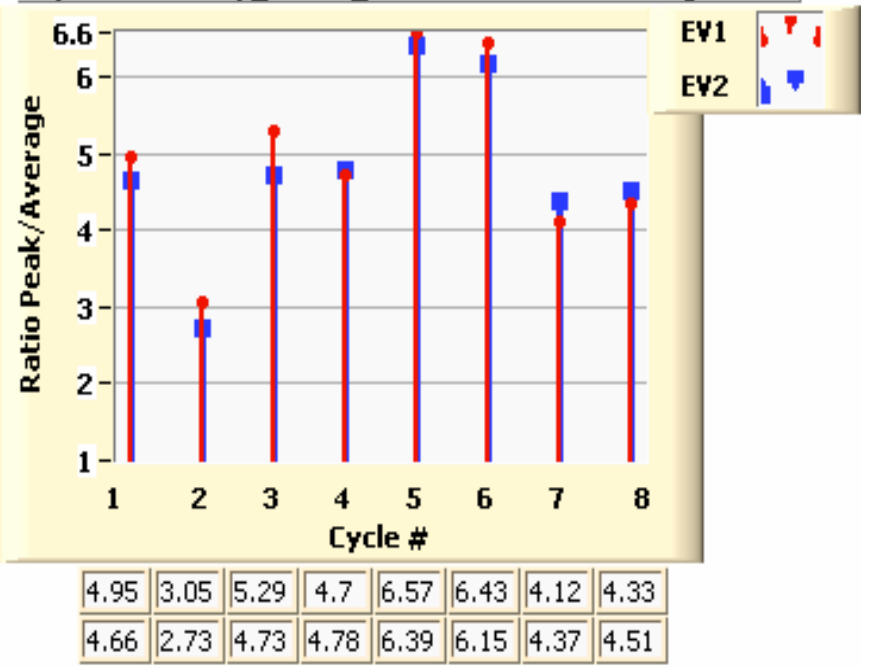

(b) Adjusted for failed periods.

Fig. 15. Peak/average ratio of battery power demand for EV1 and EV2. 


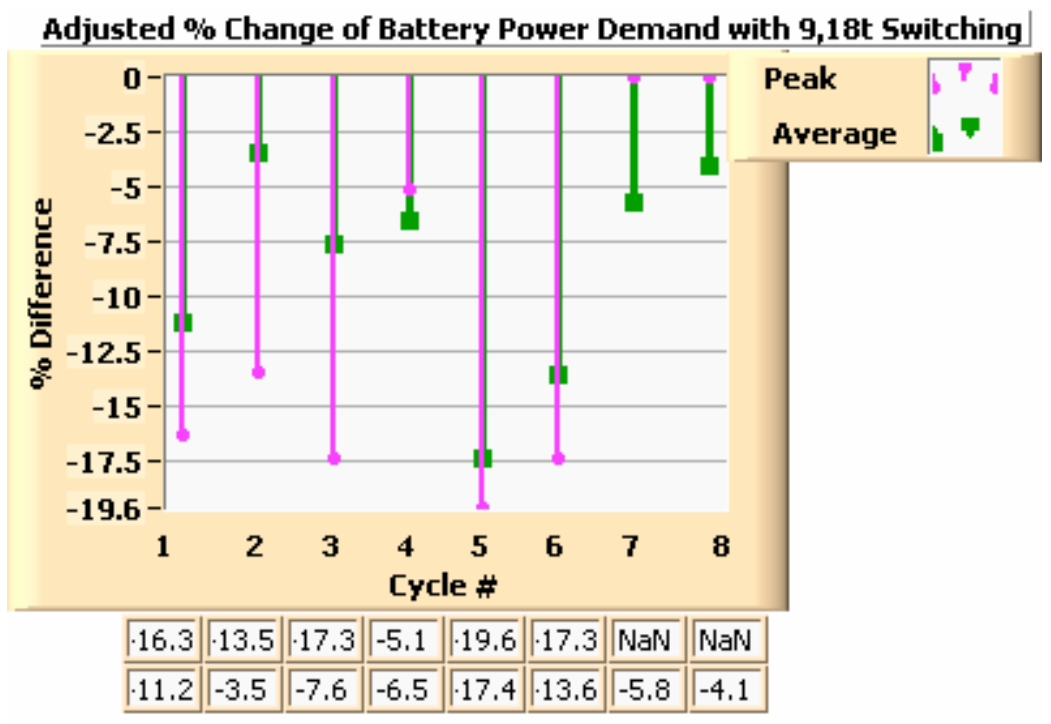

Fig. 16. Percent change of peak and average battery power demand relative to base motor (adjusted for failed periods).

Figures 15(a) and (b) show the ratio of peak-to-average power demand on the battery for EV1 and EV2 in each driving cycle. The power values in Fig. 15(a) are correct for EV2 but incorrect for those cycles in which EV1 failed to meet the demand. Figure 15(b) shows that the corrected peak-to-average ratio is better for EV2 in five of the eight cycles - numbers 1, 2, 3, 5, and 6; is similar to EV1's in cycle \#4, New Europe; and is slightly worse for both US06 cycles, numbers 7 and 8.

Figure 16, derived from data in Figs. 14(a) and 14(b), shows the relative change in peak and average battery power demands for EV2 in percent of the values for EV1 where both met the same demands. The improvement in peak and average demands vary significantly with the driving cycle. According to Fig. 16, the peak battery power demand for EV1 is between 5-19.6\% higher (i.e., worse) for six of the eight driving cycles analyzed, and appears to be the same for the two US06 cycles, numbers 7 and 8 , because of the elimination of the regions in which the motor in EV1 failed. The average battery power demand is lower for EV2 for all cycles, improving from about 3.5\% for the FHDS \#2, to about 17.4\% for the New York City cycle (NYCC) \#5.

The improvement in average power demand in all driving cycles is important since it quantifies the reduction in energy demand. Thus, from Fig. 16 we can conclude that with the turn-switching-motor savings of between 5.1-19.6\% in battery size depending on the driving cycle can be achieved when the battery is peak-power-bound.

\subsubsection{Comparison of EV1 and EV2 Battery Energy Storage Requirements}

The total battery capacity required for each driving cycle is shown in Figs. 17 and 18 in absolute energy and in energy per mile units, respectively. The total energy demand is the sum of the propulsion energy demand, previously shown in Fig. 2(a), and all losses associated with the generation of propulsion energy via the battery-cabling-inverter-electric motor system. US06 is the cycle requiring the most energy from the battery but it is also one of the longest cycles. In terms of per unit distance, the NYCC requires the most energy and the largest battery whose size depends upon the product of the specified range and the energy per mile. 


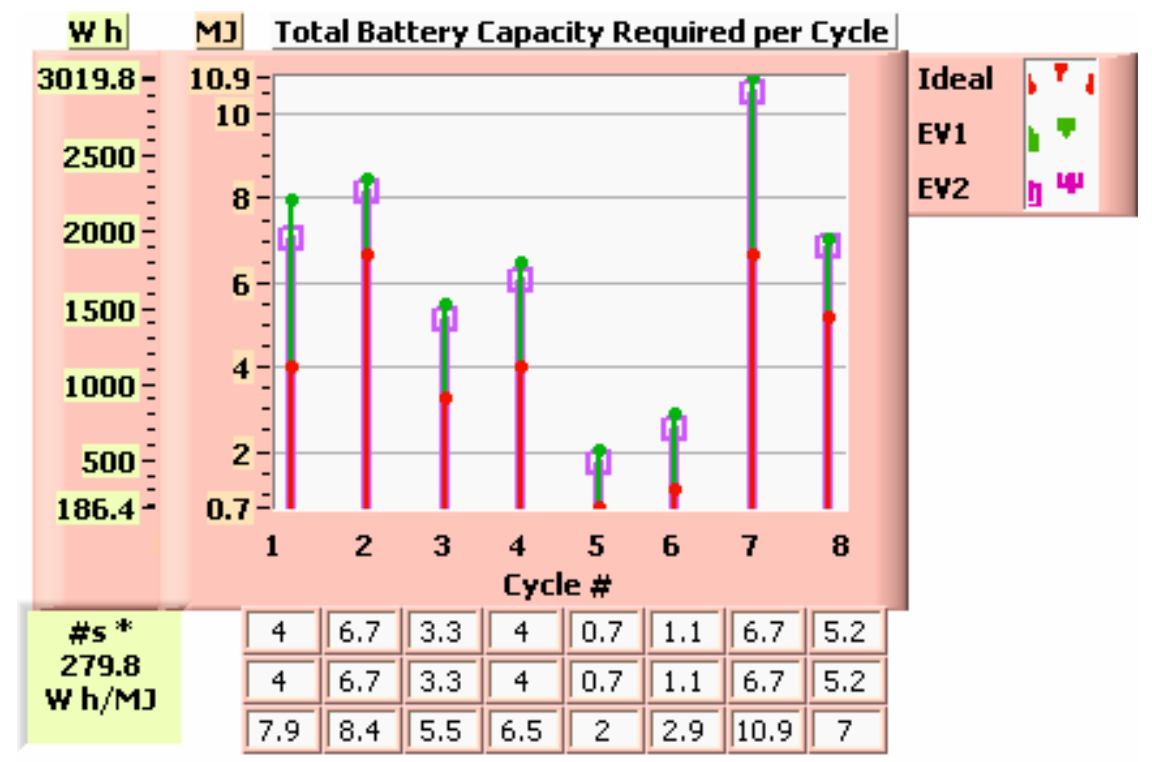

Fig. 17. Total battery energy demand with ideal propulsion with EV1's 9-turn motor and with EV2's 9-18 turn-switching motor.

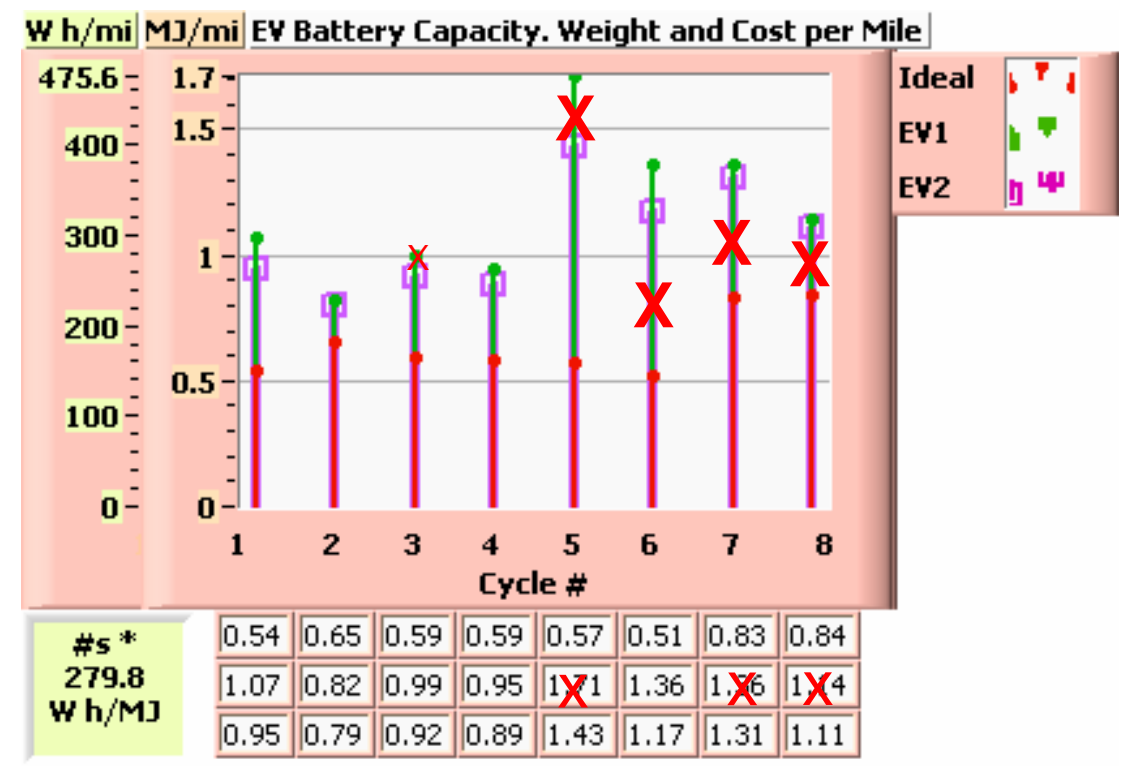

Fig. 18. Average battery energy demand per mile with ideal propulsion with EV1's 9-turn motor and with EV2's 9-18 turn-switching motor.

Figures 19(a) and 19(b) show the difference in battery energy demand between EV2 and EV1 whose absolute value is the energy savings obtained by replacing the fixed 9-turn IPM motor with its 9-18 turnswitching version. The savings vary from about 30-270 kJ per mile, with the highest reduction in battery energy demand corresponding to NYCC \#5. 


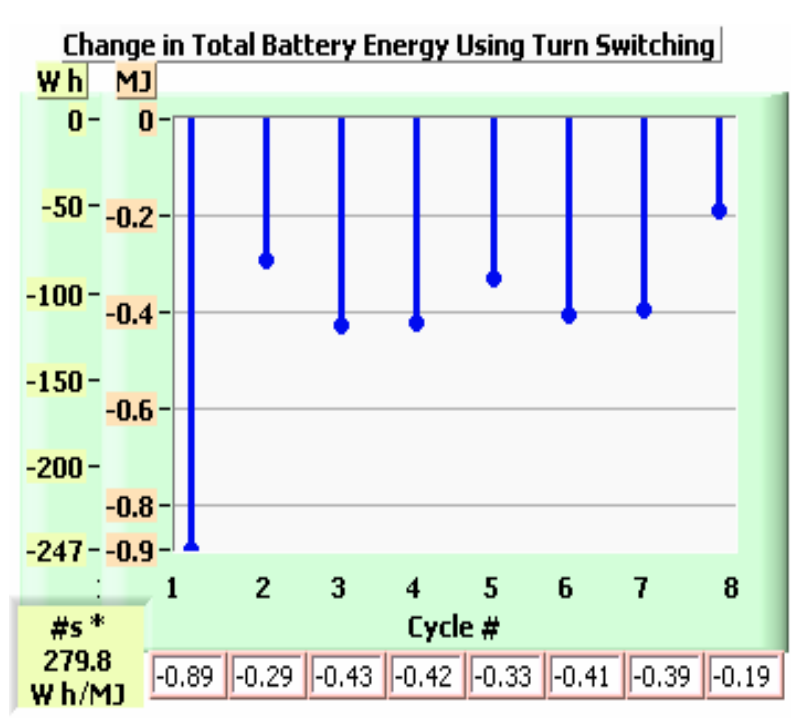

(a) Total energy.
Change in Battery Energy per Mile Using Turn Switching $\underline{W} \mathbf{h} / \mathrm{mi} \quad \mathbf{k J} / \mathrm{mi}$

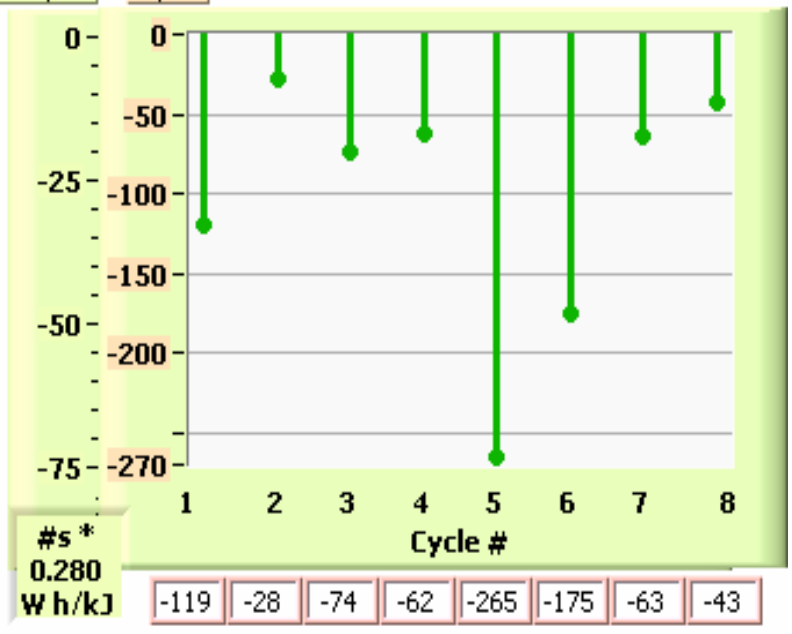

(b) Average energy per mile.

Fig. 19. Change in average battery energy demand with the 9-18 turn-switching motor.

\subsubsection{Comparison of Overall Efficiencies of EV1 and EV2}

The overall system efficiencies from battery to road surface are shown in Fig. 20. The overall efficiency varies significantly depending on the driving cycle and motor, ranging from about $32 \%$ for the NYCC \#5, to $82 \%$ for the FHDS \#2. Efficiencies are higher for EV2 in all cycles in spite of the over-estimation of efficiencies for EV1 on those cycles in which its fixed-turn-motor failed to supply some of the peak demands.

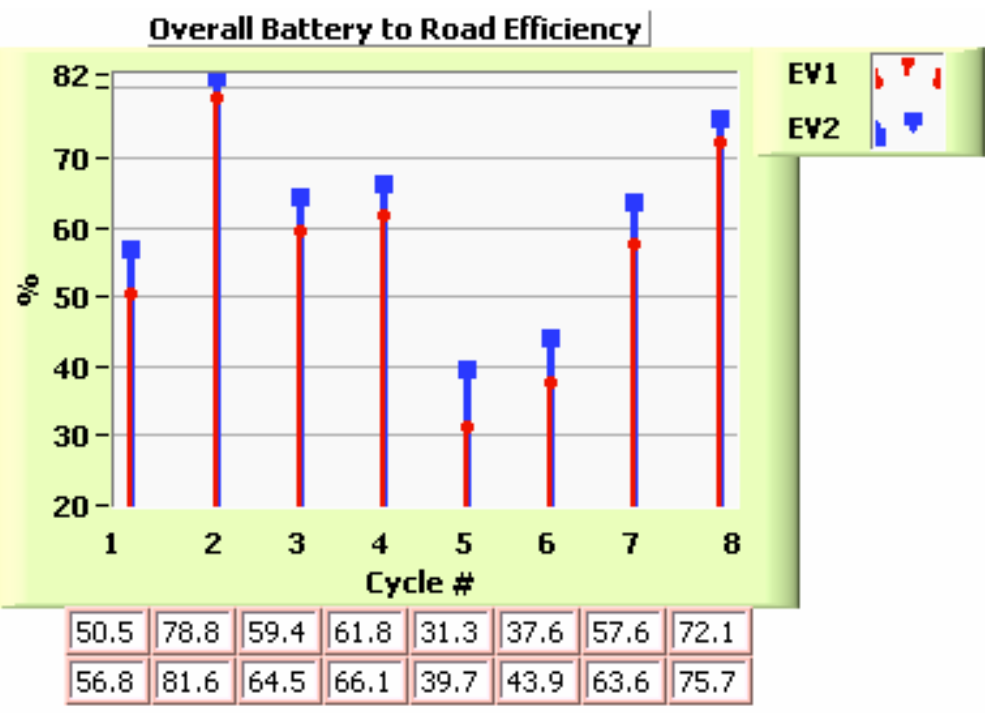

Fig. 20. Overall efficiency from battery to road for EV1 and EV2.

The efficiency gains obtained by using the turn-switching instead of the base motor are shown in Figs. 21(a) and 21(b). Figure 21(a) shows a net efficiency gain of between $2.8 \%$ for the FHDS cycle \#2, and $8.4 \%$ for the NYCC \#5. Figure 21(b) shows that EV2, the vehicle equipped with the 9-18 turn- 
switching-motor, is between 3.6-26.9\% more efficient than EV1, the vehicle equipped with the traditional 9-turn version.

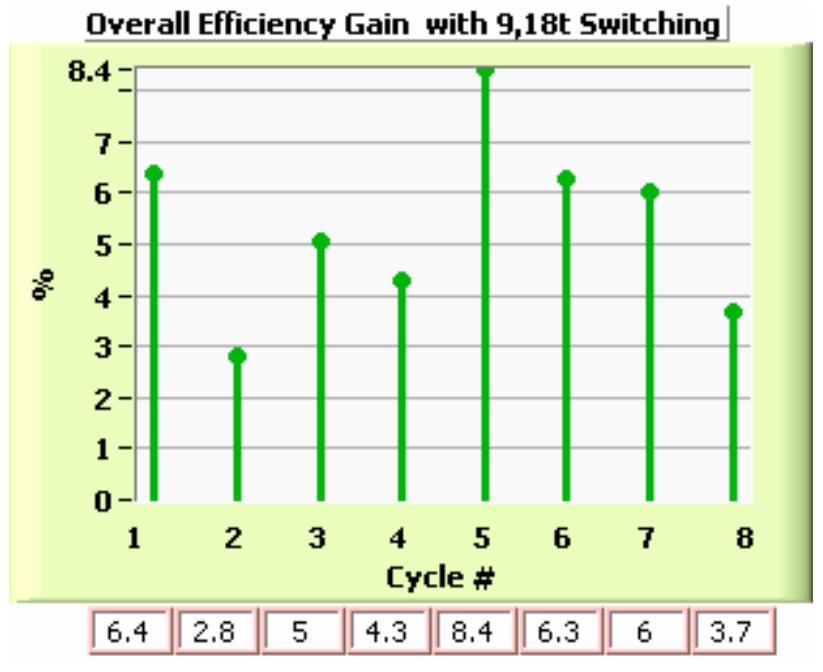

(a) Absolute net efficiency.

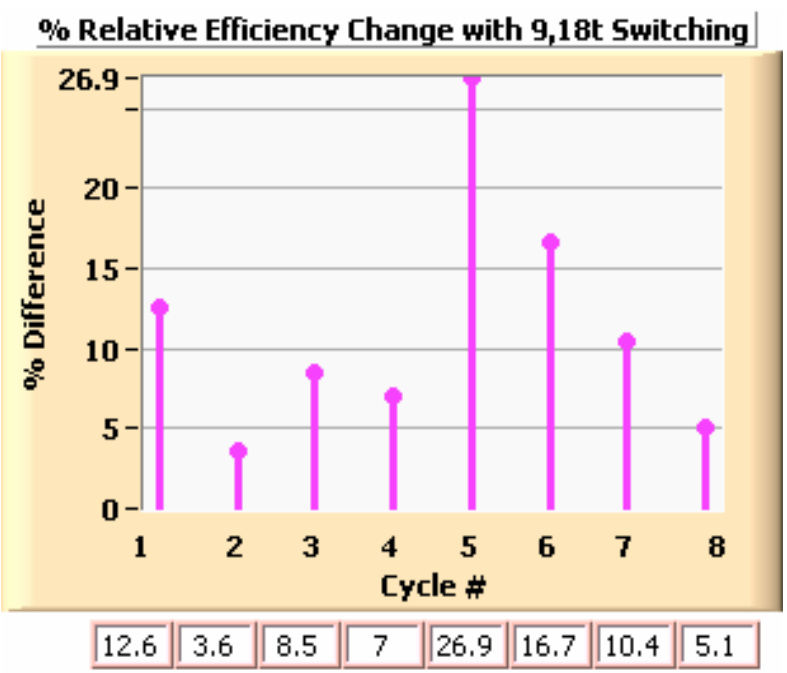

(b) Relative to efficiency of EV1.

Fig. 21. Change in overall efficiency from battery to road with 9-18 turn-switching.

\subsubsection{Impact of Turn-Switching on EV's Battery Size and Cost}

Battery size is determined by the total energy and peak power demands of the vehicle system and by the capabilities and price of the battery technology selected. Power delivery requirements set the minimum battery size, while the energy storage requirement, which depends on the travel range without recharging, determines the actual battery sizes above the minimum.

For this study we considered the reference vehicle to be outfitted with a battery that meets the U.S. Advanced Battery Consortium's minimum goals for EV batteries ${ }^{2}, 50 \mathrm{~W}$ h/kg, $300 \mathrm{~W} / \mathrm{kg}$, and 150 $\$ / \mathrm{kW}$ h, which imply costs of $22.5 \$ / \mathrm{kg}$ and $75 \$ / \mathrm{kW}$. Note that batteries cannot be discharged fully without reducing their lifespan. Presently, $20 \%$ is the low-charge limit for “deep-discharge” batteries so that, at most, $80 \%$ of the stored energy can be discharged routinely. The sizing values shown below are based on ideal $100 \%$ discharge of the batteries; consequently, actual values will be larger. For instance, for an $80 \%$ discharge limit, the weights and costs would be $25 \%$ larger than shown.

The power demand depends on the driving cycle type but not on the number of times the cycle length is driven to cover the vehicle's range. Figure 22 shows the minimum battery size and cost for each driving cycle considered. As indicated by the caption below, the weight and cost axes of this figure was obtained from the peak and average power demand data of Fig. 14(a) by dividing them by $300 \mathrm{~W} / \mathrm{kg}$ and multiplying by $75 \$ / \mathrm{kW}$, respectively.

As Fig. 22 shows, on account of peak power and average power demands, the US06 cycle would require the largest battery. For EV2, the battery would be about $400 \mathrm{~kg}$ if sized for peak power and $80 \mathrm{~kg}$ if sized for average power, at costs of about $\$ 9,000$ and $\$ 1,800$, respectively. For EV1, the sizes will be higher but it cannot be inferred exactly from Fig. 22 for those cycles marked with the red $\mathrm{X}$ in which the motor failed to follow the demands. 


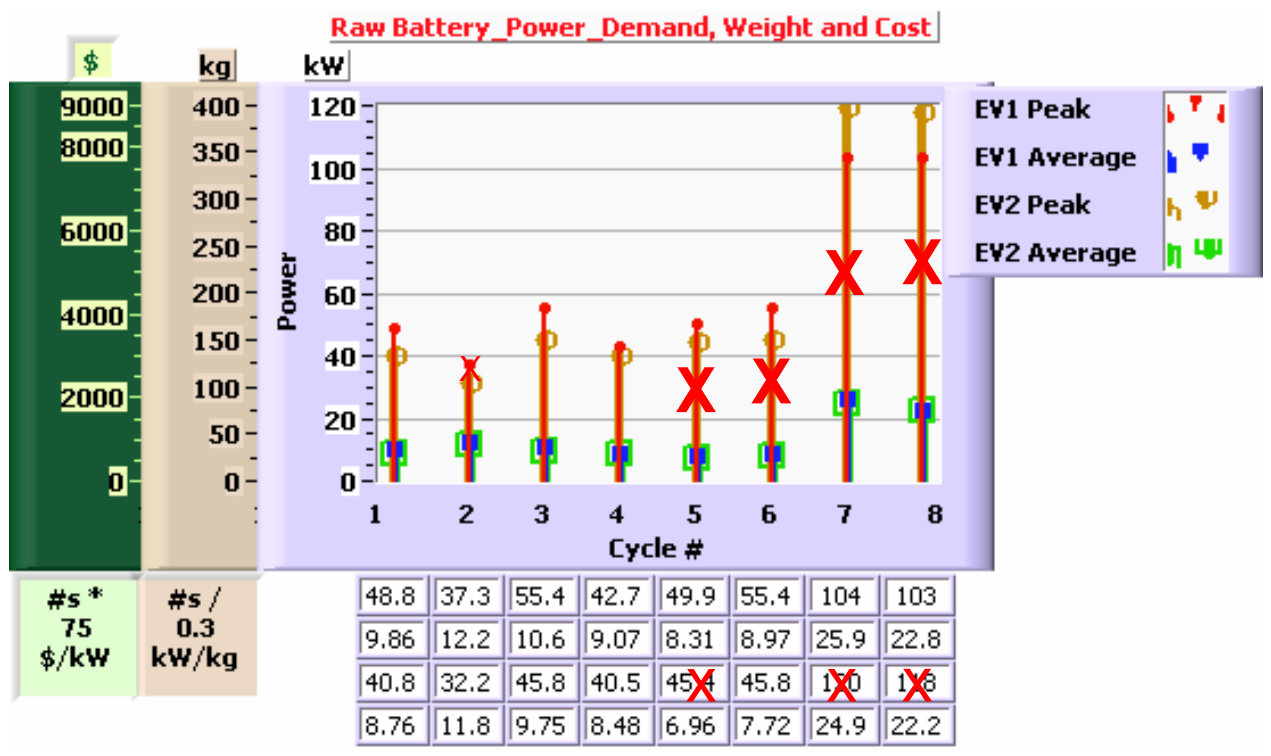

Fig. 22. Battery power demand, weight, and cost per mile for EV1 and EV2.

To determine the range of the vehicle with a particular battery size, the energy per mile demanded by each cycle must be considered. To this end, Fig. 23 shows the energy demand and associated battery weight and cost in per-mile scale to facilitate comparative analyses among the cycles and vehicles. In addition to showing the values for EV1 and EV2, the values for an ideal prime-mover are included in order to show the lowest possible battery sizes and costs for each driving cycle.

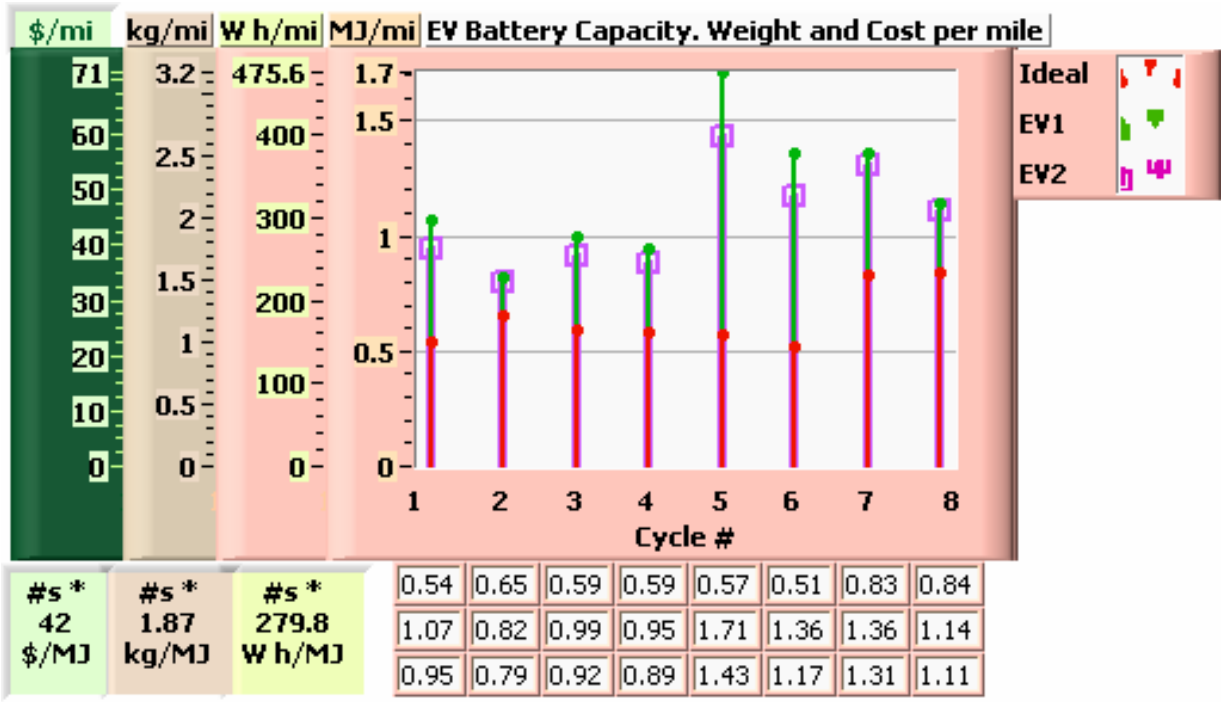

Fig. 23. Average EV battery energy demand, weight, and cost per mile with ideal base 9-turn motor and 9-18 turn-switching motor prime-movers.

For the vehicle with the ideal prime-mover, the range of energy demands goes from $0.51 \mathrm{MJ} / \mathrm{mi}$ for the NYCT \#6, to $0.84 \mathrm{MJ} / \mathrm{mi}$ for the US06 Highway cycle \#8. The corresponding weights and costs range from $0.954 \mathrm{~kg} / \mathrm{mi}$ and $21.42 \$ / \mathrm{mi}$ to $1.57 \mathrm{~kg} / \mathrm{mi}$ and $35.28 \$ / \mathrm{mi}$. Note that with a typical value of $40 \mathrm{MJ} /$ gallon corresponding to a 33\% efficiency for the process of electrical energy delivery by the battery generated with a gasoline engine, the ideal range of $0.51 \mathrm{MJ} / \mathrm{mi}$ to $0.84 \mathrm{MJ} / \mathrm{mi}$ translates to 
$0.01275 \mathrm{gal} / \mathrm{mi}$ to $0.021 \mathrm{gal} / \mathrm{mi}$ or $78.4 \mathrm{mi} / \mathrm{gal}$ to $47.6 \mathrm{mi} / \mathrm{gal}$. This is interesting because these values for the ideal $100 \%$ efficient prime-mover are so close to the federal fuel economy standards goals of exceeding $40 \mathrm{mpg}$ by the year 2015 and $55 \mathrm{mpg}$ by the year 2025 that it is clear that improving the efficiency of the prime-mover itself may not be enough. There will be a need to reduce the energy demand by reducing air-drag and tire-rolling losses and improve the efficiency of generating electricity with the primary fuel to better the 33\% typical nowadays. Note that increasing the efficiency of the combustion engine will have a doubling effect by improving both the prime-mover and the electrical generation efficiency.

Figure 23 shows the worst driving case with both electric motors is that of NYCC \#5 with per mile requirements of $1.71 \mathrm{MJ}$ and $3.2 \mathrm{~kg}$ battery, costing $\$ 72$ for EV1. For EV2, which is equipped with the turn-switching-motor, a smaller battery is needed weighing $2.7 \mathrm{~kg} / \mathrm{mi}$ and costing $\$ 60 / \mathrm{mi}$ for the same NYCC \#5. Figure 23 also shows that EV2 has its best performance when running the FHDS \#2, with requirements of $0.79 \mathrm{MJ} / \mathrm{mi}$ and battery of weight $1.48 \mathrm{~kg} / \mathrm{mi}$ and cost of $33 \$ / \mathrm{mi}$.

Note that Fig. 23 shows that for the ideal-prime-mover, the US06 cycle numbers 7 and 8 have the highest battery requirement instead of the NYCC \#5. This makes it clear that the electric motors did not run efficiently at the low speeds of the NYCC. For this cycle, the vehicle's wheel-to-rotor gear ratio should be increased above the 4.114 value shown in Fig. 1 in order to operate the IPM motors at higher speeds where they are more efficient. This illustrates the need to tune the link between the prime-mover and the vehicle in order to optimally match the prime-mover's performance to the driving cycle's demand.

\subsubsection{Vehicle Range with Minimum Battery Size Required for Power Delivery}

The ranges of the vehicles EV1 and EV2 when fitted with the minimum battery size needed to fulfill the power demand on each cycle are shown in Fig. 24 and were obtained by combining data in Figs. 22 and 23. For instance, the vehicle EV2 with the $400 \mathrm{~kg}$ battery needed for the peak US06 cycle power will have a range of 160 miles, which amounts to a distance equivalent to 20 full US06 cycle lengths.

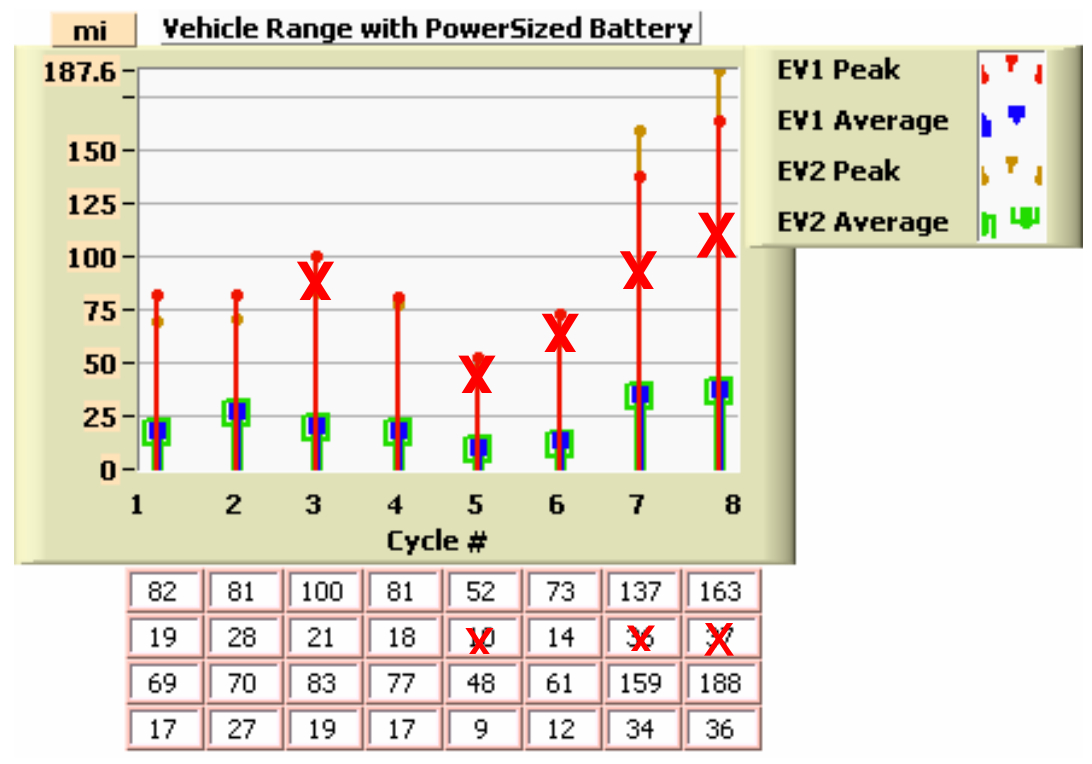

Fig. 24. Range of vehicle with the battery sized to meet the cycles' power demand when configured with the base 9-turn and the 9-18 turn-switching motors. 
The battery size and cost for a specific travel range can be directly computed from data in Fig. 23 by multiplying the axes labeled "kg/mi" and "\$/mi” by the desired range. If the battery is sized for a travel range smaller than the value shown in Fig. 24 for some driving cycle, then the vehicle will not be able to fully follow that particular cycle.

Note when the travel range desired is larger than the values in Fig. 24, then battery sizing is "energy" bound; otherwise, the battery sizing is "power" (discharge rate) bound. Thus, comparing the miles in Fig. 24 to the distances of each cycle in Table 1, it can be concluded that for runs of a single cycle length, the battery is "power-bound" for all eight cycles considered.

\subsubsection{Difference in Battery Size Required by EV1 and EV2}

This section shows the improvement in battery size when the turn-switching-motor is used. The gains are shown in absolute and relative terms of weight and cost. Absolute gains are computed by taking the difference between the needs of EV2 and EV1. The relative gains, in percent terms, are obtained by dividing the absolute gains by the values of EV1.

When the battery sizing is power-bound, Fig. 25 shows that the highest absolute gains in peak battery power correspond to both the Heavy Duty Vehicle Federal Urban Driving cycle \#3 (HDV-FUDS) and the NYCT \#6, with peak gains of $9.6 \mathrm{~kW}, 32 \mathrm{~kg}$ and \$720. Note according to Fig. 24, for EV1 power-bound for these two cycles means that the driving distances are shorter than 100 and 73 miles, respectively.

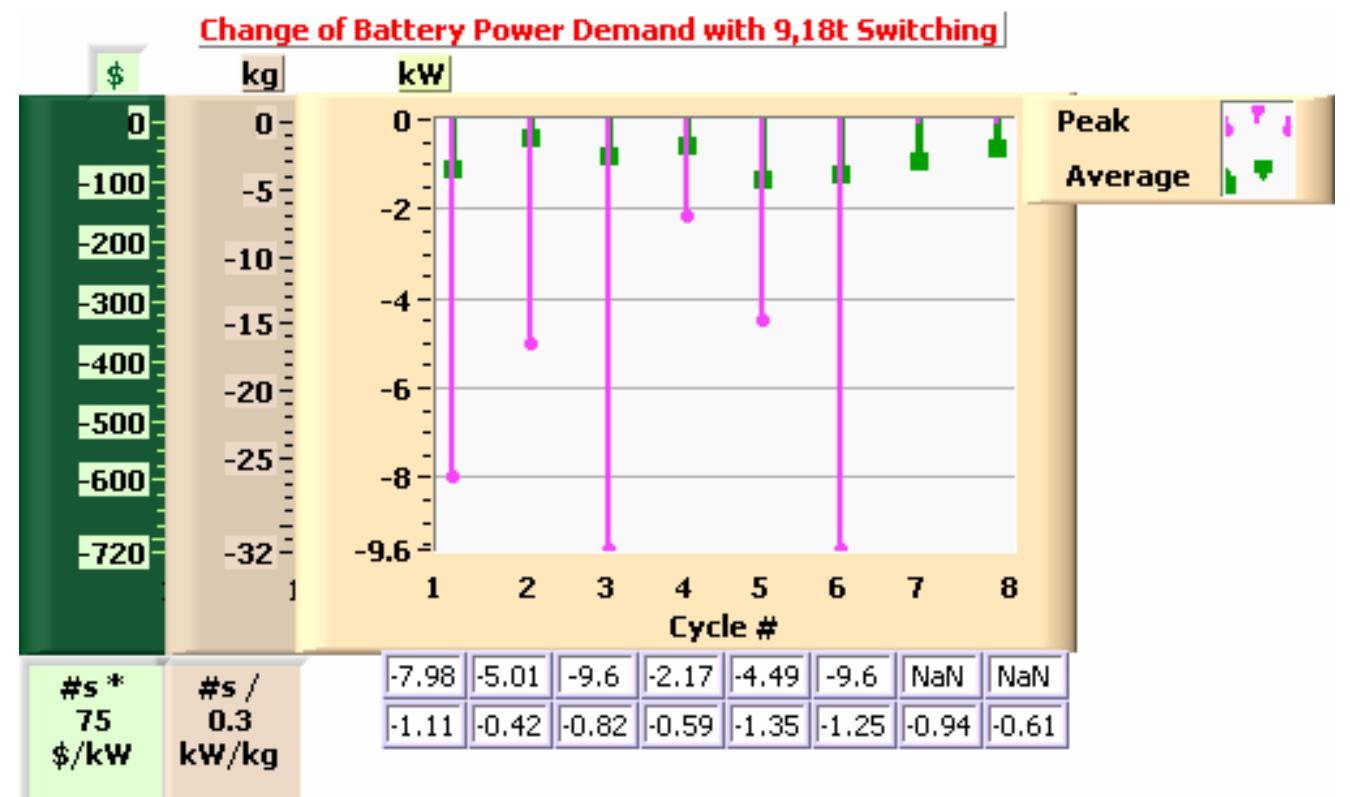

Fig. 25. Change in battery power demand, weight, and cost using the 9-18 turn-switching motor.

Figure 25 also shows that the highest absolute gains in average battery power requirement correspond to the NYCC \#5, with gains of $1.35 \mathrm{~kW}, 4.5 \mathrm{~kg}$, and $\$ 101$.

When the battery sizing is energy-bound, Fig. 26 shows that turn switching benefits the most when the vehicle runs the NYCC \#5, with per-mile savings of $265 \mathrm{~kJ}, 0.5 \mathrm{~kg}$, and $\$ 11$. For a 100 mile range, the savings in battery cost will amount to $\$ 1,125$ while saving over $50 \mathrm{~kg}$ in weight. 


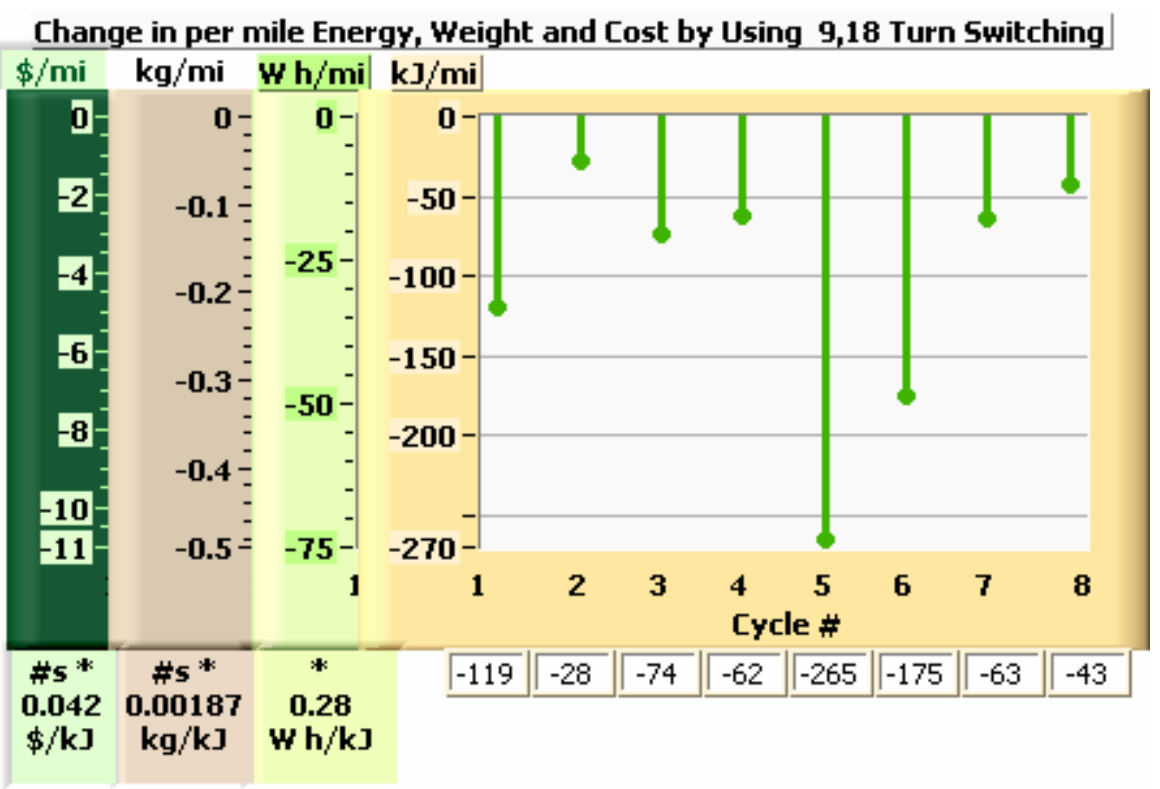

Fig. 26. Change in battery energy demand, weight, and cost per mile using the 9-18 turn-switching motor instead of the base 9-turn motor for propulsion.

To illustrate the driving-range effect, we compare the two vehicles subject to FUDS \#1 type driving, for 50 and 100 mile ranges. As shown in Fig. 25 for the 50 mile range, the battery is power-bound and the battery savings with the turn-switching-motor amounts to about $27 \mathrm{~kg}$ and $\$ 600$; while for the 100 mile range, the battery is energy-bound and the savings depend on the distance; which according to Fig. 26 will amount to $22 \mathrm{~kg}$ and $\$ 500$.

In percent terms, the benefits of turn switching in battery cost and weight also depend on whether the battery is power-bound or energy-bound. For the energy-bound case, the gains are the same as shown in Fig. 21(b) for overall efficiency; they vary between 3.8\% for FHDS \#2 driving and 27\% for NYCC \#5 driving. For the power-bound case, the gains are those shown for peak power in Fig. 16; they vary between 5\% for New Europe cycle \#4 driving and 19.6\% for NYCC \#5 driving.

The positive impact of the turn-switching-motor on the peak-to-average power demand for EV1 and EV2 is shown in Fig. 15(b). A reduction in the peak-to-average power ratio not only reduces thermomechanical stress, but when the battery sizing is power-limited it also reduces battery weight and cost.

\subsection{HEV FOR STANDARD DRIVING CYCLE STARTS}

Some hybrid vehicles use the electric motor to accelerate from zero to a set speed, at which time the internal combustion engine starts and fulfills all or part of the power demand. In order to assess the impact of turn switching on these hybrids, the performance of the two reference vehicles EV1 and EV2 renamed HEV1 and HEV2 respectively to prevent confusions when presenting the results, during the initial starting periods of the same eight driving cycles shown in Table 1.

\subsubsection{Battery Energy and Power Requirements for HEV1 and HEV2}

In the Figs. 27 and 28, the values for HEV1 on the two US06 cycles are shown crossed out because it failed to fully meet the vehicle's demand and thus they do not represent the US06 cycles. The turnswitching-motor in HEV2 fulfilled the demanded power on all cycles. 


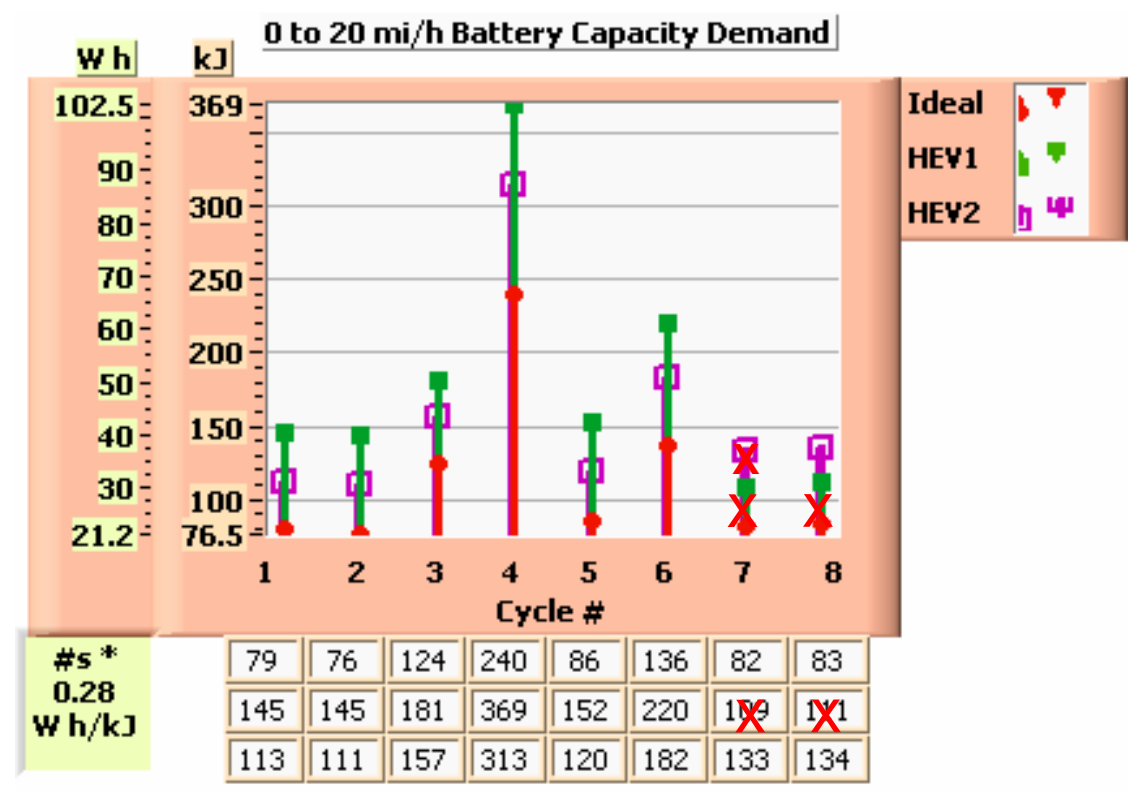

Fig. 27. Energy required for HEV from 0-20 mph for each cycle's initial start.

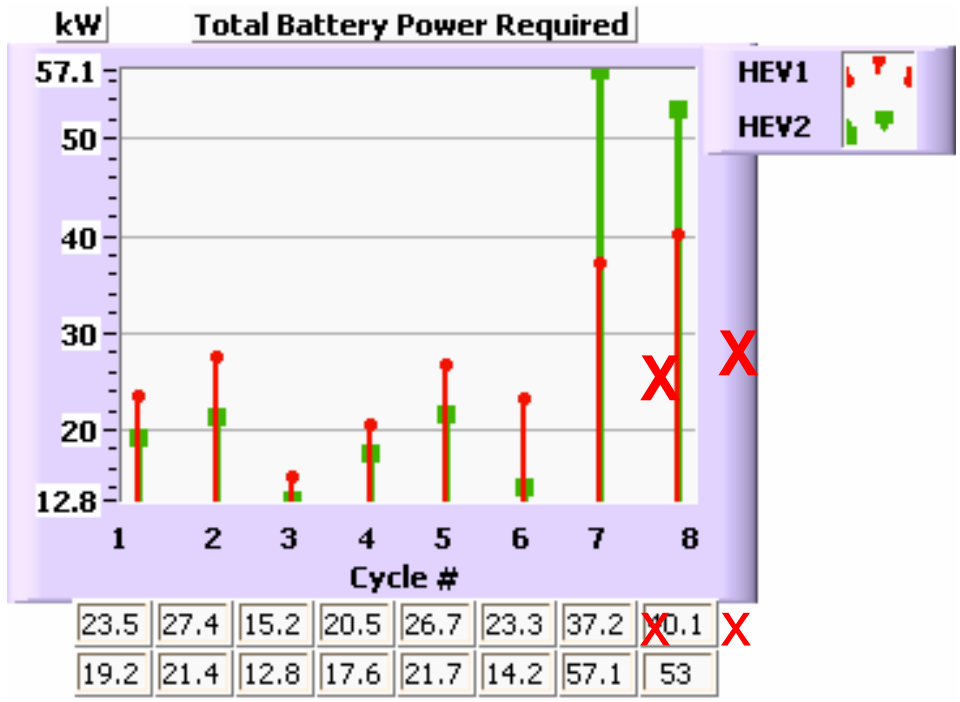

Fig. 28. Peak power required for HEV from 0-20 mph for each cycle's initial start.

Figure 27 shows the energy demanded from the battery by the reference vehicle fitted with an ideal prime-mover and for the two HEVs at the start of each cycle. As Fig. 27 shows, the New Europe cycle \#4 demands the most energy from all three vehicles. Figure 28, in turn, shows that the two US06 cycles \#7 and \#8, demand the most power during the 0-20 mph starting period.

\subsubsection{Change in HEV battery energy and power needs with turn-switching}

Figure 29 shows the difference in battery energy demand between HEV2 and HEV1. Their absolute values correspond to the reduction in energy demand associated with the replacement of the 9-turn motor with its 9-18 turn-switching version. The savings range from about $24 \mathrm{~kJ}$ for the HDV-FUDS \#3, to $56 \mathrm{~kJ}$ for the New Europe cycle \#4. 


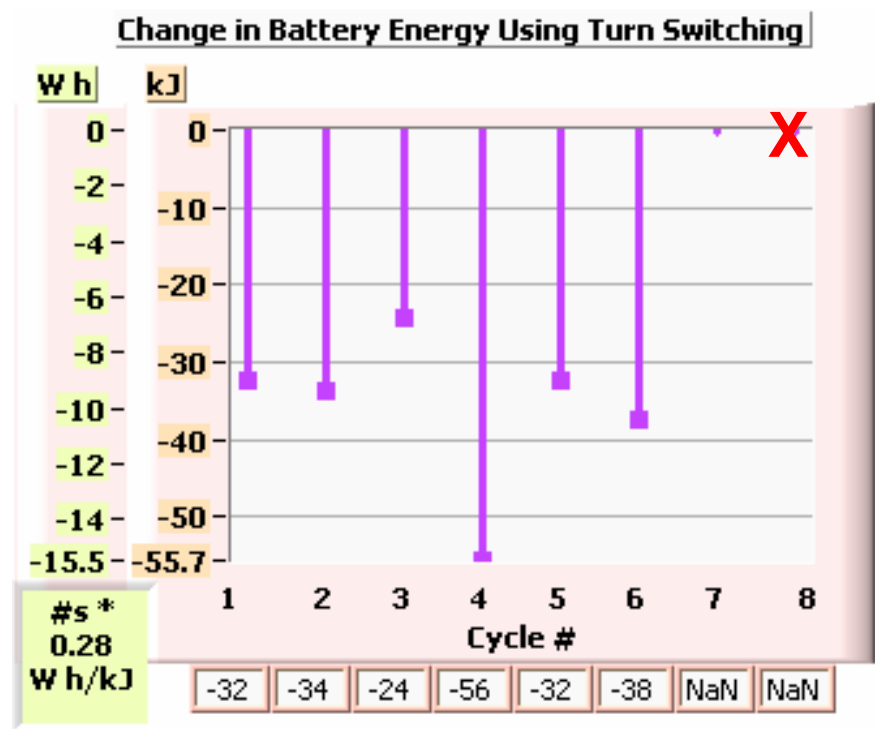

Fig. 29. Change in energy required for HEV from 0-20 $\mathrm{mph}$ with the turn-switching motor.

Figure 30 shows the difference in battery power demand between HEV2 and HEV1. Their absolute values correspond to the reduction in power demand associated with the replacement of the 9-turn motor with its 9-18 turn-switching version. The gain ranges from about $9 \mathrm{~kW}$ for the NYCT \#6, to $2.5 \mathrm{~kW}$ for the HDVFUDS \#3.

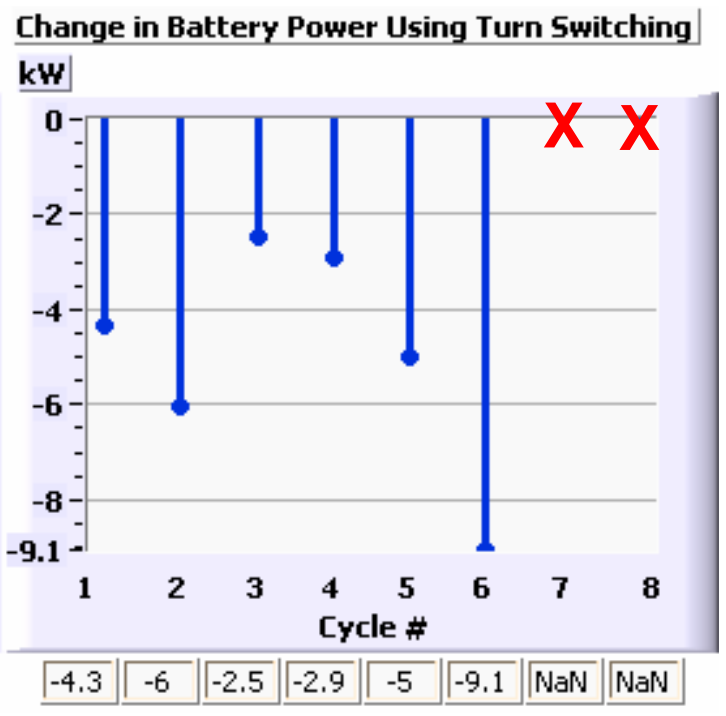

Fig. 30. Change in power required for HEV from 0-20 mph with the turn-switching motor.

Figures 31(a) and 31(b) show the percent change in battery energy and power demand between HEV1 and HEV2, respectively. The gain in energy with the turn-switching-motor ranges from $13.5 \%$ for the HDVFUDS \#3, to 23.4\% for the FHDS \#2 as indicated in Fig. 31(a). In Fig. 31(b), the gain in power ranges from about $14.2 \%$ for the New Europe cycle \#4, to 38.9\% for the NYCT \#6. 


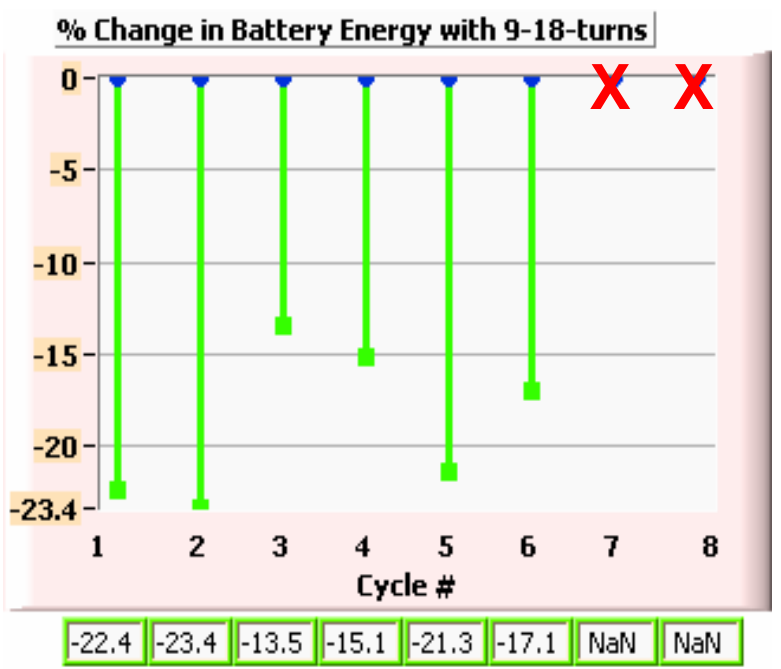

(a) Energy.

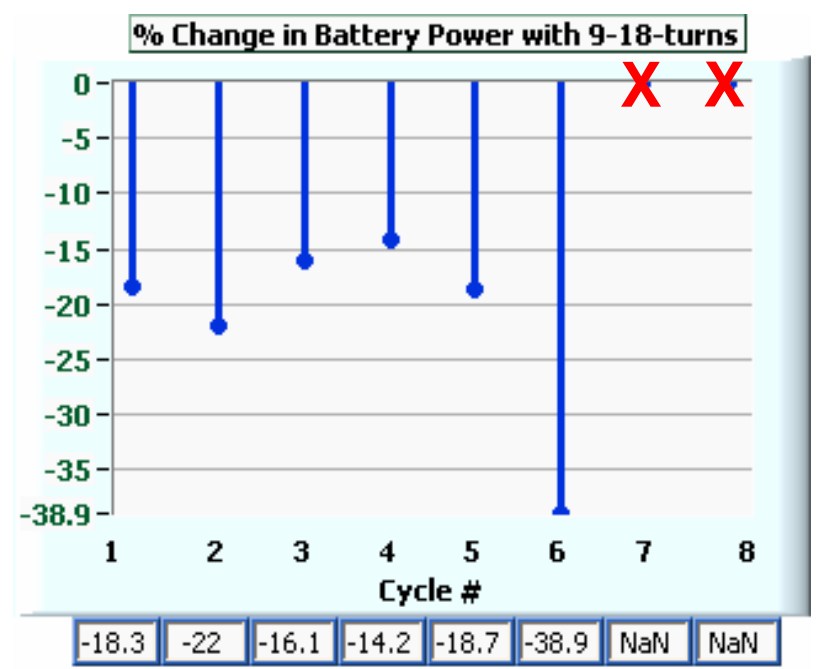

(b) Power.

Fig. 31. Percent change requirement for HEV with turn-switching motor from 0-20 mph.

\subsubsection{Impact of turn-switching on battery size and cost of HEVs}

The battery weight and costs shown in Fig. 32 for energy-bound and Fig. 33 for power-bound designs were obtained by incorporating into Figs. 27 and 28 the reference battery's specific values ${ }^{2}$ of $150 \mathrm{~W} \mathrm{~h} / \mathrm{kg}, 300 \mathrm{~W} / \mathrm{kg}$ and 22.5 \$/kg.

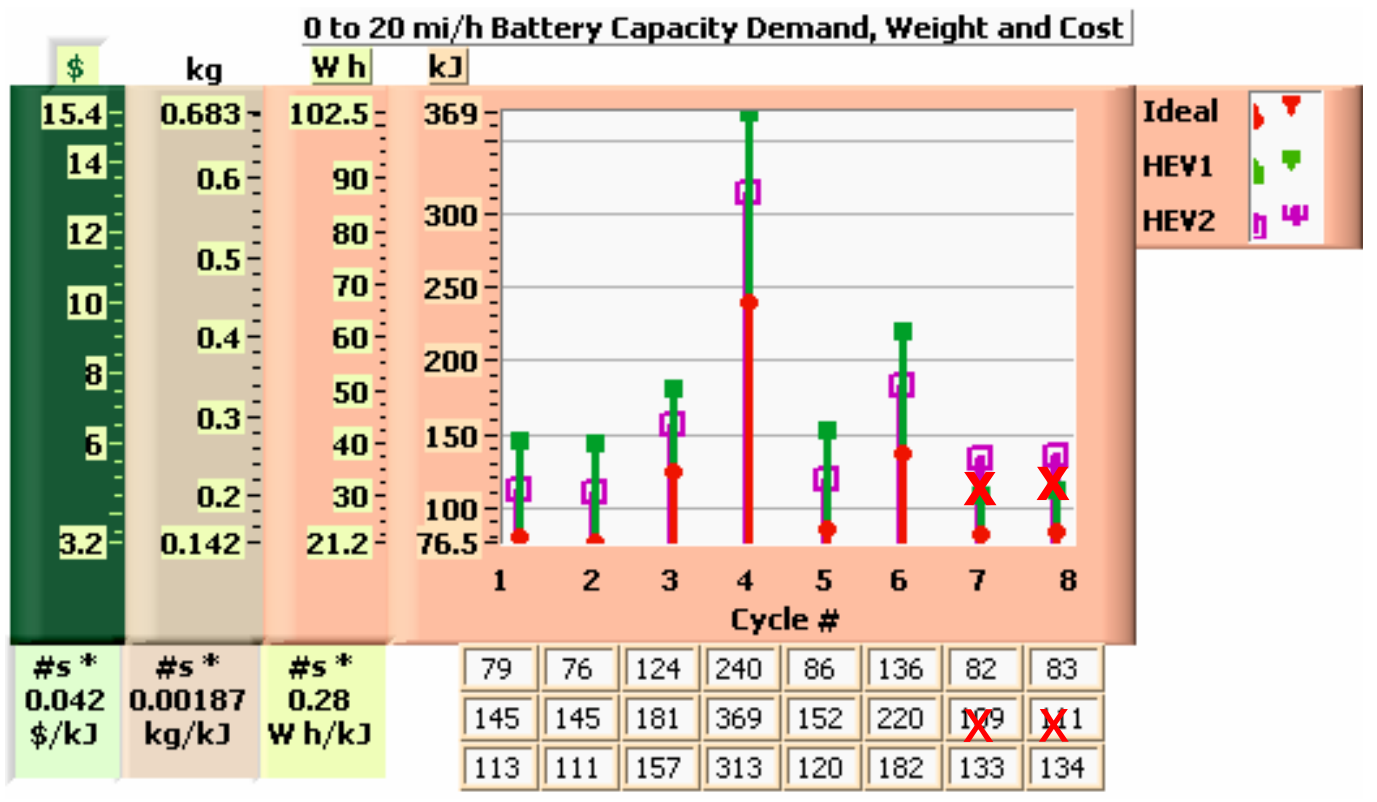

Fig. 32. HEV battery size and cost based on energy required for 0-20 mph start. 


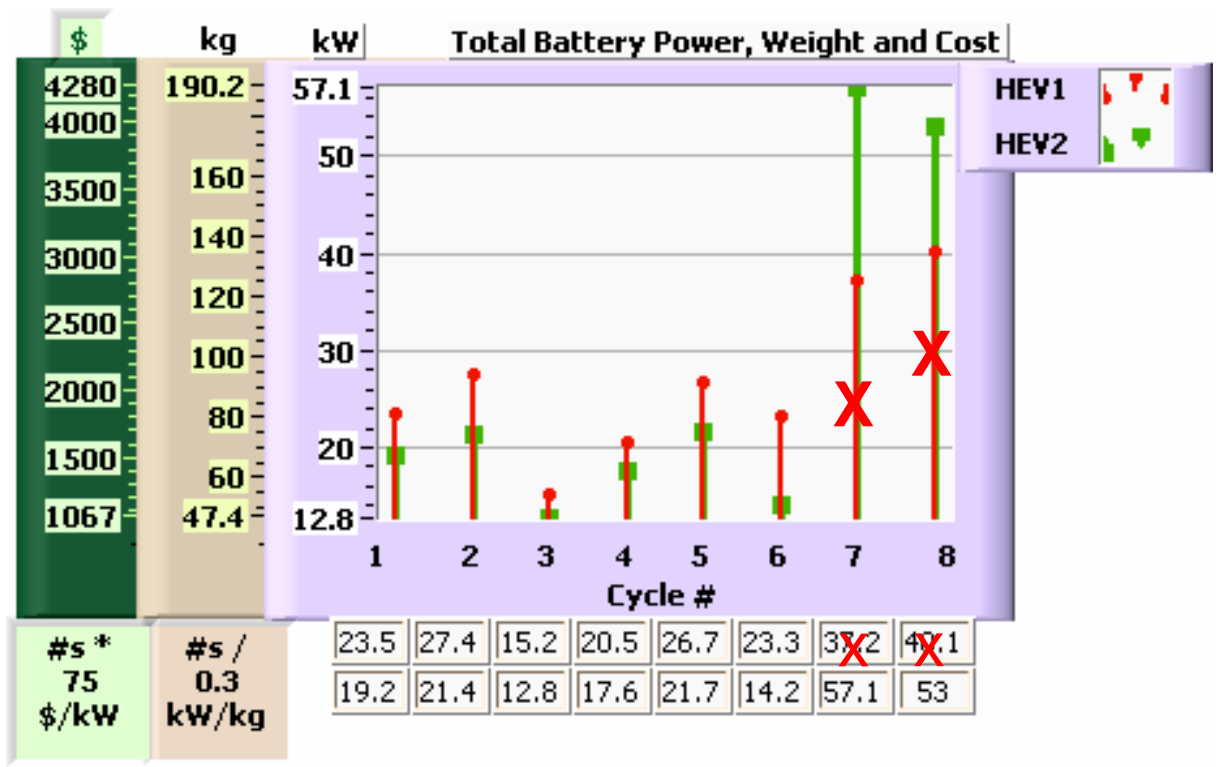

Fig. 33. EV battery size and cost based on power required for 0-20 mph start.

In Figs. 32 and 33, comparison of the values on the mass axis shows that the battery size for this kind of HEV is determined by the power demand. According to Fig. 33, the smallest battery weight is $47.4 \mathrm{~kg}$ with a cost of \$1,067 for the HEV2 for HDV-FUDS \#3 driving. The largest battery needed in the HEV2 is for US06 cycle \#7 driving with a weight of $190 \mathrm{~kg}$ at a cost of $\$ 4,275$. Considering the corresponding energy capacity values in Fig. 32, the 190 kg battery will allow HEV2 up to 770 starts of US06 driving style. In view of the data in Fig. 33 for all six other cycles, the battery requirement for HEV1 on the US06 cycles will undoubtedly be higher than for the HEV2. Since HEV1 could not accomplish the US06 cycles, their data are inaccurate; therefore, to assess the impact of turn-switching on HEV battery size and cost only the results obtained for cycles 1-6 can be used.

Figure 34 shows the change in battery size and cost for the reference HEV when the turn-switching-motor is used instead of the fixed nine-turn base motor; i.e., the values for HEV2 minus the values for HEV1. This figure is the same as Fig. 30 but with the battery data incorporated and the incomparable US06 data suppressed. The biggest savings occurred in the NYCC \#6, with $30.3 \mathrm{~kg}$ and $\$ 682$ reductions. The minimum savings are for the HDV-FUDS \#3, with reductions of $8.3 \mathrm{~kg}$ and $\$ 188$. 


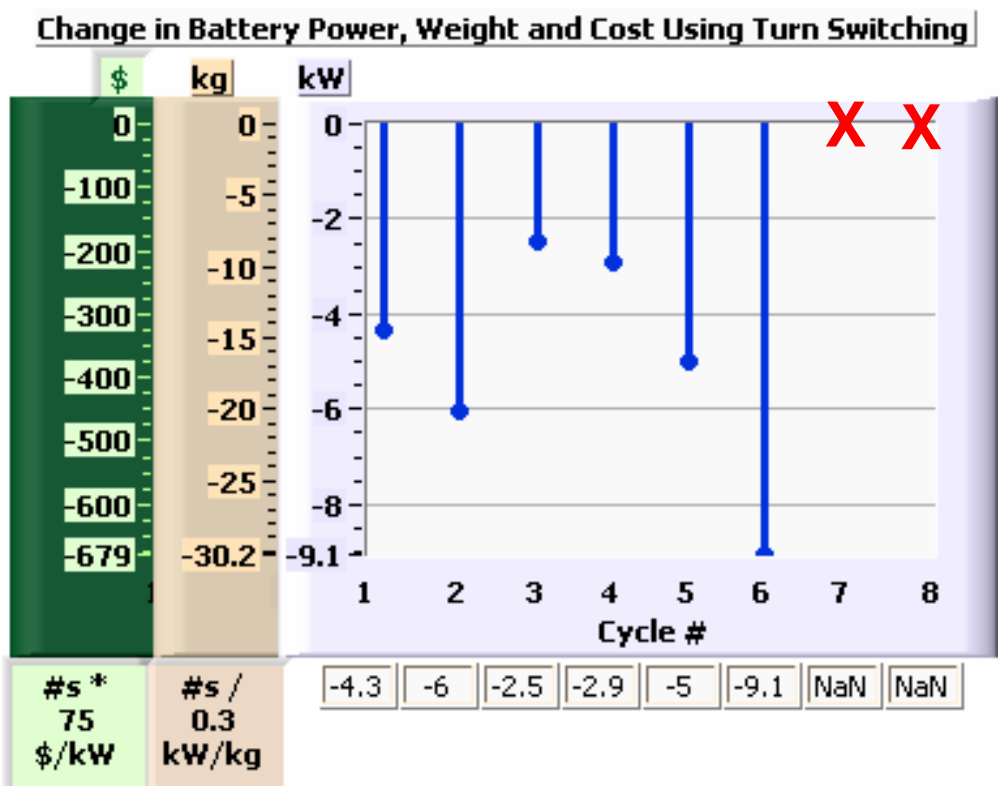

Fig. 34. Change in HEV battery size and cost based on power required from 0-20 mph.

Figure 35 shows the percent change in battery size and cost for the reference HEV when the turnswitching-motor is used instead of the fixed nine-turn base motor. This figure is the same as Fig. 31(b) but with the incompatible US06 data suppressed. In relative terms to the standard motor, the largest savings associated with the turn-switching-motor occur for NYCC \#5 with a 38.9\% gain, while the smallest is $14.2 \%$ for the New Europe cycle \#4. In other words, the battery in the HEV with the turnswitching version of the IPM motor is between 14.2-38.9\% smaller and cheaper depending on the driving cycle.

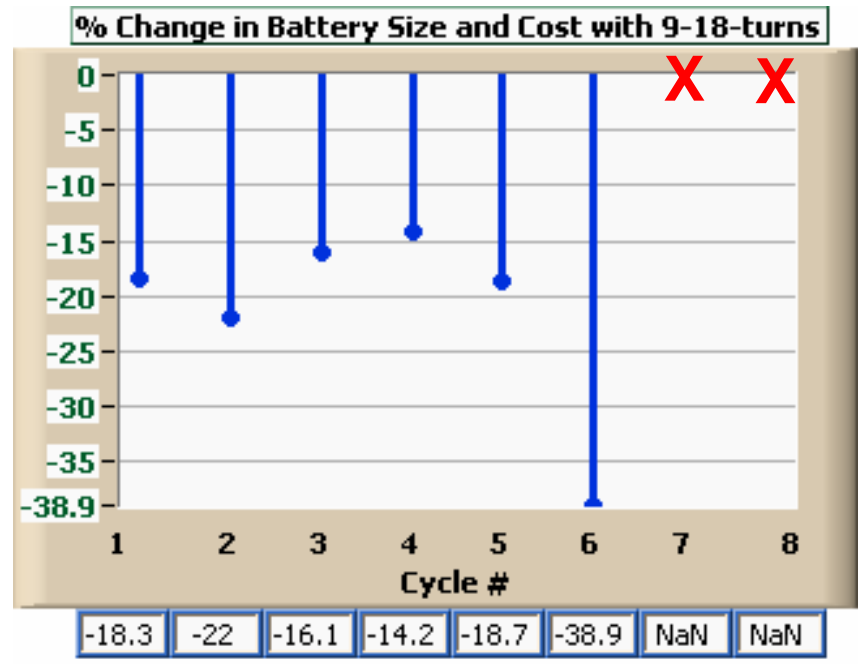

Fig. 35. Percent change in HEV battery size and cost from 0-20 mph. 


\subsection{STATOR RECONFIGURATION CONCLUSIONS}

Stator turn reconfiguration shows clear benefits over the traditional design with a fixed number of turns. It has been shown that for the particular IPM motor with 9-18 turn-switching, whether the motor is used as the only prime-mover as in fully electric propulsion or to provide propulsion from vehicle start to a set speed as in hybrid configuration, for all eight driving cycles analyzed:

- Available voltage is better utilized;

- Stator currents are lower;

- Motor efficiency is higher;

- Efficiency of PEs, battery, and cabling is higher;

- Overall vehicle system efficiency is higher;

- Battery size and cost are reduced; and

- Power demand is met everywhere along all cycles.

As indicated previously, Table 3 summarizes the savings obtained in the reference vehicle when the stator windings of the base 9-turn motor can be switched between 9-18 turns, for each driving cycle, and when the motor is used for all-electric or hybrid propulsion. Note that these savings translate directly to battery size and cost.

For the EV configuration, the vehicle with the stator turn-switching IPM motor consumes between 3.6$26.9 \%$ less energy and requires between 5.1-19.6 \% less peak power than the vehicle with the conventional nine-turn IPM motor.

For the HEVs, the vehicle with the stator turn-switching IPM motor consumes between 13.5- 23.4\% less energy and requires between 16.1-38.9\% less power than the vehicle with the conventional nine-turn IPM motor.

Note that the maximum EV savings of $265 \mathrm{~kJ} / \mathrm{mile}$ shown for the NYCC amounts to a savings of about one gallon per 151 miles of driving, when a value of $40 \mathrm{MJ} /$ gallon is used for the equivalence between battery-energy and gasoline-in-the-tank.

Similarly, the maximum HEV savings of $56 \mathrm{~kJ}$ shown for the FHDS cycle amounts to a savings of about 1.4 thousandths of a gallon or 5.3 cc of gasoline per start. 


\subsection{MECHANISMS FOR IMPLEMENTATION OF STATOR-TURN SWITCHING}

Figure 36 shows a schematic of a typical inverter driving a motor with the capability to connect its winding conductors in (a) series or (b) in parallel. The winding terminals are labeled with A1, B1, C1, $\mathrm{X} 1, \mathrm{Y} 1, \mathrm{Z} 1, \mathrm{~A} 2, \mathrm{~B} 2, \mathrm{C} 2, \mathrm{X} 2$, Y2, and Z2.

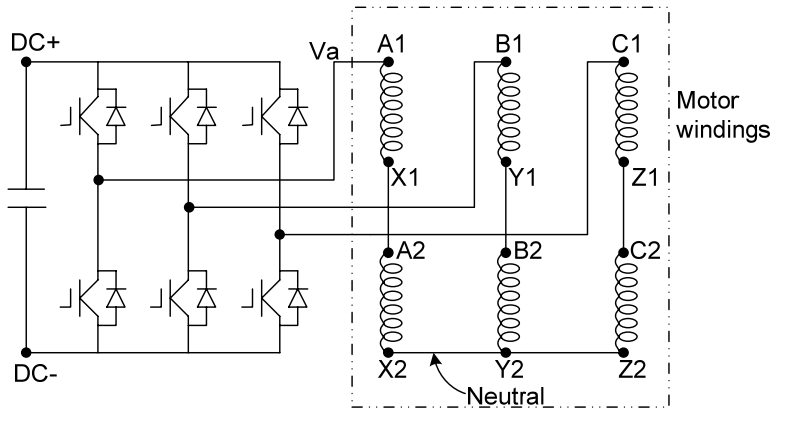

(a) Series connection.

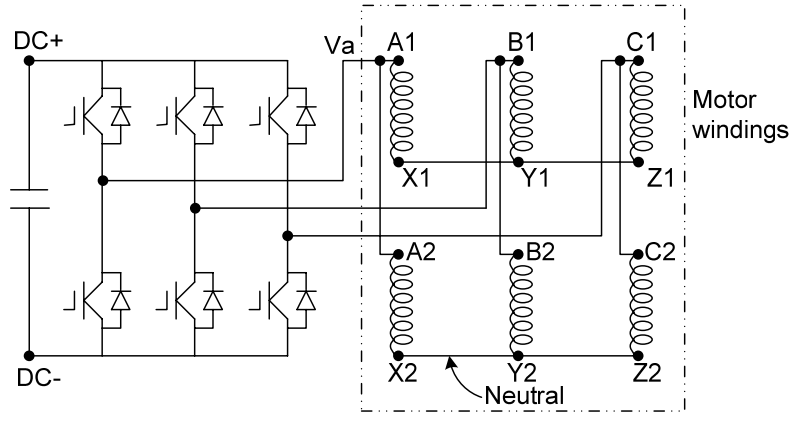

(b) Parallel connection.

Fig. 36. Conventional motor windings schematic.

Figure 37 shows the schematic diagram of a series/parallel connection-change switch consisting of a group of eight on/off bi-directional switches.

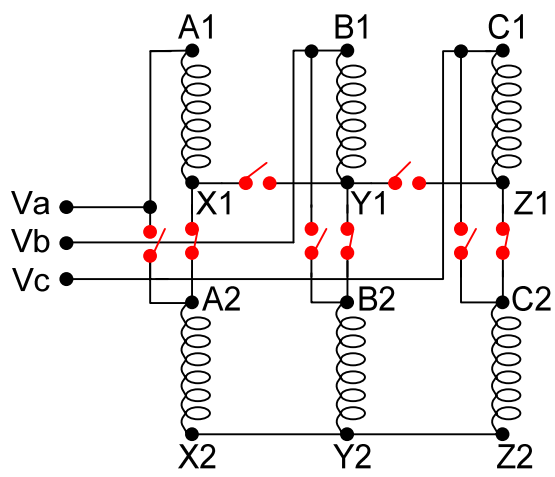

(Series connection)

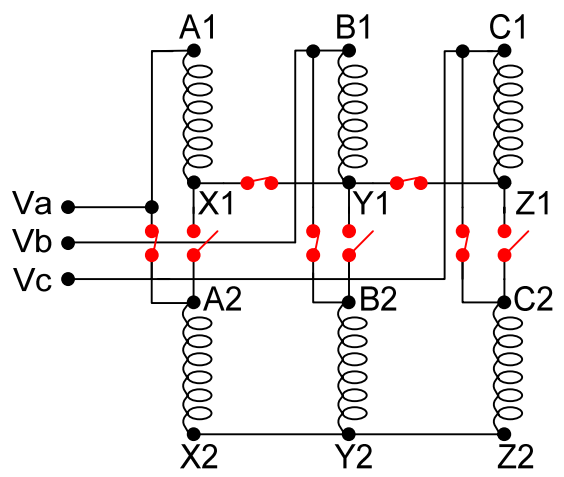

(Parallel connection)

Fig. 37. Series to parallel connection-change switch schematic.

The on/off switches in Fig. 37 can be mechanical or electrical. Mechanical on/off switches cannot handle the breaking of high currents in the motor windings during the change of connections because arc flashing will rapidly destroy the contacts. Figure 38 shows that if contact opening while in series configuration takes place at the time phase-a's alternating current (ac) is at its peak 400 A value (top waveform), a voltage spike of 62,000 V develops across the opening contacts (middle waveform). 


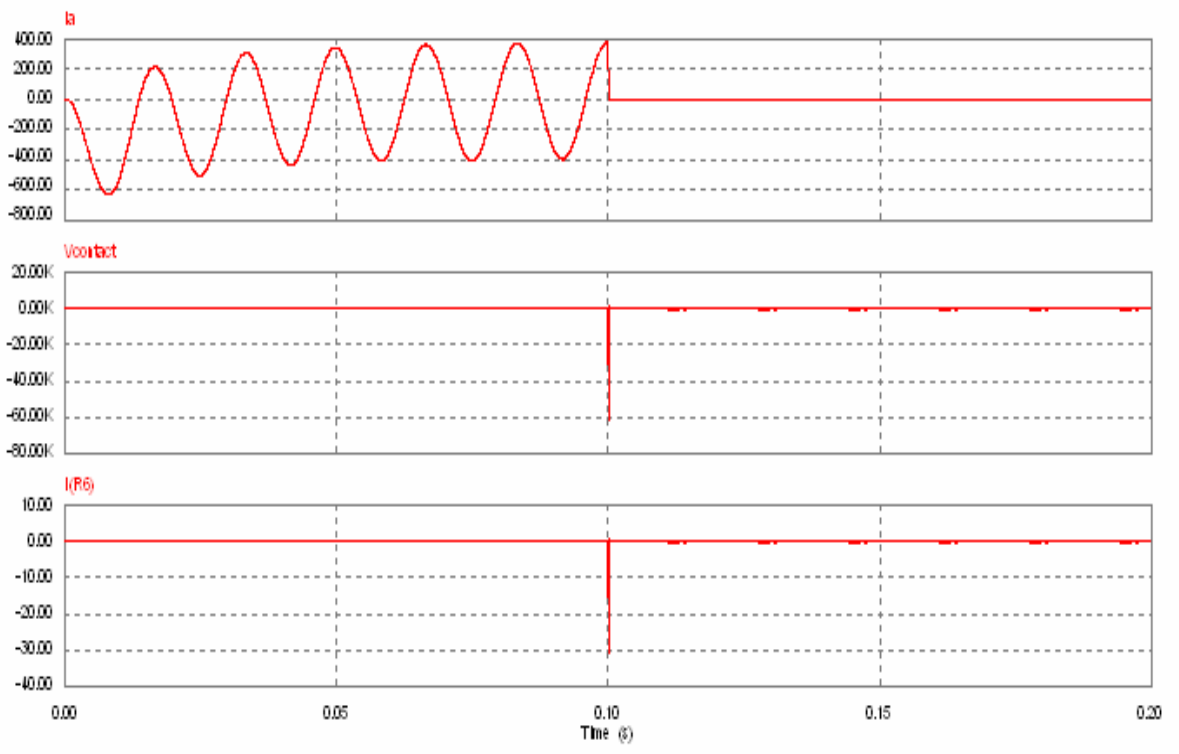

Fig. 38. Current and voltage waveforms at serial winding opening transition. (The top waveform is the winding current, the middle is the voltage at the switch contacts and the bottom is the current in the shunt-resistor.)

Reducing the winding current will reduce the magnitude of the voltage spike proportionally to the square of the current fraction. Damage to the contacts will be prevented by making the winding current zero prior to throwing the switches. This could be done:

(1) While the rotor turns and is engaged to the mechanical system and produces back-emf:

a. With the conventional PEs used in HEVs: by requesting a zero current in the windings. The $\mathrm{PE}$ will match the back-emf voltage and the windings current will be zeroed in a matter of milliseconds.

b. With a modified PE design in which the presently uncontrolled return current path through the diode can be blocked when the current is zero. Then the insulated gate bipolar transistors (IGBTs) could be turned-off and the current in the diode path be blocked at the moment the back-emf attempts to change the current direction towards the battery.

(2) While the rotor does not turn:

By requesting zero power or turning off the PE's IGBTs and disengaging the motor's rotor from the mechanical drive so that the back-emf disappears as the rotor stops.

Once zero current in the windings has been achieved, reconfiguration can be performed and PE normal operation can be resumed. In this case, one single-pole-double-throw (SPDT) and one single-pole (SP) are needed for series-to-parallel and parallel-to-series reconfiguration.

At the moment of reconnection, the discrepancy between the PE voltage - equal to the preswitching back-emf - and the new back-emf generated in the windings will cause a short-lived transient: (a) when changing from series to parallel the windings impedance is reduced by a factor of four and the back-emf by a factor of two from their pre-switching values; consequently, there will be a positive torque-producing inrush of current into the motor; and (b) when changing from parallel to series the windings impedance increases by a factor of four 
and the back-emf by a factor of two from their pre-switching values; consequently, there will be a negative torque-producing inrush of current into the battery.

This approach is not too different from the conventional clutch/accelerator pedal sequencing performed regularly in straight gear shift combustion engines even to the accelerating and braking effects when the clutch re-engages after changing gears, with higher gear ratio being akin to higher number of turns. The advantage for stator reconfiguration over conventional gear changing is that torque production is suppressed for a much shorter time period.

Operation in a parallel configuration results in a lower number of turns and back-emf, thus it is preferred for high speeds while series configuration is in general better for low speed-high torque operation. Still, one can envision the possibility of having to establish maximum speed limits for switching using approach (1) above in order to ensure that the back-emf does not exceed the battery voltage.

Switching turn configuration while no current circulates in the windings has the advantage of only having to contend with the back-emf for arcing at the contact points if the rotor is turning and requires at most six switches.

An approach for changing windings between series and parallel configurations while current circulates through the windings, better than the random switch opening simulated in Fig. 38, is to switch each phase at the moment the ac crosses the zero level. This can be accomplished using a combination of highcurrent electronics switches such as IGBTs and silicon-controlled rectifiers (SCRs). The SCR automatically stops the conduction when it sees the zero current. A minimum number of 16 heavycurrent SCRs would be required for the three-phase series/parallel diagram shown in Fig. 36. In this approach, the SCRs stay in the current path continuously and thus contribute additional losses and cooling requirements. In addition, at the present time the cost for high current electronics switches is high.

A novel approach, in which the SCRs are taken out of the winding's electrical current path, is described below.

\subsection{THE ELECTRONICALLY-COMMUTATED CONNECTION-CHANGE SWITCHER}

The electronically-commutated connection-change switcher is a novel approach developed during this research that has the potential of being low in cost, small, easy to cool, long-lived, and has a benign failure mode. It is basically a hybrid mechanical and electronic switch arrangement. A movable disc per phase, consisting of alternating insulator and conductor regions and signal triggering nodes, moves in contact with a set of four stationary brushes welded to the ends of each coil. The triggering nodes send pulses to a set of SCRs prior to circuit opening. The SCRs are not in the current path during normal operation.

Figure 39 shows the parallel connection for one phase. Terminals Va and A2, as well as X1 and neutral are connected together, respectively, through the conductors that are located in the movable disc. The timing of the SCR triggering signals can be changed by the locations and the widths of the triggering signal nodes in the disc. 

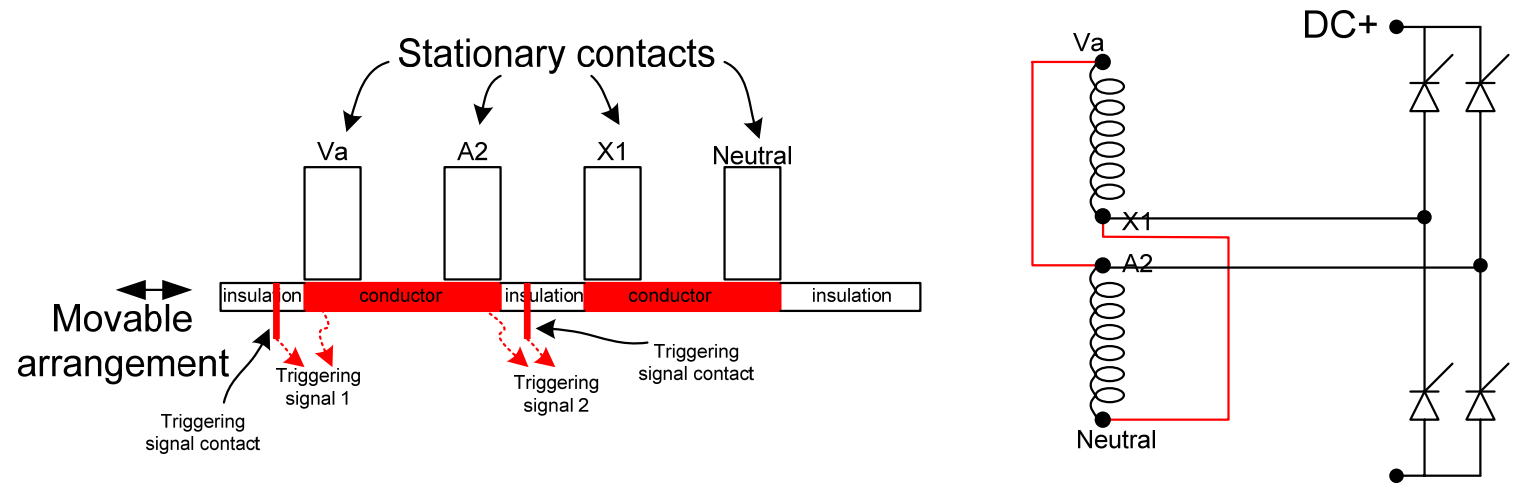

Fig. 39. Disk positioning and schematic for parallel connection of one phase.

Figure 40 shows that during the connection change immediately before the opening of the parallel circuit, two triggering signal nodes will produce gate signals to the SCRs. Because the conduction of the SCRs occurs only during connection changing, the SCRs can take a very high current pulse (normally greater than 10 times its continuous current), the cost of the SCRs for this application is low. Furthermore, since the heat generated by the SCRs is low due to the short current pulses, cooling will be easier than for continuously operated SCRs.
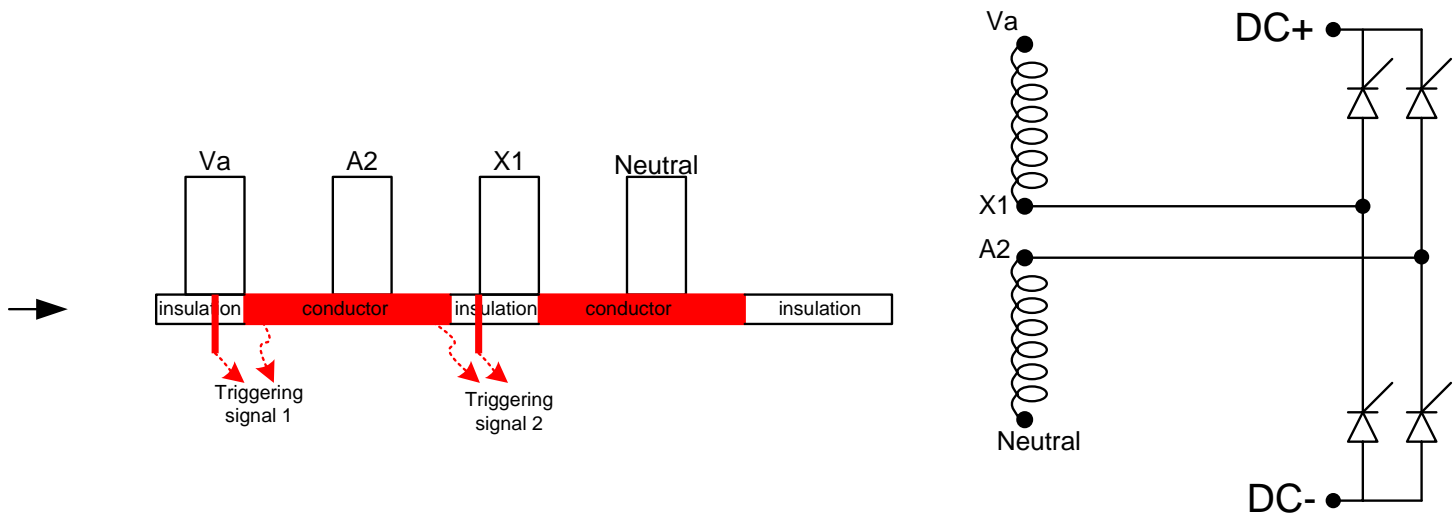

Fig. 40. Disk positioning and schematic for SCR gate triggering right before parallel circuit opening for serial reconfiguration.

Figure 41 shows the disk positioning and schematic for series connection of one-phase winding. 


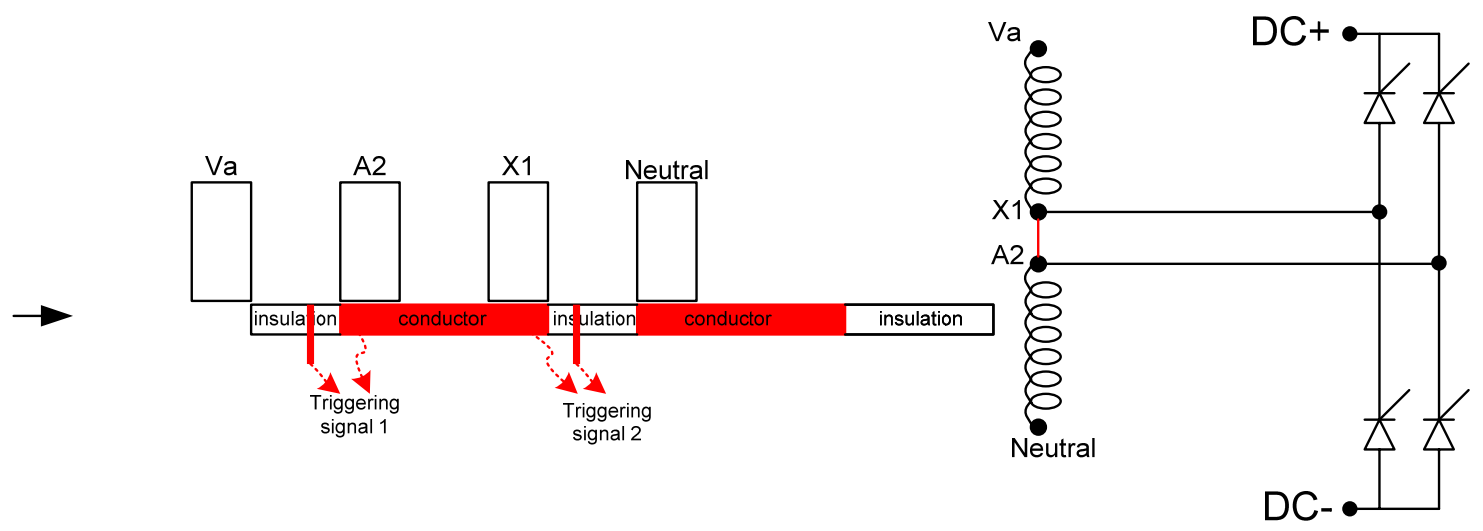

Fig. 41. Disk positioning and schematic for series connection for one phase.

Figure 42 shows the disc moving in the opposite direction when changing from a series connection to a parallel connection. The SCR gate triggering signals will be produced right before the circuit opening of the windings.
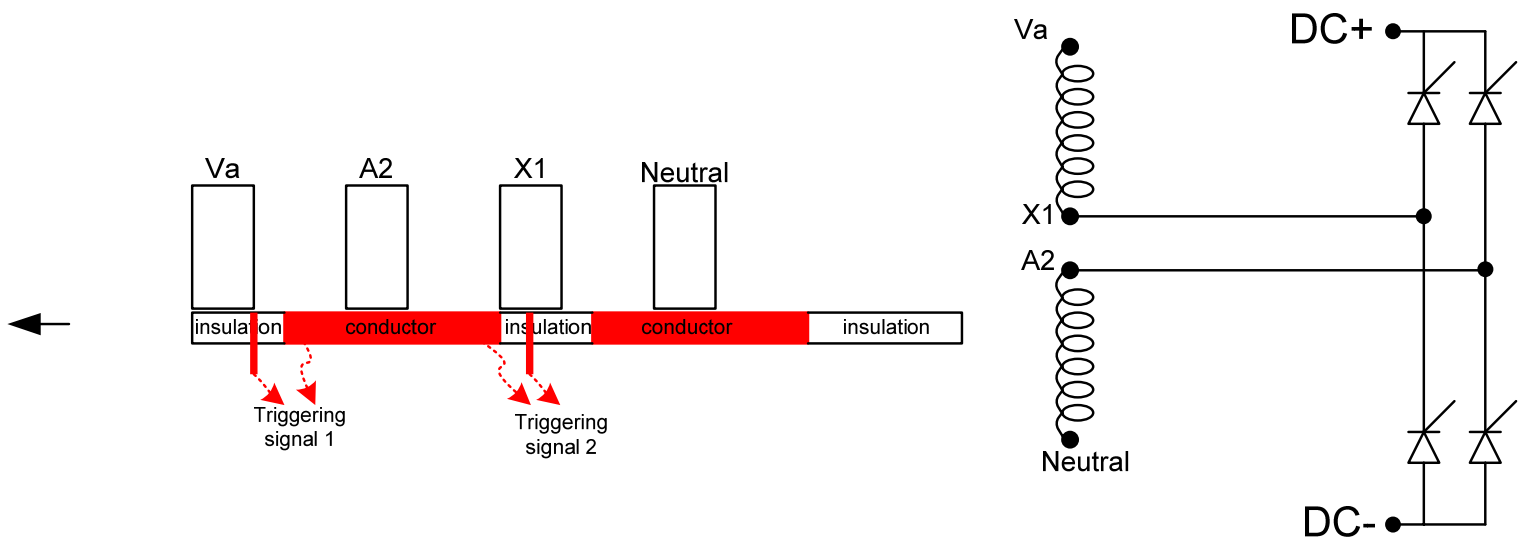

Fig. 42. Disk positioning and schematic of SCR gate triggering immediately before opening the series circuit prior to parallel reconfiguration.

\subsubsection{Performance Simulation of the Electronically-Commutated Configuration Switcher}

Figure 43 shows the computed current and voltages for this novel approach when opening the serial connection while full current is circulating in the winding and leaving it open. Note that the current spike in the SCR is below $400 \mathrm{~A}$ and that the peak back-emf voltage at the opening contacts does not reach $1,000 \mathrm{~V}$. These values compare favorably with the 62,000 V shown in the second waveform of Fig. 38. 


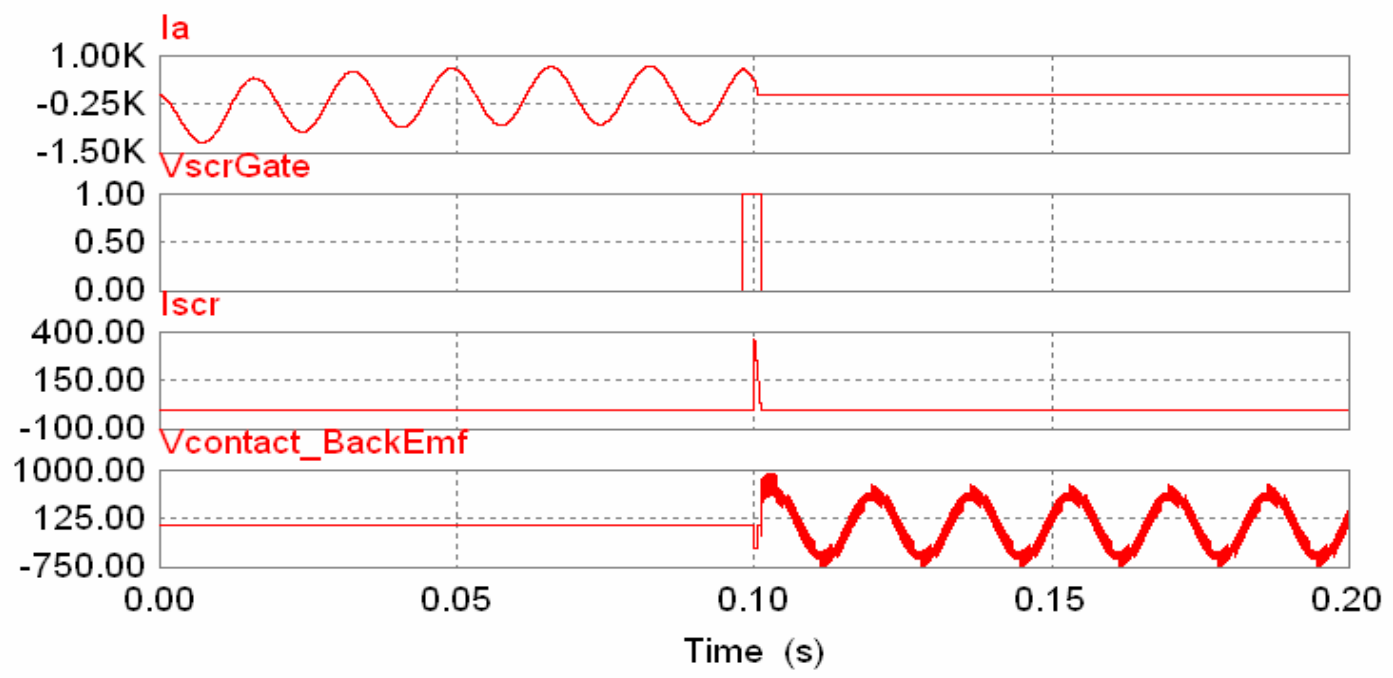

Fig. 43. Current and voltage waveforms at series winding opening transition with the electronicallycommutated configuration switcher.

Figure 44 shows the computed current and voltages for this novel approach when opening the serial connection while full current is circulating in the winding followed by closing to the parallel configuration. Note the increase in the magnitude of the winding current upon reconnection in parallel which is associated with the reduction in winding impedance by factor of four when switching from series $2 \mathrm{Z}$ to parallel $\mathrm{Z} / 2$, where $\mathrm{Z}$ represent the impedance of one single coil.

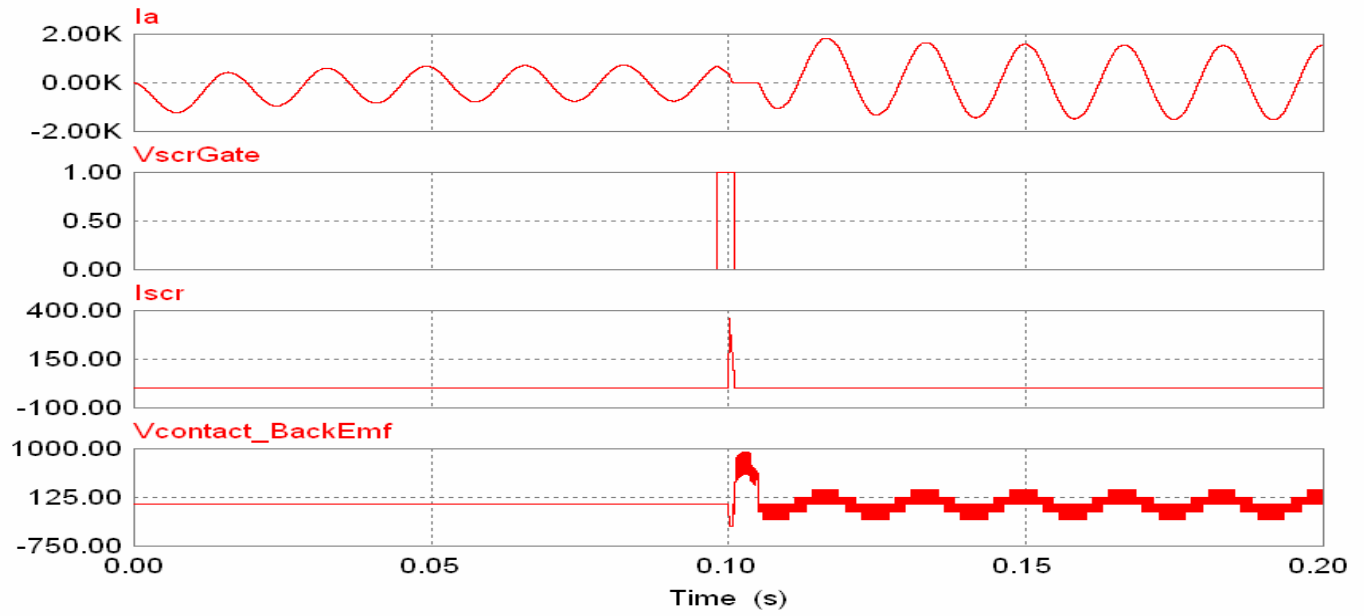

Fig. 44. Simulation of series-to-parallel winding reconfiguration with the electronically-commutated configuration switcher.

\subsection{SWITCHING MECHANISM CONCLUSIONS}

For switching while the motor is providing active torque, the electronically-commutated connectionchange switcher described has the following characteristics:

(1) All winding wires are connected to stationary contacts. 
(2) There are many other possible embodiments for making winding connection change switches. For example, the switch can be made differently by changing from a linear sliding mode of operation to a circular arrangement.

(3) A solenoid can be used for the actuation in all cases.

(4) Because of the short traveling distance and the relatively low speed of the movable portion, contact lubrications, such as oil, and various types of brushes such as rollers, copper fibers, etc. can optionally be used for improving the life expectancy of the contacts.

(5) The SCRs do not stay in the main current path and have small duty cycles; consequently they can be of low rating, small, and inexpensive.

(6) For the same reason given in Eq. (5), the cooling can be made simple.

(7) The motor current can be controlled to a lower value before switching the winding connections.

(8) The connection-change switch can be incorporated with the motor and inverter.

For switching while the motor is providing no torque, one of the three approaches described for reducing the winding current to zero prior to performing turn-switching may be most desirable.

Further research and hardware demonstration is needed to realize the potential gains shown for stator turn reconfiguration. 


\section{APPENDIX A SET OF DRIVING CYCLES}

In Figs. A1(a) and (b) and Fig. A2, the meanings of the colors are as follows: black identifies the time ranges in which the prime-mover of the vehicle used in this study could be turned OFF; red identifies ranges in which the prime-mover failed to provide as much torque as was needed; and the remainder time periods are colored according to the number of turns active in the prime-mover. In this particular case the color orange indicates operation with 9 active turns, while green indicates operation with 18 active turns. 


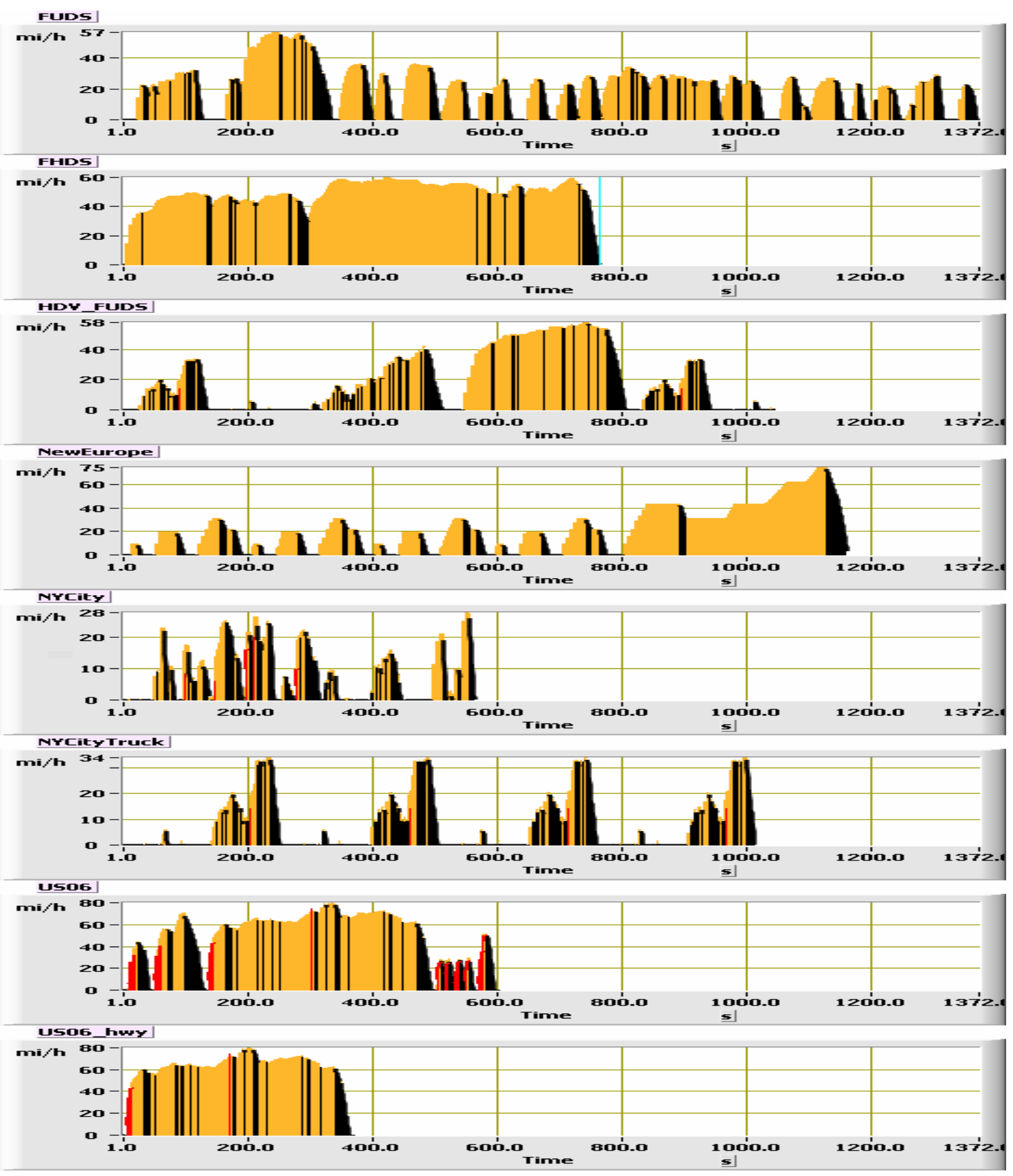

Fig. A1(a). Driving cycles: same time scale with the nine-turn motor: red $=$ failure and black $=$ OFF. 


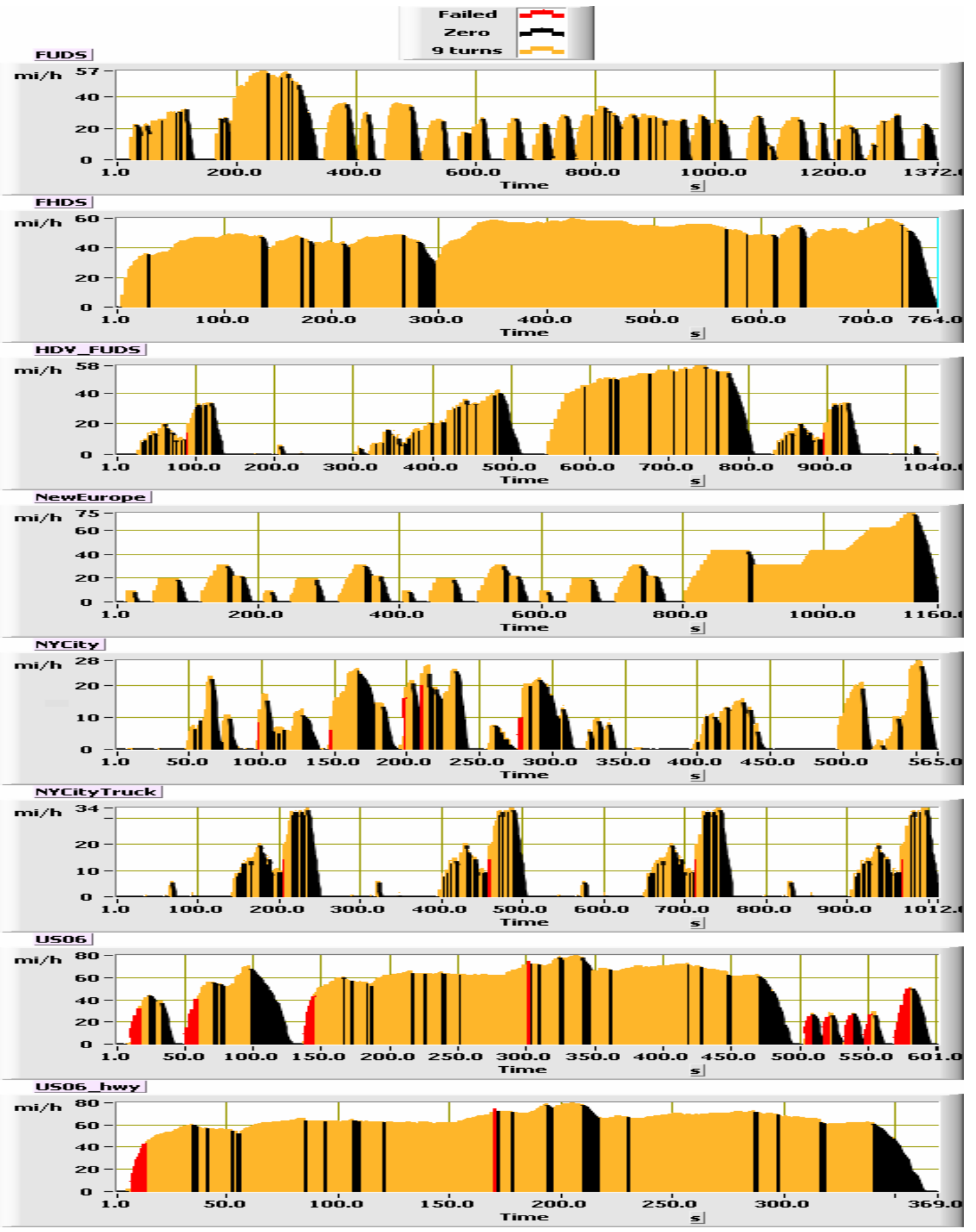

Fig. A1(b). Driving cycles with the nine-turn motor: red $=$ failure, black $=$ OFF, and orange $=$ nine turns . 


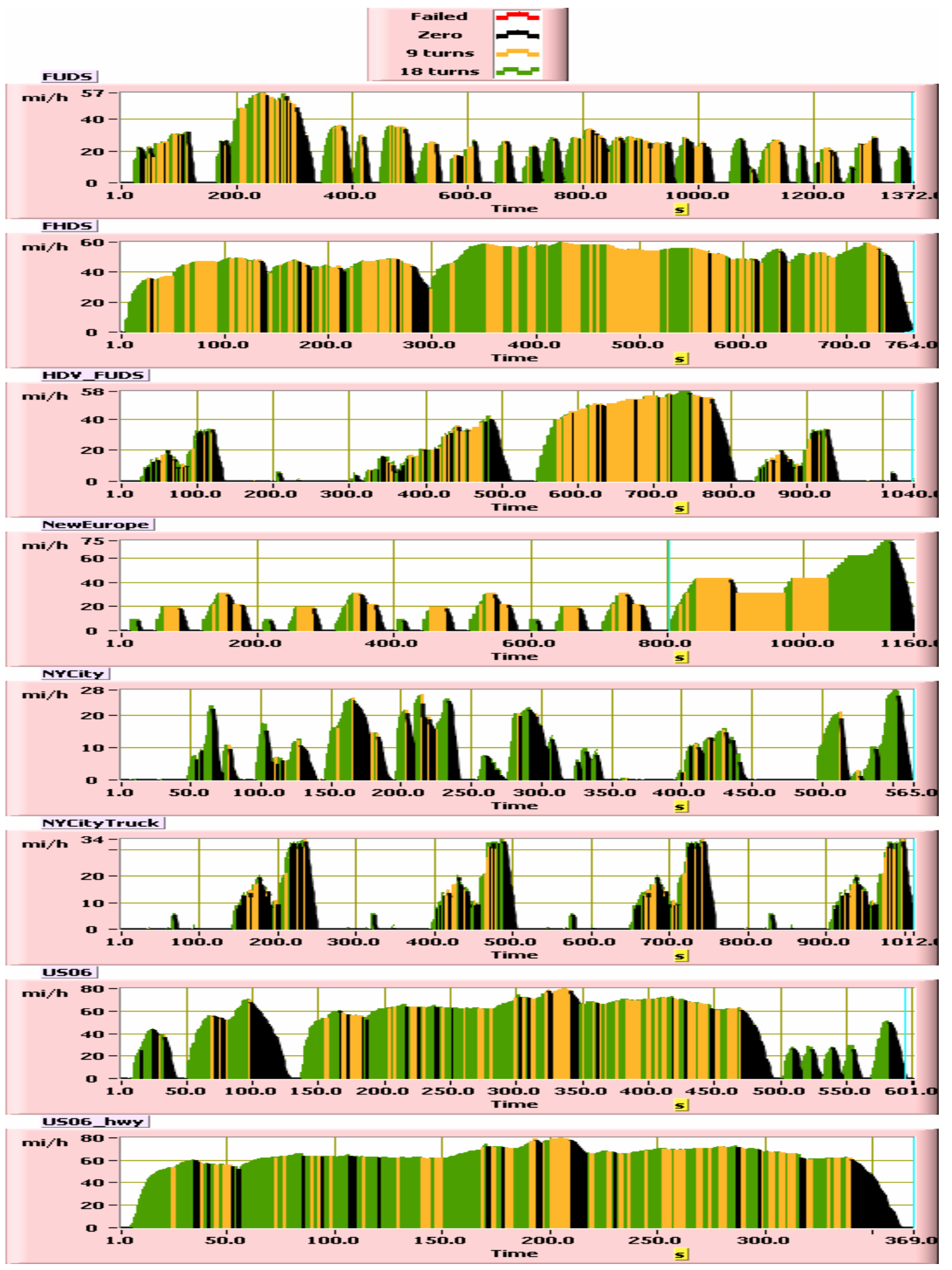

Fig. A2. Driving cycles with the 9-18 turn-switching motor: black $=$ OFF, orange $=9$ turns, and green $=18$ turns. 


\section{APPENDIX B SIMULATION OF SERIES TO PARALLEL COMMUTATION STAGES}

Figure B1 shows the simulation circuit for series contact opening in a system consisting of a three-phase inverter, motor, and mechanical switches at the mid-point of the windings. The motor winding is represented by resistance, inductance, and back-emf. The results are shown in Fig. 38. It should be noted that without the 2,000 Ohm resistor in the circuit, the peak voltage at the contacts will be higher than the computed 62,000V.

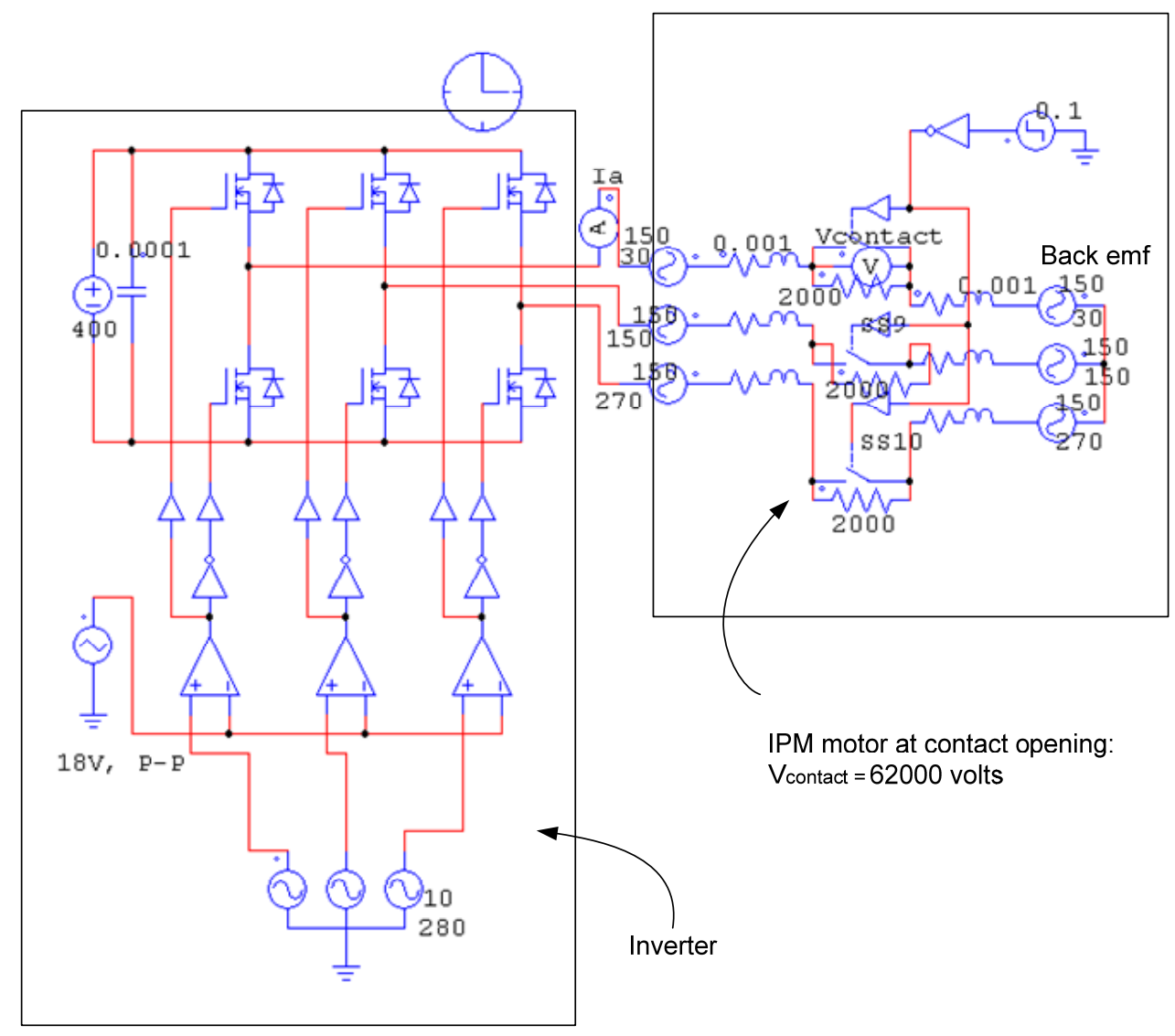

Fig. B1. Simulation circuit for serial contact opening showing inverter, motor, and mechanical switches.

Figure B2 shows the simulation circuit for series contact opening in a system consisting of a three-phase inverter, motor, and the electronically-commutated connection-change switcher. The results are shown in Fig. 43. 


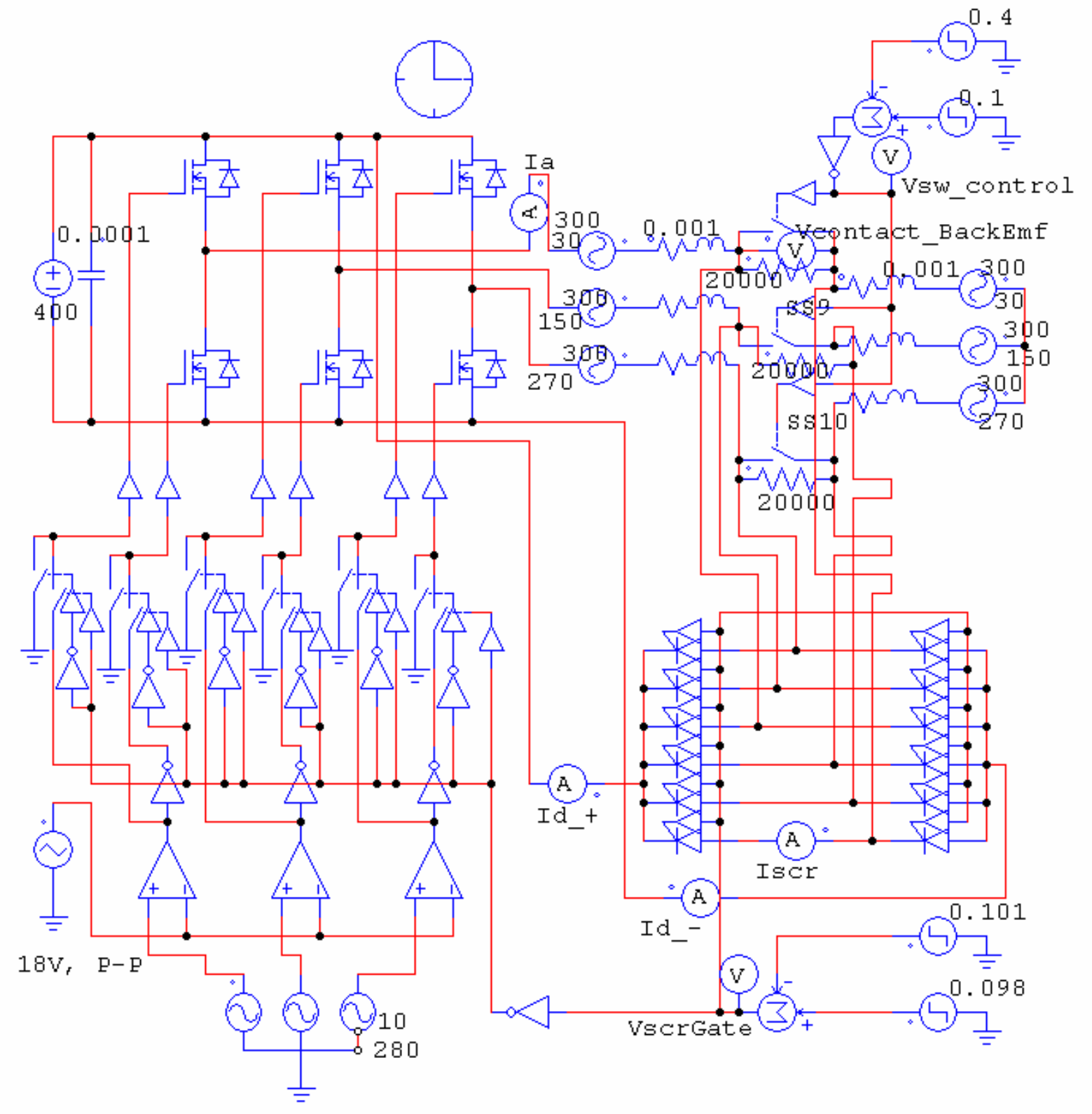

Fig. B2. Simulation circuit for opening a series configured winding with the electronically-commutated connection-change switcher.

Figure B3 shows the simulation circuit for serial contact opening and parallel closing in a system consisting of a three-phase inverter, motor, and the electronically-commutated connection-change switcher. The results are shown in Fig. 44. 


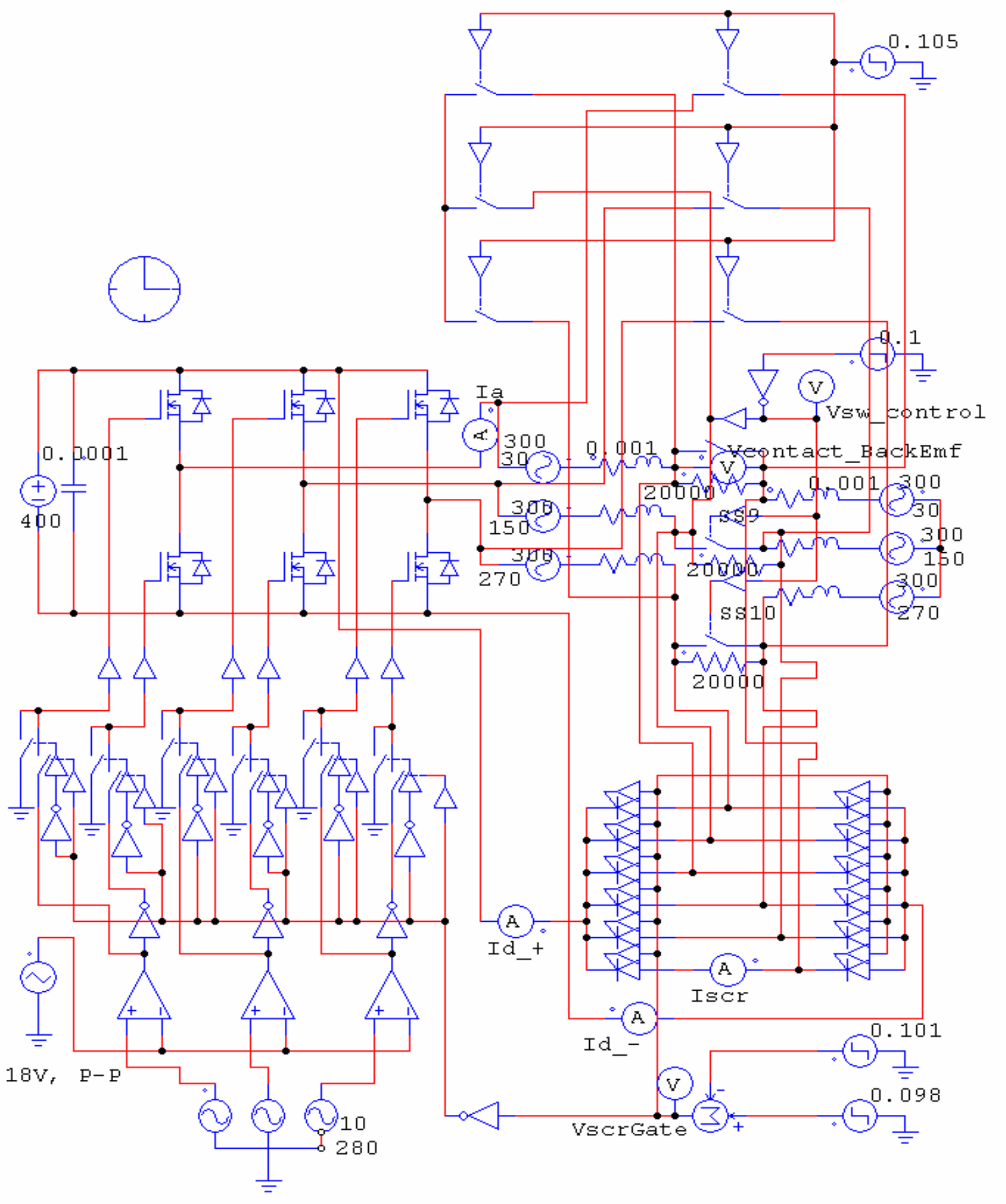

Fig. B3. Simulation of winding opening from series configuration followed by reconnection in parallel configuration using the electronically-commutated connection-change switcher. 


\section{REFERENCES}

1. IEEE Transactions on Magnetics, 26(5), September 1990.

2. Goals_for_Advanced_EV_Batteries.pdf, http://www.uscar.org/guest/article_view.php?articles_id=85 


\section{DISTRIBUTION}

\section{Internal}

\author{
1. D. J. Adams \\ 2. E. C. Fox \\ 3. K. P. Gambrell \\ 4. J. S. Hsu
}

5. L. D. Marlino

6. M. Olszewski

7. P. J. Otaduy

8. Laboratory Records

\section{External}

9. R. Al-Attar, DCX, raa9@dcx.com.

10. T. Q. Duong, U.S. Department of Energy, EE-2G/Forrestal Building, 1000 Independence Avenue, S.W., Washington, D.C. 20585.

11. R. R. Fessler, BIZTEK Consulting, Inc., 820 Roslyn Place, Evanston, Illinois 60201-1724.

12. G. Hagey, Sentech, Inc., 501 Randolph St., Williamsburg, Virginia 23185.

13. E. Jih, Ford Motor Company, Scientific Research Laboratory, 2101 Village Road, MD-1170, Rm. 2331, Dearborn, Michigan 48121.

14. K. J. Kelly, National Renewable Energy Laboratory, 1617 Cole Boulevard, Golden, Colorado 80401.

15. A. Lee, Daimler Chrysler, CIMS 484-08-06, 800 Chrysler Drive, Auburn Hills, Michigan 483262757.

16. F. Leonardi, Ford Motor Company, 15050 Commerce Drive, North, Dearborn, Michigan 481201261.

17. F. Liang, Ford Motor Company, Scientific Research Laboratory, 2101 Village Road, MD1170, Rm. 2331/SRL, Dearborn, Michigan 48121.

18. M. W. Lloyd, Energetics, Inc., 7164 Columbia Gateway Drive, Columbia, Maryland 21046.

19. J. Maquire, General Motors Advanced Technology Center, 3050 Lomita Boulevard, Torrance, California 90505.

20. M. Mehall, Ford Motor Company, Scientific Research Laboratory, 2101 Village Road, MD-2247, Rm. 3317, Dearborn, Michigan 48124-2053.

21. J. A. Montemarano, Naval Surfae Warfare Center, Carderock Division; Code 642, NSWD, 9500 MacArthur Boulevard; West Bethesday, Maryland 20817.

22. N. Olds, United States Council for Automotive Research (USCAR), nolds@uscar.org

23. S. A. Rogers, U.S. Department of Energy, EE-2G/Forrestal Building, 1000 Independence Avenue, S.W., Washington, D.C. 20585.

24. G. S. Smith, General Motors Advanced Technology Center, 3050 Lomita Boulevard, Torrance, California 90505.

25. E. J. Wall, U.S. Department of Energy, EE-2G/Forrestal Building, 1000 Independence Avenue, S.W., Washington, D.C. 20585.

26. B. Welchko, General Motors Advanced Technology Center, 3050 Lomita Boulevard, Torrance, California 90505.

27. P. G. Yoshida, U.S. Department of Energy, EE-2G/Forrestal Building, 1000 Independence Avenue, S.W., Washington, D.C. 20585. 